\title{
Association of changes in norepinephrine and serotonin transporter expression with the long-term behavioral effects of antidepressant drugs
}

\section{Zaorui Zhao}

West Virginia University

Follow this and additional works at: https://researchrepository.wvu.edu/etd

\section{Recommended Citation}

Zhao, Zaorui, "Association of changes in norepinephrine and serotonin transporter expression with the long-term behavioral effects of antidepressant drugs" (2008). Graduate Theses, Dissertations, and Problem Reports. 2697.

https://researchrepository.wvu.edu/etd/2697

This Dissertation is protected by copyright and/or related rights. It has been brought to you by the The Research Repository @ WVU with permission from the rights-holder(s). You are free to use this Dissertation in any way that is permitted by the copyright and related rights legislation that applies to your use. For other uses you must obtain permission from the rights-holder(s) directly, unless additional rights are indicated by a Creative Commons license in the record and/ or on the work itself. This Dissertation has been accepted for inclusion in WVU Graduate Theses, Dissertations, and Problem Reports collection by an authorized administrator of The Research Repository @ WVU.

For more information, please contact researchrepository@mail.wvu.edu. 
Association of changes in norepinephrine and serotonin transporter expression with the long-term behavioral effects of antidepressant drugs

\section{Zaorui Zhao}

Dissertation submitted to the

School of Pharmacy

at West Virginia University

in partial fulfillment of the requirements

for the degree of

Doctor of Philosophy

in

Pharmaceutical and Pharmacological Sciences

James M. O'Donnell, Ph.D., Chair

Patrick S. Callery, Ph.D.

Han-Ting Zhang, M.D., Ph.D.

Adrienne K. Salm, Ph.D.

Jason D. Huber, Ph.D.

Department of Basic Pharmaceutical Sciences

Morgantown, West Virginia

2008

Keywords: norepinephrine transporter, serotonin transporter, norepinephrine, serotonin, depression, antidepressant drugs, alphamethyl-p-tyrosine, para-chlorophenyalanine, protein kinase $\mathbf{C}$ Copyright 2008 Zaorui Zhao 


\title{
$\underline{\text { Abstract }}$ \\ Association of changes in norepinephrine and serotonin transporter expression with the long-term behavioral effects of antidepressant drugs
}

\author{
Zaorui Zhao
}

The relationship between the ability of repeated antidepressant treatment to cause down-regulation of the norepinephrine and serotonin transporters (NET, SERT) and produce antidepressant-like effects on behavior was determined. Treatment of rats with $15 \mathrm{mg} / \mathrm{kg}$ /day desipramine reduced NET expression, measured by ${ }^{3} \mathrm{H}$-nisoxetine binding and SDS-PAGE/immunoblotting, in cerebral cortex and hippocampus and reduced the time of immobility in the forced-swim test. The antidepressant-like effect on forcedswim behavior was evident two days following discontinuation of desipramine treatment when plasma and brain levels of desipramine and its major metabolite desmethyldesipramine were not detectable. Reduced NET expression resulted in decreased norepinephrine (NE) uptake, measured in vitro, and increased noradrenergic neurotransmission, measured in vivo using microdialysis. Fourteen-day treatment of rats with $20 \mathrm{mg} / \mathrm{kg} /$ day protriptyline or $7.5 \mathrm{mg} / \mathrm{kg} /$ day sertraline reduced NET and SERT expression, measured by ${ }^{3} \mathrm{H}$-nisoxetine ${ }^{3} \mathrm{H}$-citalopram binding and SDSPAGE/immunoblotting, in cerebral cortex and hippocampus and reduced the time of immobility in the forced-swim test. Six-week, but not 2-week, treatment with 20 $\mathrm{mg} / \mathrm{kg} /$ day reboxetine caused down-regulation of NET and an antidepressant-like effect in the forced-swim test. Antidepressant-induced NET and SERT down-regulation was not due to the reduction of gene transcription, as determined using quantitative, real-time RT-PCR.

Since studies using cell cultures have revealed a role of protein kinase C (PKC) in NET regulation, experiments were carried out to assess the importance of this mechanism in brain tissues and determine its role in the mediation of antidepressant-like effects on behavior. It was found that the PKC activators $\beta$-PMA and bryostatin-1 reduced NE uptake in cerebrocortical slices; this was due to decreased $V_{\max }$ and unchanged $\mathrm{K}_{\mathrm{m}}$ values. Further, bilaterally intracerebroventricular (ICV) administration of $\beta$-PMA produced a significant antidepressant-like effect on forced-swim behavior, which was reversed by co-administration of 1-(5-isoquinolinesulfonyl)-2-methylpiperazine (H-7), a $\mathrm{PKC}$ inhibitor.

Overall, antidepressant-induced changes in NET/SERT expression paralleled those in the antidepressant-like effects on behavior. The antidepressant-like effects of desipramine and sertraline were blocked by inhibition of catecholamine synthesis with alpha-methyl-p-tyrosine (AMPT) and inhibition of serotonin (5-HT) synthesis with parachlorophenylalanine (PCPA), respectively, suggesting that increased noradrenergic or serotonergic neurotransmission is an important mechanism underlying antidepressant activity. In addition, the results, which are consistent with clinical data in terms of timecourse respone, suggest an important role of NET and SERT regulation in the long-term 
behavioral effects of antidepressant drugs and that enhanced noradrenergic or serotonergic neurotransmission is necessary, but not sufficient, for its antidepressant actions. Understanding the mechanisms underlying NET and SERT regulation in vivo may suggest novel pharmacological targets for treating depression. Future studies may focus on identifying the role of PKC signaling in NET regulatio, given thaht this signaling pathway appears to be an important mediator contributing to the long-term behavioral effects of antidepressant treatment. 


\title{
Dedicated to
}

\author{
My Parents
}

Jifa Zhao and Yiping Fan

\author{
My Wife \\ Yang Bai \\ AND \\ My beloved newborn baby boy \\ Devin Zhao
}




\section{ACKNOWLEDGEMENTS}

I would like to express my deepest gratitude to my advisor, Dr. James M. O’Donnell, for providing me an opportunity to pursue my $\mathrm{PhD}$ thesis research in his laboratory, for his support, guidance and encouragement throughout my graudate studies, research and writing of this dissertation.

I would like to thank Dr. Patrick Callery, Dr. Han-Ting Zhang, Dr. Adrienne Salm, and Dr. Jason Huber for participating in the committee of my $\mathrm{PhD}$ program.

I want to thank Dr. Alicia M. Baros, Meidcal University of South Carolinaa, Charleston, SC, for her pilot work on part of my dissertation research.

I would like to thank Dr. David Morilak, Dr. M.Danet S. Lapiz, Corina O. Bondi, at University of Texass Health Science Center at San Antonio; for providing the technical support on in vivo micordialysis.

I would also like to thank the faulty, staff and graduate students in the department of Basic Pharmaceutical Sciences and Department of Neurobiology and Anatomy for their help.

Thanks also to Ying Huang, a researcher specialist, as well as all of laboratory members, for teaching me various experimental methods.

Thanks also to my parent for their encouragement, care and love to lead my life.

Most importantly, I would express my cordial appreciation to my wife, Yang Bai, for her support through my $\mathrm{PhD}$ training and for making it worthwhile. I could not have done this without her. 


\section{TABLE OF CONTENTS}

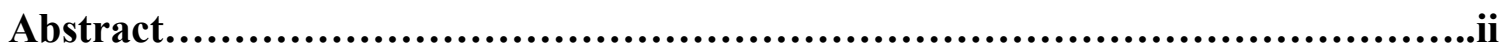

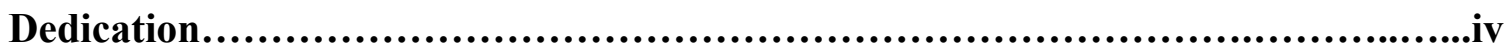

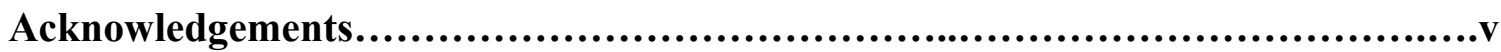

Table of Contents.......................................................................

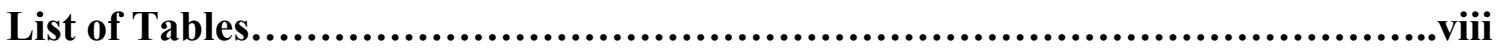

List of Figures............................................................................

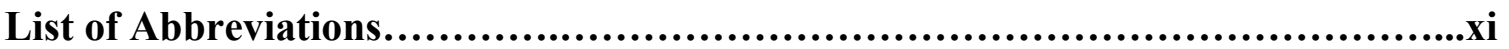

\section{CHAPTER 1. Introduction (Literature Review)}

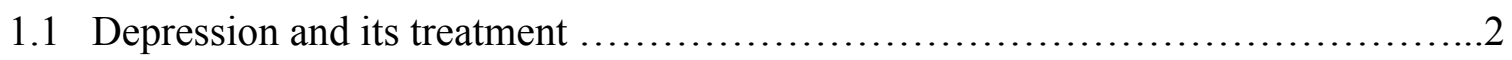

1.2 Delayed onset of antidepressant effect......................................

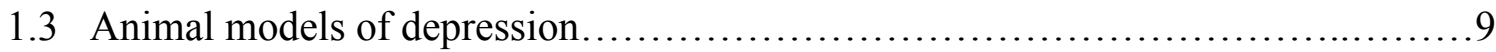

1.4 Molecular structure and function of NET and SERT ..........................12

1.5 Noradrenergic and selective serotonergic reuptake inhibitors.....................17

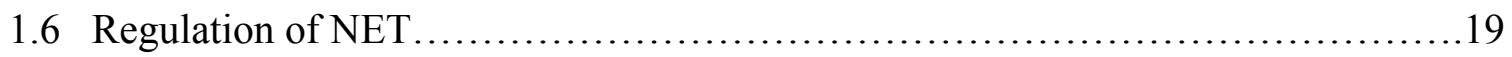

CHAPTER 2. Norepinephrine transporter regulation mediates long-term behavioral effects of antidepressant desipramine

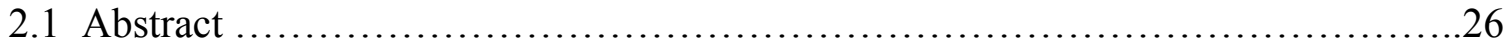

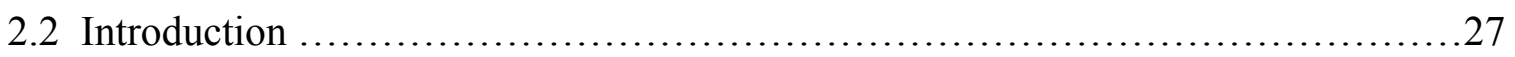

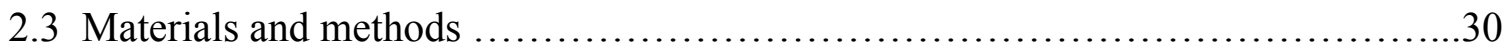

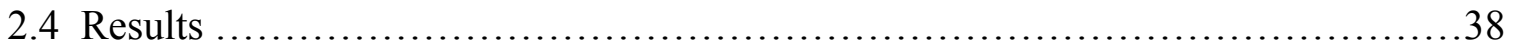


2.5 Discussion

CHAPTER 3. Association of changes in norepinephrine an serotonin transporter expression with the long-term behavioral effects of antidepressant drug treatment

3.1 Abstract................................................................. 59

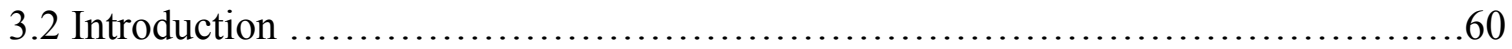

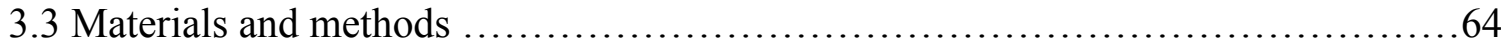

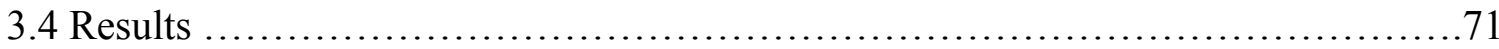

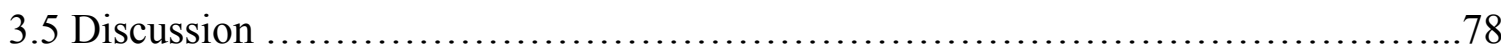

CHAPTER 4. Role of PKC in NET activity in cerebral cortical slices and antidepressant-like effects on behavior.

4.1 Abstract................................................................ 97

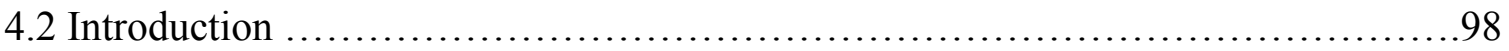

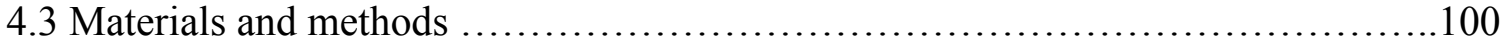

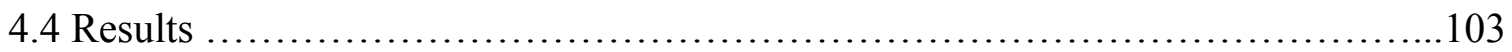

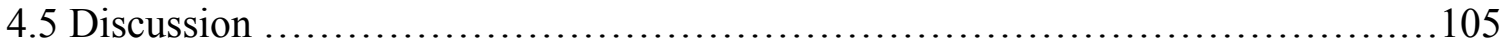

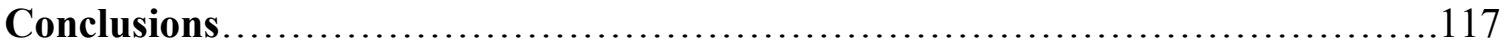

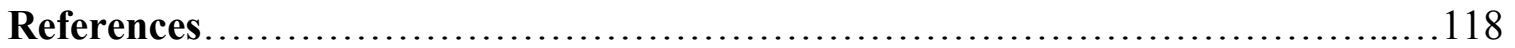

Curriculum Vitae........................................................ 151 


\section{LIST OF TABLES}

Table 1.1 Examples of animal models used in depression research...................11

Table 1.2 Structure of antidepressants and $\mathrm{K}_{\mathrm{i}}$ values for inhibition of

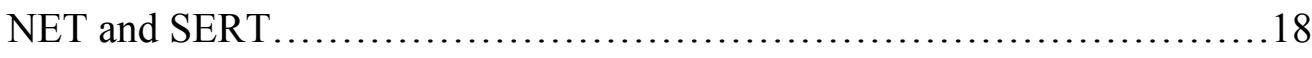

Table 3.1 Effects of chronic antidepressant treatment on NET mRNA

expression...................................................... 86 


\section{LIST OF FIGURES}

Figure 1.1 Schematic representation of neurotransmission steps at a synapse............................................................ 14

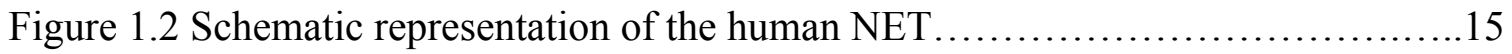

Figure 1.3 Alignment of the amino acid sequence of human NET and

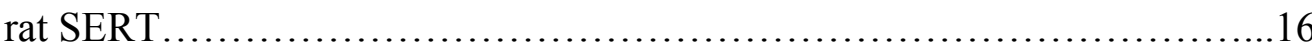

Figure 2.1 Dose-response of chronic desipramine-induced down-regulation of NET and antidepressant-like effect on behavior.

Figure 2.2 The recovery time-course of chronic desipramine on NET expression and antidepressant-like effect on behavior .51

Figure 2.3 The recovery time-course of chronic desipramine on extracellular NE level. ...

Figure 2.4 Effects of AMPT on chronic desipramine-induced antidepressant-like effect on behavior 56

Figure 3.1 The relationship between the effect of chronic protriptyline treatment on NET expression and its effect on behavior

Figure 3.2 The relationship between the effect of chronic reboxetine treatment on NET expression and its effect on behavior

Figure 3.3 The relationship between the effect of chronic sertraline treatment on SERT expression and its effect on behavior.

Figure 3.4 The relationship between the effect of chronic venlafaxine treatment on NET/SERT expression and its effect on behavior. .92 
Figure 3.5 Effects of repeated phenelzine treatment on NET/SERT

expression and behavior in the forced-swim test........................94

Figure 4.1 Ability of $\beta$-PMA and bryostatin- 1 to reduce immobility

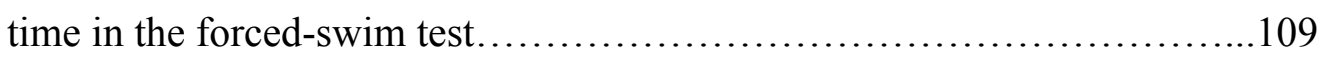

Figure 4.2 Effect of $\beta$-PMA on NET activity in rat cerebral coretex slices............111

Figure 4.3 Effect of bryostatin-1 on NET activity in rat cerebral

coretex slices..............................................113

Figure 4.4 Effects of okadaic acid, calyculin A and 2-APB on NET

activity in rat cerebral coretex slices...............................115 


\section{LIST of ABBREVIATIONS}

5-HT

AMPT

$\mathrm{CRH}$

ECT

HPA

ICV

IP

LC

MAOI

NE

NET

NK1R

NRIs

PCPA

PDE4

PKA

PKC

RT-PCR

SERT

SNRIs

SSRIs serotonin

alpha-methyl-para-tyrosine

corticotropin releasing hormone

electroconvulsive therapy

hypothalamic-pituitary-adrenal

intracelebroventracular

intraperitoneal

locus celeulous

monoamine oxidase inhibitor

norepinephrine

norepinephrine transporter

neurokinin-1 receptor

noradrenergic reuptake inhibitors

para-chlorophenyalanine

phosphodiesterase 4

protein kinase A

protein kinase $\mathrm{C}$

real-time polymerase chain reaction

sertonin transporter

serotonin-norepinephrine reuptake inhibitors

selective serotonin reuptake inhibitors 


\title{
CHAPTER 1
}

\author{
INTRODUCTION
}




\section{LITERATURE REVIEW}

\subsection{Depression and its treatment}

The mood disorders, primarily major depressive-anxiety and bipolar disorder, are among the most prevalent forms of mental illness and are associated with dramatic reductions in work capacity, overall health, and longevity (Thase and Denko, 2008; Nestler et al., 2002). Severe depression affects $2 \%-5 \%$ of the U.S. population during a single year; $20 \%$ of the population suffers from milder depression. Mood disorders are life threatening due to the high risk of suicide (Blazer, 2000; Akiskal, 2000).

Diagnosis of depression is based on symptomatic criteria in the Diagnostic and Statistical Manual (DSM-IV, 2000) and its severity can be quantified using the Hamilton depression rating scale (HAM-D) (Hamilton, 1960; Hamilton, 1967). These symptomatic criteria consist of depressed mood, irritability, low self-esteem, feelings of hopelessness, worthlessness, and guilt, decreased ability to concentrate and think, decreased or increased appetite, weight loss or weight gain, insomnia or hypersomnia, low energy, fatigue and increased agitation.

Roughly $40 \%-50 \%$ of the risk of depression is genetic (Sanders et al., 1999; Fava and Kendler, 2000), which makes depression a highly heritable disorder. However, the difficulty in finding specific genes implicated in depression is likely due to the fact that it is a complex psychiatric disease with many genes involved (Burmeister, 1999). Thus, any single gene might produce a relatively small effect and therefore its role would be difficult to detect experimentally. In addition, nongenetic factors are also the causes of depression. The nongenetic etiology of depression consists of stress, emotional trauma, viral infections, and random processes during brain development (Akiskal, 2000; Fava 
and Kendler, 2000). Episodes of depression usually occur in the context of stress, but stress is not sufficient to produce depression; i.e., not all people developing depression do so after a serious stress experience. It appears that depression is caused by interactions between genetic predisposition and environmental factors.

The finding that depletion of brain monoamines by reserpine, which blocks vesicular monoamine storages, induces despression-like symptoms, led to speculation that $\mathrm{NE}$ is deficient in depression. However, only a small number of individuals given reserpine actually develop depression. Further, depletion of monoamines by AMPT in normal subjects does not induce significant changes in mood (Salomon et al., 1997). Acute treatment with antidepressants that block the NET does not produce remission of symptoms of depression, even though the extraceullar NE level is elevated. Taken together, these findings argue against a simple role for NE in the pathology of depression and indicate that monoamine deficiency itself is insufficient to cause symptoms of depression (Miller et al., 1996b). However, rapid depletion of NE by AMPT results in depression relapse in the patients who have successfully responded to desipramine, an antidepressant that blocks the NET. A specific role for noradrenergic neurotransmission is suggested by the finding that NE-deficient mice fail to respond to the behavioral effects of the NE reuptake inhibitor desipramine. Restoration of NE by 1-threo-3,4dihydroxyphenylserine reinstates the behavioral effects of desipramine in these mice (Cryan et al., 2004).

Most of the NE in the brain arises from the cell bodies in the locus ceruleus (LC). The projections of these neurons are diffuse and overlap, nerve terminals in a wide range of brain regions including prefrontal and cingulate cortex, hippocampus, striatum, 
amygdala, and thalamus (Drevets, 2001; Liotti and Mayberg, 2001). These brain regions play an important role in the mediation of cognition, depression, and emotional memory. The function of these brain regions suggests the aspects of depression to which they may contribute. Neocortex and hippocampus might mediate the cognitive aspects of depression, e.g. impairment of memory, feeling of worthless, guilt and suicidality. The striatum and amygdala are believed to relate to emotional memory, anxiety, and reduced motivation, symptoms observed in depressed patients. The role of the hypothalamus is speculated to involve sleep, activity, appetite, energy and a loss of interest in sex in depression (Nestler et al., 2002).

The role of 5-HT in the mediation of depression parallels, in many ways, that of NE. Clinically, in untreated patients, it has been reported that reducing serotonergic activity with tryptophan depletion does not produce symptoms of depression in normal subjects (Miller et al., 1996b). However, inhibition of 5-HT synthesis with PCPA or a tryptophan-free amino-acid drink reverses the antidepressant effects of selective serotonin reuptake inhibitors (SSRIs) in depressed subjects (Miller et al., 1996a; Salomon et al., 1993).

The majority of brain serotonergic innervation originates in the dorsal and median raphe nuclei. The serotonergic neurons in these two nuclei project to almost every region of the brain, including cortical and subcortical areas. Neurons in the dorsal raphe project mostly to striatum and substantia nigra, while those in the median raphe project to septum and hippocampus. Serotonergic terminals densely innervate the limbic system.

The majority of depressed patients show improvement with antidepressant medications or electroconvulsive therapy (ECT). Specific antidepressant medications 
were first developed in the 1950s, with the discovery of two classes of agents, the monoamine oxidase inhibitors (MAOI) and tricyclic antidepressants. MAOI, e.g., phenelzine and iproniazid, elevate neurotransmission by inhibition of monoamine oxidase, a major catabolic enzyme involved in the degradation of monoamine neurotransmitters. Tricyclic antidepressants, e.g. imipramine and desipramine, inhibit the reuptake of NE or 5-HT by blocking the transporters (NET, SERT). Progress in antidepressant development advanced notably with the SSRIs, e.g., fluoxetine, sertraline, paroxetine; these result in fewer serious side effects and have less overdose hazard (Murphy et al., 2000). Subsequently, a selective norepinephrine reuptake inhibitors (NRIs) antidepressant was developed, i.e., reboxetine. The dual norepinephrine-serotonin reuptake inhibitors (NSRIs), venlafaxine and duloxetine, were then developed. Studies in inpatients and outpatients comparing venlafaxine with SSRIs e.g, fluoxetine, sertraline, and paroxetine reveal higher response or remission rates with the dual inhibitor venlafaxine (Clerc et al., 1994; Dierick et al., 1996; Ballus et al., 2000; Poirier and Boyer, 1999; Mehtonen et al., 2000) although other studies have not demonstrated superior efficacy (Thase et al., 2006). $\alpha-2$ Adrenergic receptor antagonists, e.g., idazoxan, yohimbine, and antipamizole, have been shown to exhibit some antidepressant-like activity, and increase neuronal firing and synaptic NE levels in conjunction with NRIs antidepressants in a synergistic manner (Dhir and Kulkarni, 2007; Schramm et al., 2001). 5- $\mathrm{HT}_{1 \mathrm{~A}}$ receptor agonists, e.g., buspirone, gepirone, and ipsapirone, were found to have antidepressant-like effects in animal models (Schreiber and de Vry, 1993; Yocca, 1990). Further, 5- $\mathrm{HT}_{2 \mathrm{~A}} / 5-\mathrm{HT}_{2 \mathrm{C}}$ antagonists, e.g., methysergide and cyproheptidine, produce antidepressant effects in depressed patients (Eison et al., 1990). 
Rolipram, a phosphodiesterase 4 (PDE4) inhibitor, also appears to have antidepressant activity (O’Donnell, 1993; Fleishchhacker et al., 1992), but its clinical efficacy compared with other antidepressants has been questioned (Hebenstreit et al., 1989). Although rolipram increases cyclic AMP by inhibiting its degradation, its effects are not mimicked by forskolin, an activator of adenylyl cyclase (O’Donnell, 1993). Rolipram was believed to increase NE turnover (Kehr et al., 1985) and the firing rate of neurons in the LC (Scuvee-Moreau et al., 1987). The antidepressant activity of rolipram has led to the hypothesis positing an inbalance between adenylyl cyclase/protein kinase A (PKA) systems and phospholipase C/PKC systems in depression (Wachtel, 1983).

Substance $\mathrm{P}$ antagonists and corticotropin releasing hormone (CRH) antagonists are two new classes of putative antidepressants. MK869, a substance P antagonist that blocks neurokinin-1 receptors (NK1R), has been found to be as effective as paroxetine in a 6-week double-blind trial in outpatients (Kramer et al., 1998; Maubach et al., 1999), although there have been subsequent failures in clinical trials (Herpfer and Lieb, 2005). The clinical failures suggest that, in addition to NK1R, other neurokinin receptors might be involved in the modulation of stress-related behaviors and that exclusive blockade of the NK1R might not be sufficient to produce consistent anxiolytic and antidepressant effects. NK2 (saredutant) and NK3 (osanetant) antagonists have been found to produce anxiolytic- and antidepressant-like effects in gerbils (Salome et al., 2006). Of special interest might be compounds that block more than one receptor type, e.g., NK1/2R antagonists or NK1/2/3R antagonists (Herpfer and Lieb, 2005; Griebel et al., 2001; Steinberg et al., 2001). The other mechanism of antidepressant effect of substance P antagonist is not clear, but may be associated with desensitization of $\alpha-2$ adrenergic 
receptors or 5- $\mathrm{HT}_{1 \mathrm{~A}}$ serotonergic autoreceptors (Fisher et al., 2007; Froger et al., 2001; Santarelli et al., 2001). CRH mediates hypothalamic-pituitary-adrenal (HPA) axis function, including autonomic and behavioral responses to acute and chronic stress (Owens and Nemeroff, 1993; Arborelius et al., 1999).

\subsection{Delayed onset of antidepressant effects}

The therapeutic actions of antidepressant drugs develop gradually over time with repeated treatment (Frazer and Benmansour, 2002; Nelson et al., 2004; Wong and Licinio, 2001). This is sometimes referred to as the "therapeutic lag" and appears to be a graded response that is somewhat symptom-dependent, rather than a lack of any therapeutic effect followed by its emergence (Katz et al., 2004; Frazer, 2000).

Both pharmacokinetic and pharmacodynamic mechanisms may underlie the progressively developing effects of antidepressants. Drugs such as desipramine have relatively long half-lives and their metabolites often have even longer half-lives (Ziegler et al., 1978). Thus, accumulation of both parent drug and active metabolites can occur with repeated treatment (Ordway et al., 2005). Further, it appears that the lipophilic nature of many antidepressants, including desipramine, contributes to their accumulation in membranes, where they have the potential to interact with the NET to an extent greater than would be predicted from plasma concentrations (Zhu et al., 2004; Mandela and Ordway, 2006).

$\alpha-2$ Adrenergic receptors, located presynaptically on noradrenergic neurons, regulate neuronal firing and NE release by a negative feedback mechanism. Excessive synaptic 
NE inhibits $\alpha-2$ adrenergic receptors and subsequently reduces the release of NE. Studies to date indicate that $\alpha-2$ adrenergic autoreceptors remain largely functional after chronic desipramine treatment (Garcia et al., 2004; Lapiz et al., 2007b) and likely cannot account for time-dependent changes resulting from such treatment.

The $5-\mathrm{HT}_{1 \mathrm{~A}}$ serotonergic autoreceptor plays a role in the effects of SSRIs treatment, because this receptor regulates neuronal firing and 5-HT release (Pineyro and Blier, 1999; Celada et al., 2004). It has been found that somantodetric $5-\mathrm{HT}_{1 \mathrm{~A}}$ autoreceptors are densensitized after chronic fluoxetine or sertraline treatment, which might be one of the mechanisms underlying the SSRIs-induced antidepressant-like effect. The receptor desensitization occurs at the level of effector coupling (Ase et al., 2001); a decrease in presynaptic 5- $\mathrm{HT}_{1 \mathrm{~A}}$ receptor G-protein coupling is observed after chronic fluoxetine treatment.

Repeated desipramine treatment causes other neuronal changes that may contribute to antidepressant activity, including increased expression of cAMP response element binding protein (CREB) and brain-derived neurotrophic factor (BDNF; Nibuya et al., 1996) and neurogenesis in the dentate gyrus of the hippocampus (Santarelli et al., 2003; Kodama et al., 2004; Chen at al., 2006; Sairanen et al., 2005). These findings could be involved in the delayed onset of antidepressants, since they require sufficient time to develop. In many cases of neuronal adaptation produced by antidepressant treatment, e.g., down-regulation of $\beta$-adrenergic receptors, the antidepressant-induced adaptation is homeostatic, i.e., in opposition to the acute drug effect. This contrasts with the progressive, unidirectional development of antidepressant effects in the clinical setting (Katz et al., 2004). It appears that similar neuroadaptive changes occurr for the long-term 
effects of SSRIs. Using quantitative autoradiography, a marked reduction of ${ }^{3} \mathrm{H}$-cyanoimipramine binding to the SERT is observed after chronic paroxetine or sertraline treatment. Similarly, using homogenate binding with ${ }^{3} \mathrm{H}$-citalopram, SERT binding sites in the rat prefrontal cortex are reduced after chronic paroxetine or sertraline treatment (Gould et al., 2006). Accordingly, the SERT reuptake activity (i.e., clearance) in the CA3 region of hippocampus is reduced after chronic treatment with SSRIs such as paroxetine and sertraline; desipramine does not affect SERT function (Benmansour et al., 2002). The extracellular 5-HT concentration, measured by in vivo microdialysis, is elevated in the hippocampus and caudate nucleus in the awake monkey after 3-day fluoxetine treatment (Smith et al., 2000).

\subsection{Animal models of depression}

The lack of fully validated animal models retards depression research to some degree; the symptoms of depression (e.g. depressed mood, feeling of worthlessness, guilty and suicidality) are not easily produced in laboratory animals. Also, the genetic causes of depression cannot be replicated in animals since the depression vulnerability genes are still unknown. The dilemma is that animal depression models are needed to explore the mechanism of depression, but such models can only be developed after mechanisms underlying depression are better understood. Animal behaviors that model particular aspects of depression, e.g. impairment of cognition, abnormal psychomotor activity, responses to stresses and pleasurable stimuli, appetite, and sleep can be 
evaluated, as can behavior that exhibits sensitivity to antidepressant treatment (Table $1.1)$. 
Table 1.1 Examples of animal models used in depression research

\begin{tabular}{|c|c|}
\hline 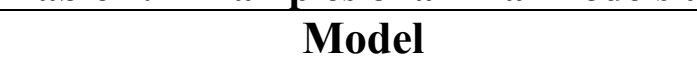 & Features \\
\hline Forced-swim test & $\begin{array}{l}\text { Antidepressants decrease immobility time in } \\
\text { a cylinder of water; lack of movement } \\
\text { thought to represent a state of despair } \\
\text { (Porsolt et al., 1977). }\end{array}$ \\
\hline Tail-suspension test & $\begin{array}{l}\text { Antidepressants increase the struggling time } \\
\text { of mice when suspended by the tail; lack of } \\
\text { movement thought to represent a state of } \\
\text { despair; Used in mice only. }\end{array}$ \\
\hline $\begin{array}{l}\text { Differential-reinforcement-low-rate 72-s } \\
\text { operant schehdule }\end{array}$ & $\begin{array}{l}\text { Antidepressants reduce the response rate and } \\
\text { increase the reinforcement rate (O'Donnell, } \\
2005 \text { ) }\end{array}$ \\
\hline Chronic mild stress & $\begin{array}{l}\text { The animals subjected to random sequence } \\
\text { of mild stresses, i.e. cold, restrain, cages } \\
\text { tilting, disruption of light-dark cycle, } \\
\text { develop a series of abnormal behavioral and } \\
\text { physiological responses. These } \\
\text { abnormalities are corrected by chronic } \\
\text { antidepressant. (Willner, 1997) }\end{array}$ \\
\hline Learned helplessness & $\begin{array}{l}\text { The animals are exposed to inescapable foot } \\
\text { shock and then develop escape deficit. This } \\
\text { deficit is reversed by chronic antidepressants } \\
\text { (Chen et al., 2001; Shirayama et al., 2002; } \\
\text { Vollmayr and Henn, 2001). }\end{array}$ \\
\hline Olfactory bulbectomy & $\begin{array}{l}\text { Chemical or surgical lesions of olfactory } \\
\text { cause hyperactivity and other abnormal } \\
\text { behaviors, which are reversed by chronic } \\
\text { antidepressants (Kelly et al., 1997) }\end{array}$ \\
\hline Open space swim test & $\begin{array}{l}\text { Antidepressants increase the swimming } \\
\text { distance (Sun and Alkon, 2005). }\end{array}$ \\
\hline
\end{tabular}




\subsection{Molecular structure and function of NET and SERT}

The duration and the intensity of noradrenergic and serotonergic neurotransmitter action are controlled by plasma membrane-bound transporters. After release into the synapse, neurotransmitters activate pre- or postsynaptic receptors. The termination of synaptic transmission is mostly completed by reuptake back into neurons or uptake into glial cells by neurotransmitter transporters (Figure 1.1).

The NET and SERT belong to a family of $\mathrm{Na}^{+} / \mathrm{Cl}^{-}$dependent symporters that also include transporters for dopamine, glycine, and GABA (Amara, 1992; Masson et al., 1999). Electrochemical energy derived from the inward gradient of $\mathrm{Na}^{+}$, provided by $\mathrm{Na}^{+} / \mathrm{K}^{+}$-ATPase, drives the intracellular accumulation of neurotransmitter via the NET or SERT. Binding of $\mathrm{Na}^{+}$and then $\mathrm{Cl}^{-}$is a prerequisite for the substrate to bind to the transporter (Trendelenburgh, 1999). Following the binding of substrate, both $\mathrm{Na}^{+}$and $\mathrm{Cl}^{-}$ are co-transportered along with the substrate into the cytoplasm.

Both NET and SERT proteins include 12 transmembrane domains and sites for glycosylation and phosphorylation (Figure 1.2). Analysis of NET and SERT structure reveals important information regarding the residues and domains responsible for NET function, substrate binding, drug binding, phosphorylation and regulation. The NET protein consists of 617 (human NET and rat NET) or 615 (bovine NET) amino acids (Pacholczyk et al., 1991). Both amino and carboxy termini of the NET are located on the cytoplasmic side. The NET contains a large hydrophilic loop between TMD3 and TMD4, within which are located the canonical sites for N-linked glycoslation (Blakely, 1994). Inability to N-glycosylate the NET is associated with reduced protein stability, surface trafficking, and transporter activity (Melikian et al., 1994). Addition of a 
carbohydrate moiety was shown to significantly increase uptake (Melikian et al., 1994; Nguyen and Amara, 1996). It is likely that glycosylated NET proteins are expressed on the membrane and non-glycosylated forms are retained in the cytoplasm, which makes the glycosylation site a poteintial domain for regulation of NET function. In addition to glycosylation sites, there are sites of potential phosphorylation by PKC within the intraceullar part of the NET. For example, the phosphorylation of threonine-258 and serine-259 located at the small intracellular loop between DM4 and DM5 is linked to PKC-mediated NET protein internalization (Jayanthi et al., 2006). Several sites of phosphorylation by other protein kinases also have been found. Threonine-30, threonine58, and serine-502 are potential PKA phosphorylation sites. Threonine-19 and threonine583 are potential phosphorylation sites for casein kinase II (CKII) (Jayanthi et al., 2006). The predicted topological structure of SERT is very similar with the NET. The SERT also has N-linked glycosylation sites on the large extracellular loop between TMD 3 and TMD4 as well as homologous, potential phosphorylation sites. 


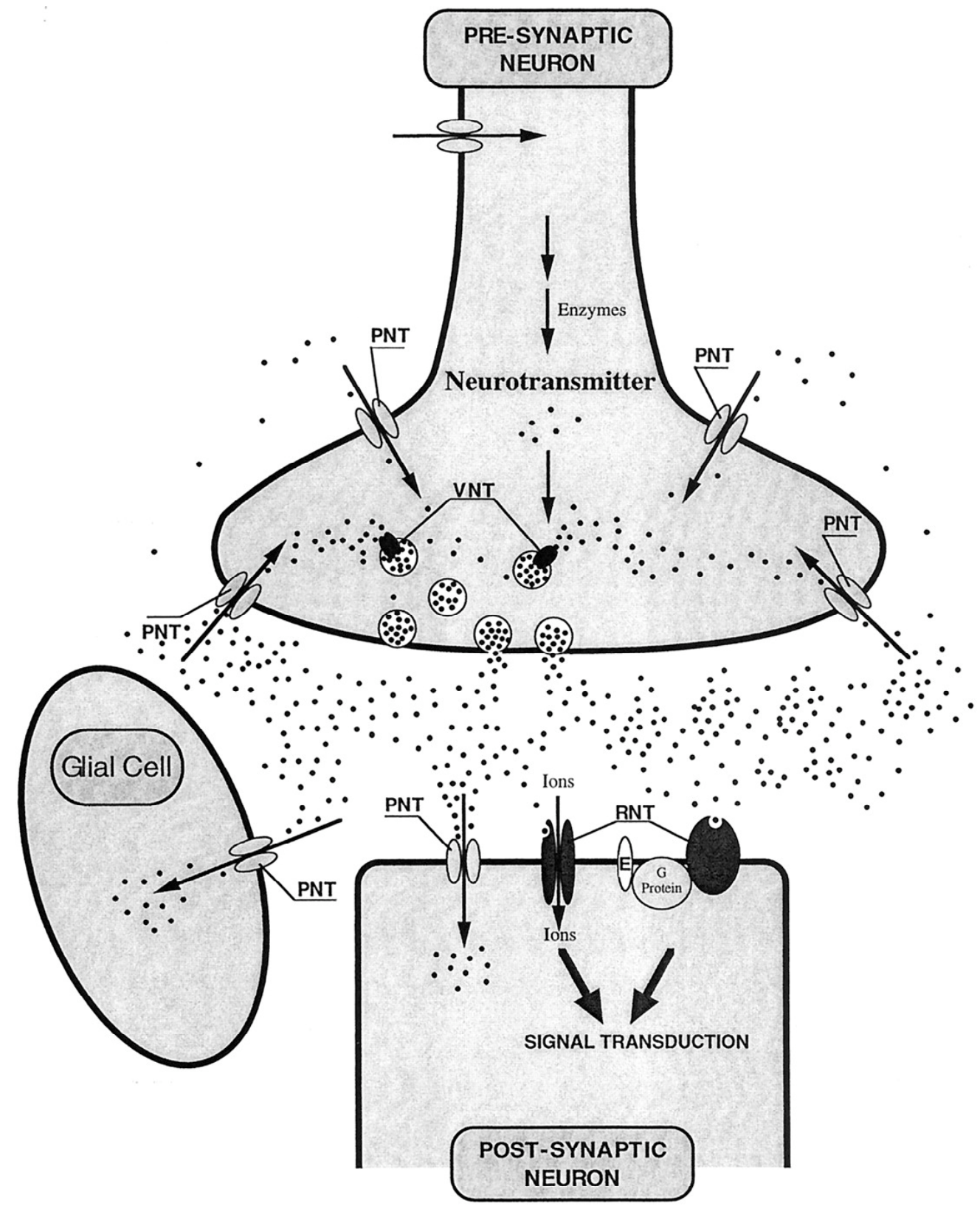

Figure 1.1 Schematic representation of neurotransmission steps at a synapse. The neurotransmitter is synthesized in the presynaptic neuron, stored in synaptic vesicles by the VNT, and released by exocytosis. The neurotransmitter then binds to receptors as an effector, and is removed from the synaptic cleft by membrane-bound neurotransmitter transporters (NET or SERT) through the reuptake process in presynaptic or postsynaptic neurons and/or glial cells (Masson et al., 1999). 


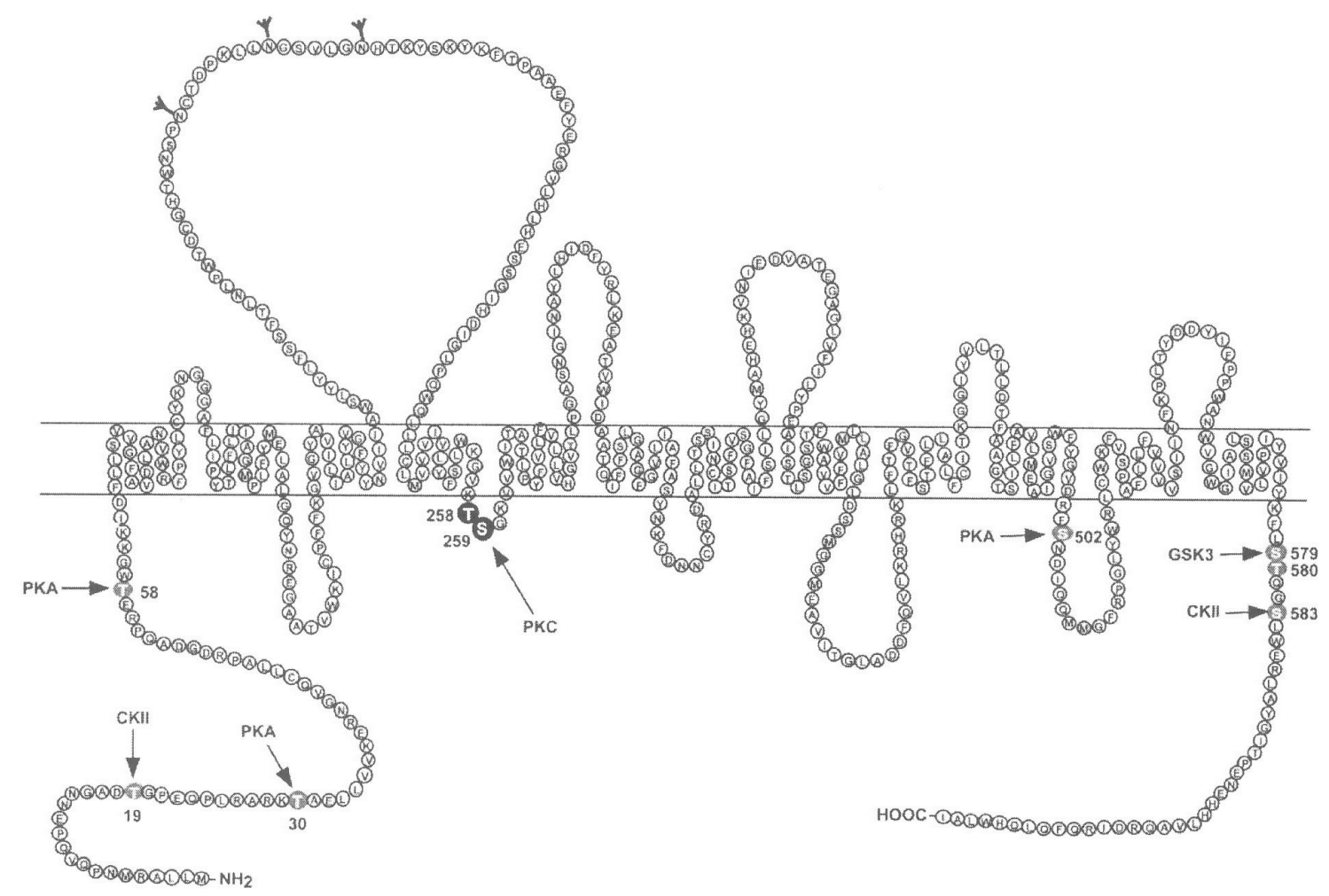

Figure 1.2 Schematic representation of the human NET. Large black circles indicate potential phosphorylation sites for $\mathrm{PKC}$; large gray circles indicate potential phosphorylation sites for other kinases (Jayanthi et al., 2006). 


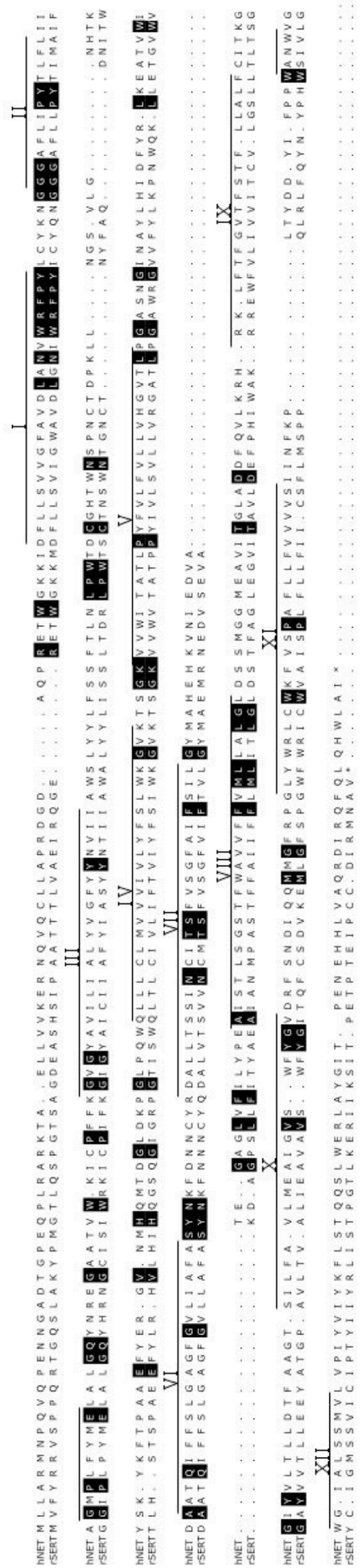

Figure 1.3 Alignment of the amino acid sequence of human NET and rat SERT. The putative $\alpha$-helical membrane spanning domains (I - XII) are indicated by bars. Conserved residues are shaded (Pacholczyk et al., 1991; Blakely et al., 1991; Hoffman et al., 1991). 


\subsection{Noradrenergic reuptake inhibitors and selective serotonin reuptake inhibitors}

NRIs and SSRIs elevate synaptic NE and 5-HT levels, respectively, by blocking the NET or SERT. The first tricyclic antidepressant, imipramine, elicited antidepressant effects by inhibiting NET and SERT with some unfavorable side effects due to antihistaminic, antiadrenergic, and anticholinergic effects (Ban, 2001). Other tricyclic antidepressants exhibit some selectivity for inhibition NE reuptake, e.g, desipramine, protriptyline, and nortriptyline, or 5-HT reuptake, e.g., clomipramine; however, the side effect profiles were still unfavorable. The introduction of fluoxetine in 1988 provided a safer treatment alternative to the tricyclic antidepressants since its side effect profile was significantly improved. However, some have questioned whether the SSRIs are as efficacious at treating depression as the tricyclic antidepressants (Song, 1993). The thought that actions on both noradrenergic and serotonergic neurotransmission may be advantageous led to the development of venlafaxine and duloxetine, which inhibit both the NET and SERT and which have a favorable side-effect profile (Shelton, 2004). The development of reboxetine, a potent, selective, and specific NE reuptake inhibitor, shifts from focusing on the 5-HT system to the NE system. In vitro, reboxetine is about 120fold more potent at blocking NE reuptake than 5-HT reuptake (Wong et al., 2000). Extensive clinical study indicated that reboxetine is a clinically active, efficacious, and well tolerated antidepressant (Berzewdski et al., 1997). 
Table 1.2 Structure of antidepressants and Ki values for inhibition of NET and SERT

\begin{tabular}{|c|c|c|c|}
\hline Structure & Antidepressant & $\begin{array}{l}{\left[{ }^{3} \mathrm{H}\right] 5-\mathrm{HT} \text { uptake }} \\
\text { inhibition } \\
\mathrm{Ki}(\mathrm{nM})\end{array}$ & $\begin{array}{l}{\left[{ }^{3} \mathrm{H}\right] \mathrm{NE} \text { uptake }} \\
\text { inhibition } \\
\mathrm{Ki}(\mathrm{nM})\end{array}$ \\
\hline & Imipramine & $20 \pm 2$ & $142 \pm 8$ \\
\hline & Desipramine & $163 \pm 5$ & $3.5 \pm 0.6$ \\
\hline & Protriptyline & 3.4 & 161 \\
\hline & Fluoxetine & $20 \pm 2$ & $2186 \pm 142$ \\
\hline & Sertraline & $3.3 \pm 0.4$ & $1716 \pm 151$ \\
\hline & Venlafaxine & $102 \pm 9$ & $1644 \pm 84$ \\
\hline & *Reboxetine & $1070 \pm 3$ & $8 \pm 4$ \\
\hline
\end{tabular}

Data were obtained in HEK and *MDCK cells expressing hSERT and hNET (White et al., 2005; Wong et al., 2000; Sanchez and Hyttel, 1999; Zhou, 2004) 


\subsection{Regulation of NET}

The NET is regulated by several intraceullar signaling molecules including cAMP, PKA, PKC, p38 MAPK, $\mathrm{Ca}^{2+}$, CaM kinase II, protein phosphatases P1/PP2A, and ATP.

\section{cAMP and PKA}

cAMP, produced by activation of adenylyl cyclase, is a key component linking upstream $\mathrm{G}$ protein-coupled receptors to downstream signaling cascades, e.g., activation of PKA. Research on the regulation by cAMP and PKA of NET activity has yielded results that are not consistent across cell lines or species. For example, membrane permeable cAMP analogue 8 Br-cAMP induces a dose-dependent reduction of NET activity in bovine adrenal medullary chromaffin cells (Bunn et al., 1992). However, 8 Br-cAMP doesn't change the NET activity in SK-N-SH (Apparsundaram et al., 1998b) and SK-N-SH-SY5Y cells (Bonisch et al., 1998). Forskolin, a compound that increases intracellular cAMP by directly activating adenylyl cyclase, shows biphasic effects on NET activity in chromaffin cells. At a low concentration, forskolin increases in NET activity; while at a high concentration it inhibits NET activity (Bunn et al., 1992). BryanLluka et al. (2001) found that short-term (15 min) or long-term $(24 \mathrm{~h})$ treatment with forskolin decreases NET activity in PC12 cells. However, in COS7 cells transiently transfected with rat NET cDNA, short-term treatment with forskolin does not affect NET activity, while long-term treatment increases the NET activity (Bryan-Lluka et al., 2001). Taken together, these data suggests that cAMP regulation is not a general mechanism in NET regulation but is cell line- and species-dependent. 


\section{PKC}

The NET is the target for PKC; phosphorylation sites for this kinase have been shown for this transporter. $\beta$-PMA, a PKC activator, reduces NET activity and surface expression in HEK-293 and LLC-PK1 cells stably transfected with hNET (Apparsundaram et al., 1998a) as well as rat placental trophoblasts (Jayanthi et al., 2004). The decreased NET activity is characterized by a decrease in maximum transport velocity $\left(\mathrm{V}_{\max }\right)$ and a slight decrease in substrate affinity $\left(\mathrm{K}_{\mathrm{m}}\right)$. This reduction is primarily due to the internalization of surface NET protein (Jayanthi et al., 2004). Site-directed mutagenesis reveals that threonine-258 and serine-259 on the hNET are phosphorylated by PKC and that this results in transporter internalization (Jayanthi et al., 2006). NET activity also is reduced by the protein phosphatase 1/protein phosphatase $2 \mathrm{~A}(\mathrm{PP} 1 / 2 \mathrm{~A})$ inhibitors okadaic acid and calyculin A; these compounds prevent dephosphorylation (Bauman et al., 2000).

\section{P38 MAPK}

A trafficking-independent mode of NET and SERT regulation that is sensitive to p38 MAPK has been identified in RBL-2H3, RN46A, and CHO cells transfected with either NET or SERT (Zhu et al., 2004; Zhu et al., 2005). NET activity measured by NE uptake assay is stimulated by anisomycin, a p38 MAPK activator. Also, SB203580, a p38 MAPK inhibitor, blocks anisomycin-induced activation of NET. In comparison with trafficking-depedent, PKC-dependent regulation in which the surface transporter density changes with unchanged catalytic activation, anisomycin treatment does not change maximal transport capacity $\left(\mathrm{V}_{\max }\right)$ but significantly reduces the affinity $\left(\mathrm{K}_{\mathrm{m}}\right)$, indicating a 
trafficking-independent regulation mode. Moreover, a reduced displacement of $\left[{ }^{125} \mathrm{I}\right] \mathrm{RTI}-55$, a competitive antagonist of 5-HT, from the SERT was observed, suggesting a reduced affinity of SERT for 5-HT. The observation that inhibiton of PP2A by okadaic acid and calyculin A reverses anisomycin-induced activation of the transporters indicates that PP2A is downstream of the p38 MAPK signaling pathway. At high concentrations, PP2A inhibitors reduce transporter activity, which might be due to the actions of PKC and subsequent sequestration of surface transporters.

\section{$\mathrm{Ca}^{2+}$ and CaM kinase II}

Extraceullar $\mathrm{Ca}^{2+}$ plays an important role in NET activity. NET activity in PC12 cells shows a robust increase after incubation with $0.3-10 \mathrm{mM} \mathrm{Ca} 2^{2+}$ (Uchida et al., 1998). Intraceullar $\mathrm{Ca}^{2+}$ released from endoplastic reticulum also is important in regulating NET activity. $\mathrm{IP}_{3}$ receptors located on the membrane of the endoplasmic reticulum regulate release of $\mathrm{Ca}^{2+}$ stores. 2-APB, an $\mathrm{IP}_{3}$ receptor inhibitors, reduces NET activity by inhibiting the $\mathrm{Ca}^{2+}$ release from endoplasmic reticulum in SH-SY5Y cells (Amano et al., 2006) and rat cerebral cortex slices (unpublished data). $\mathrm{Ca}^{2+} /$ calmodulin dependent kinase II (CaMKII) is able to directly phosphorylate the trasnporter and increase NET activity by translocation of NET from the cytoplasm to the membrane. Myosin light chain kinase (MLC kinase) also enhances NET activity by phosphorylation of specific amino acid residues on the transporter. CaMKII and MLC kinase inhibitors robustly inhibit $\mathrm{Ca}^{2+}$-dependent increases in NET activity. External $\mathrm{Ca}^{2+}$ regulates transporter activity by increasing NE uptake through CaM kinase II and MLC kinase rather than decreasing NE uptake via the PKC signaling pathway, suggesting that NET activity is 
regulated by both an external $\mathrm{Ca}^{2+}$ activation-induced pathway and an internal pathway regulating release of $\mathrm{Ca}^{2+}$ stores.

\section{ATP}

ATP is an important molecule in biological systems, providing the energy for a variety of cellular functions. ATP is present in the vesicles that store neurotransmitters, which raises the possibility that ATP might be a co-transmitter. Geffen and Livett (1971) found that ATP is released with NE during depolarization. Further study shows that the high-affinity uptake of NE in PC12 cells is increased in the presence of $\mathrm{Ca}^{2+}$ and $0.1 \mu \mathrm{M}$ ATP or ATP-gamma-S, an analog of ATP (Hardwick et al., 1989). This ATP-induced increase of $\mathrm{NE}$ uptake is reduced by $\operatorname{App}(\mathrm{NH}) \mathrm{p}$, a competitive antagonist of ATP (Hendley et al., 1988). NE uptake is inhibited when the $\mathrm{Ca}^{2+}$ and $\mathrm{Mg}^{2+}$ are both absent from the incubation medium, suggesting that divalent cations are required for ATP to have its effect on NE uptake.

\section{Regulation of the NET by neurotransmitters}

The following neurotransmitters are found to be involved in the regulation of NET activity: acetylcholine, insulin, GABA, angiotensin, nerve growth factor, natriuretic peptides, and nitric oxide. Some are to be discussed below.

\section{Acetylcholine}

The muscarinic acetylcholine receptor agonist methacholine significantly reduces NET maximum transport velocity with no change in $\mathrm{K}_{\mathrm{m}}$ value in SK-N-SH cells 
(Apparsundaram et al., 1999). Methacholine treatment decreases NET binding sites measured by ${ }^{3} \mathrm{H}$-nisoxetine in intact cells but not in total membrane factions. These studies provide evidence in support of G-protein coupled receptor-mediated regulation of the NET.

\section{Insulin}

Insulin is a hormone involved in regulating glucose homeostasis. The effect of insulin on NET activity has been studied in SK-N-SH and PC12 cells. Acute insulin treatments increases NE uptake in a time- and dose-dependent manner with enhancement of NE transport capacity $\left(\mathrm{V}_{\max }\right)$ without an alteration in the $\mathrm{K}_{\mathrm{m}}$ for $\mathrm{NE}$ (Apparsundaram et al., 2001). Acute insulin treatment decreases NE uptake in PC12 cells (Figlweicz et al., 1993a) and this decrease may be due to the effect of insulin on the transporter gene transcription, as insulin is found to decrease NET mRNA expression in LC of the rat (Figlewicz et al., 1993b). The insulin receptor is a tyrosine kinase that phosphorylates substrate proteins, including the insulin receptor substrate (IRS) family. Once phosphorylated, the IRS binds to and activates its downstream proteins including phosphatidylinositol 3-OH kinase (PI3K). Tyrosine kinase and PI3K inhibitors produce time- and concentration-dependent reduction of NE uptake, indicating that constitutive tyrosine kinase and PI3K activity is necessary for NET activity (Apparsundaram et al., 2001). Effects of tyrosine kinase and PI3K inhibitors on basal NET uptake might contribute to a loss of cell surface NET protein expression (Apparsundaram et al., 2001). 


\section{Nitric oxide}

Nitric oxide is a signaling molecule in the cardiovascular system and central nervous system. After exposure to the NO donor S-nitroso-N-acetylpenicillamine (SNAP), NET activity is reduced through a cyclic GMP-independent manner in CHO cells (Kaye et al., 2000), indicating a potential regulatory role for nitric oxide in modulating NET activity. However, in SK-N-SH cells, SNAP treatment shows an elevation of uptake activity (Apparsundaram et al., 1998a). More research is needed to explore the molecular mechanism of nitric oxide. 


\section{CHAPTER TWO}

\section{Norepinephrine transporter regulation mediates long- term behavioral effects of antidepressant desipramine}

This chapter is identical to a manuscript, which has been published in

Neuropsychopharmacology, 2008 Apr 16. [Epub ahead of print] 


\subsection{Abstract}

The relationship between the ability of repeated desipramine treatment to cause downregulation of the norepinephrine transporter (NET) and produce antidepressant-like effects on behavior was determined. Treatment of rats with $15 \mathrm{mg} / \mathrm{kg} /$ day desipramine reduced NET expression, measured by ${ }^{3} \mathrm{H}$-nisoxetine binding and SDSPAGE/immunoblotting, in cerebral cortex and hippocampus and reduced the time of immobility in the forced-swim test. The antidepressant-like effect on forced-swim behavior was evident two days following discontinuation of desipramine treatment when plasma and brain levels of desipramine and its major metabolite desmethyl-desipramine were not detectable. Reduced NET expression resulted in reduced norepinephrine uptake, measured in vitro, and increased noradrenergic neurotransmission, measured in vivo using microdialysis. Overall, the dose-response and time-of-recovery relationships for altered NET expression matched those for production of antidepressant-like effects on behavior. The importance of increased noradrenergic neurotransmission in the persistent antidepressant-like effect on behavior was confirmed by demonstrating that it was blocked by inhibition of catecholamine synthesis with alpha-methyl-p-tyrosine. The present results suggest an important role for NET regulation in the long-term behavioral effects of desipramine and are consistent with clinical data suggesting that enhanced noradrenergic neurotransmission is necessary, but not sufficient, for its antidepressant actions. Understanding the mechanisms underlying NET regulation in vivo may suggest novel targets for therapeutic intervention in the treatment of depression. 


\subsection{Introduction}

The therapeutic actions of antidepressant drugs develop gradually over time with repeated treatment (Frazer and Benmansour, 2002; Nelson et al., 2004; Wong and Licinio, 2001). This is sometimes referred to as the "therapeutic lag" and appears to be a graded response that is somewhat symptom-dependent, rather than a lack of any therapeutic effect followed by its emergence (Katz et al., 2004; Frazer, 2000). This delayed activity has raised questions regarding the relevance of the acute neurochemical effects of antidepressants, such as enhancement of monoaminergic neurotransmission, to their long-term effects on behavior. It has been argued that since the acute neurochemical effects manifest early, they cannot, in and of themselves mediate the slower developing therapeutic effects. However, while enhancement of monoaminergic activity may not be sufficient to produce antidepressant effects, it does appear to be necessary. This is evident from the finding that inhibition of synthetic enzymes for norepinephrine (NE) or 5-HT results in a rapid return of symptoms in depressed patients treated successfully with desipramine or fluoxetine, respectively (Charney, 1998; Miller et al., 1996a). Further, inhibition of catecholamine synthesis with alpha-methyl-ptyrosine (AMPT) increases depressive symptoms in patients with seasonal affective disorder (Lam et al., 2001). Similarly, reduction of 5-HT synthesis with parachlorophenylalanine or a tryptophan-free amino acid drink reverses symptom remission induced by serotonin reuptake inhibitors (SRIs) (Salomon et al., 1993).

Both pharmacokinetic and pharmacodynamic mechanisms may underlie the progressively developing effects of antidepressants. Drugs such as desipramine have relatively long half-lives and their metabolites often have even longer half-lives (Ziegler 
et al., 1978). Thus, accumulation of both parent drug and active metabolites can occur with repeated treatment (Ordway et al., 2005). Further, it appears that the lipophilic nature of many antidepressants, including desipramine, contributes to their accumulation in membranes, where they have the potential to interact with the NE transporter (NET) to an extent greater than would be predicted from plasma concentrations (Zhu et al., 2004; Mandela and Ordway, 2006).

At early stages of desipramine treatment, noradrenergic neurotransmission is enhanced as a direct consequence of transporter blockade (See et al., 1992). Subsequently, dynamic, adaptive neuronal changes occur, such as down-regulation of $\beta$ adrenergic receptors (Frazer and Conway, 1984; Ordway et al., 1988; Duncan et al., 1993), desensitization of presynaptic $\alpha-2$ adrenergic receptors (Sacchetti et al., 2001), and down-regulation of the NET (Weinshenker et al., 2002). In many cases of neuronal adaptation, e.g., down-regulation of $\beta$-adrenergic receptors, the antidepressant-induced adaptation is homeostatic, i.e., in opposition to the acute drug effect. This contrasts with the progressive, unidirectional development of antidepressant effects in the clinical setting (Katz et al., 2004). Further, studies to date indicate that $\alpha-2$ adrenergic autoreceptors remain largely functional after chronic desipramine treatment (Garcia et al., 2004; Lapiz et al., 2007b) and likely cannot account for time-dependent changes resulting from such treatment. However, antidepressant-induced NET regulation appears to be consistent with the clinical data. It shows a time-course consistent with the delayed therapeutic effects and parallels the gradual onset of antidepressant-induced effects on depressive symptoms (Benmansour, et al., 2002; Katz et al., 2004). Repeated, but not acute, treatment with desipramine reduces NET expression in brain, determined by ${ }^{3} \mathrm{H}$ - 
nisoxetine binding and Western blotting (Benmansour et al., 2004; Zhu et al., 2002). This may be a direct effect of desipramine, rather than being secondary to increased synaptic concentrations of $\mathrm{NE}$, since it also occurs in vitro with $\mathrm{PC} 12$ and human neuroblastoma cells (Zhu and Ordway, 1997; Zhu et al., 2005), as well as HEK-293 cells transfected with the NET (Zhu et al., 1998).

The goal of the present study was to determine the relationship between effects of repeated desipramine treatment on NET expression and function in the brain and its antidepressant-like effects on behavior. This was determined by assessing the effects of repeated desipramine treatment on NET expression and function in cerebral cortex and hippocampus, noradrenergic neurotransmission using in vivo microdialysis, and effects on behavior using the forced-swim test. The results indicate that repeated treatment with desipramine down-regulates the NET in the cerebral cortex and hippocampus, reducing NE uptake, which results in increased noradrenergic neurotransmission and antidepressant-like effects on behavior. 


\subsection{Materials and Methods}

\section{Animals}

Male Sprague-Dawley rats (Harlan, Indianapolis, IN), weighing 300-350g, were housed 2 per cage in a temperature-controlled room $\left(22-23^{\circ} \mathrm{C}\right)$ with a $12-\mathrm{h}$ on/12-h off light cycle (lights on at 6:00 AM). Food and water were freely provided. Blind observations were used throughout all behavioral testing, which was carried out from 1:00 PM - 5:00 PM in a quiet room. All procedures were reviewed and approved by the Animal Care and Use Committees of West Virginia University Health Sciences Center and the University of Texas Health Sciences Center at San Antonio, and are consistent with the NIH "Guidelines for the Care and Use of Laboratory Animals" (NIH publication No. 80-23, revised 1996).

\section{Chronic desipramine administration}

Rats were anesthetized with ketamine $(100 \mathrm{mg} / \mathrm{kg})$ and xylazine $(10 \mathrm{mg} / \mathrm{kg})$ and implanted subcutaneously with osmotic minipumps (model 2ML2, Alzet Corporation, Palo Alto, CA) preloaded with either vehicle (50\% saline, 40\% DMSO, and 10\% ethanol) or desipramine (Sigma-Aldrich, St Louis, MO) at a concentration that delivered 5, 10, or $15 \mathrm{mg} / \mathrm{kg} /$ day of the free base (Benmansour et al., 2004). Minipumps were removed, under anesthesia, 14 days later. Rats were tested for antidepressant-like behavior in the forced-swim test $2-8$ days after pump removal and discontinuation of desipramine treatment. Following the completion of the behavioral tests, rats were killed by decapitation, their brains removed, and cerebral cortex and hippocampus dissected for neurochemical analyses. 


\section{Forced-swim test}

The forced-swim test was carried out as described previously (Porsolt et al., 1977; Zhang et al., 2006). Plexiglas cylinders (40 cm high and $18 \mathrm{~cm}$ in diameter) were filled with water $\left(30 \mathrm{~cm}\right.$ depth, $\left.22-23{ }^{\circ} \mathrm{C}\right)$; at this depth, rats could not touch the bottom of the cylinder with their tails or hind limbs. On day 1 (i.e., 1 day after cessation of desipramine treatment), the rats were pre-tested for 15 min to develop an immobility posture after initial escape-oriented movements (Cryan et al., 2002). On day 2 (2 days after cessation of desipramine treatment), rats were subjected to the 5-min forced-swim test and immobility time was recorded; immobility was defined as floating on the surface of the water with the only movement being that required to keep the head above water. Some rats were subjected to 5-min forced-swim testing 5 or 8 days after the end of the desipramine treatment regimen (15-min pre-test after 4 or 7 days, respectively), in order to determine the time of recovery. Finally, in some tests, rats were administrated 150 or $300 \mathrm{mg} / \mathrm{kg}$ AMPT (Sigma-Aldrich, St Louis, MO) 4 hours prior to the 5-min forcedswim test, to examine the effects of catecholamine depletion on chronic desipramineinduced changes in immobility.

\section{SDS-PAGE/Immunoblotting of NET protein in the rat brain}

Cerebral cortex and hippocampus were homogenized in TEVP buffer (10 mM Tris base, $5 \mathrm{mM} \mathrm{NaF}, 1 \mathrm{mM} \mathrm{Na} \mathrm{VO}_{4}, 1 \mathrm{mM}$ EDTA, 1 mM EGTA, 320 mM sucrose; $\mathrm{pH}$ 7.4) with a glass homogenizer and centrifuged at $1,000 \times \mathrm{g}$ for $20 \mathrm{~min}$ at $4^{\circ} \mathrm{C}$. The supernatant was centrifuged at $20,000 \times \mathrm{g}$ for $30 \mathrm{~min}$ to obtain a crude synaptosomal fraction (Lin et al., 1998; Wyszynski et al., 1998; Dunah and Standaert, 2001). The 
pellets were re-suspended and solubilized with RIPA buffer (50 mM Tris, $150 \mathrm{mM} \mathrm{NaCl}$, 2\% IGEPAL CA-630, 0.5\% sodium deoxycholate, $0.1 \%$ SDS, and $0.1 \%$ Triton X-100; $\mathrm{pH}$ 8.0) containing protease inhibitors (Roche, Indianapolis, IN). Protein content of membrane lysate was measured using the bicinchoninic acid protein assay (Smith et al., 1985; Pierce, Rockford, IL). Equal amounts of protein from both control and treated rats were mixed with $2 \mathrm{X}$ Laemmli sample buffer (Bio-Rad, Hercules, CA) and boiled at $100^{\circ}$ C for 3 min. Samples were loaded onto $8 \%$ polyacrylamide gels for electrophoresis and, after separation, transferred to the nitrocellulose membranes. The membranes were blocked in TBST buffer containing 5\% nonfat milk for $2 \mathrm{~h}$ at room temperature, washed with TBST buffer, and incubated overnight at $4^{\circ} \mathrm{C}$ with a specific polyclonal antibody generated against a unique 22 amino acid peptide sequence mapping to the first extracellular domain of the NET (Chemicon, Temecula, CA). After washing with TBST, membranes were incubated for $1 \mathrm{~h}$ at room temperature with horseradish peroxidaseconjugated goat anti-rabbit immunoglobulin G (Pierce, Rockford, IL). The labeled protein bands were detected by chemiluminescence imaging (Bio-Rad, Hercules, CA) and quantified by densitometry. Comparisons of treatment effects were carried out within single gels.

\section{${ }^{3}$ H-Nisoxetine binding assay}

${ }^{3} \mathrm{H}-\mathrm{Nisoxetine} \mathrm{binding} \mathrm{to} \mathrm{the} \mathrm{NET} \mathrm{was} \mathrm{carried} \mathrm{out} \mathrm{as} \mathrm{described} \mathrm{previously} \mathrm{(Tejani-}$ Butt et al., 1990; Bryan-Lluka et al., 2001). Briefly, half of the entire cerebral cortex and hippocampus were homogenized in $5 \mathrm{ml}$ of ice-cold binding buffer (50 $\mathrm{mM}$ Tris base, $120 \mathrm{mM} \mathrm{NaCl}, 5 \mathrm{mM} \mathrm{KCl}$; pH 7.4) using a Polytron (Brinkman Instruments, Westbury, 
$\mathrm{NY}$ ) and then centrifuged at $36,000 \times \mathrm{g}$ for $10 \mathrm{~min}$ at $4^{\circ} \mathrm{C}$. The supernatant was discarded, the pellet re-suspended in ice-cold binding buffer, centrifuged at 36,000 $\times \mathrm{g}$ for $10 \mathrm{~min}$ at $4^{\circ} \mathrm{C}$, and the pellet re-suspended in binding buffer to obtain a protein concentration of $1 \mathrm{mg} / \mathrm{ml}$ as assayed using the bicinchoninic acid method (Smith, 1985; Pierce, Rockford, IL). Triplicate tubes containing $100 \mu 1$ incubation buffer (total binding) or $100 \mu \mathrm{l}$ desipramine (final concentration $50 \mu \mathrm{M}$; non-specific binding), $100 \mu \mathrm{l}$ tissue sample, and $50 \mu 1{ }^{3} \mathrm{H}$-nisoxetine (final concentration $5 \mathrm{nM} ; 72 \mathrm{Ci} / \mathrm{mmol}$, PerkinElmer, Boston, MA) were incubated in a shaking ice bath for $4 \mathrm{~h}$. Non-specific binding (i.e., in the presence of $50 \mu \mathrm{M}$ desipramine) was approximately $10 \%$ of total binding. Bound ${ }^{3} \mathrm{H}$-nisoxetine was captured by rapid filtration through glass fiber filters (GF/B Brandel, Gaithersburg, MD) that were pre-soaked in 5\% polyethyleneimine, under vacuum with a cell harvester (Brandel, Gaithersburg, MD). Filters were washed twice with ice-cold binding buffer and radioactivity determined by liquid scintillation counting.

\section{${ }^{3} \mathrm{H}-\mathrm{NE}$ uptake assay}

Uptake assays were carried out as described previously (Apparsundaram et al., 1998a,b; Vizi et al., 2004). Fresh rat cerebral cortex and hippocampus were placed in ice-cold Krebs-Ringer/HEPES (KRH) buffer $(125 \mathrm{mM} \mathrm{NaCl}, 5.2 \mathrm{mM} \mathrm{KCl}, 1.2 \mathrm{mM}$ $\mathrm{CaCl}_{2}, 1.4 \mathrm{mM} \mathrm{MgSO}_{4}, 1.2 \mathrm{mM} \mathrm{KH_{2 }} \mathrm{PO}_{4}, 5 \mathrm{mM}$ glucose, $20 \mathrm{mM}$ HEPES, $0.2 \mathrm{mg} / \mathrm{ml}$ ascorbic acid and $100 \mu \mathrm{M}$ pargyline; $\mathrm{pH}$ 7.4) gassed with $95 \% \mathrm{O}_{2} / 5 \% \mathrm{CO}_{2}$. The tissues were cut into $0.4 \mathrm{~mm}$ slices using a McIlwain tissue chopper (Brinkmann, Westbury, NY). Slices were separated by gentle shaking and washed with oxygenated KRH buffer. Uptake assays were performed by incubating the tissue slices with $30 \mathrm{nM}{ }^{3} \mathrm{H}-\mathrm{NE}$ (10.9 
$\mathrm{Ci} / \mathrm{mmol}$, PerkinElmer, Boston, MA) for $10 \mathrm{~min}$ at $37^{\circ} \mathrm{C}$. Assays were terminated by rapid washing of slices with $0.5 \mathrm{ml}$ of ice-cold $\mathrm{KRH}$ buffer three times. Buffer was aspirated and slices were then sonicated in $10 \%$ trichloroacetic acid and centrifuged at

$30,000 \times \mathrm{g}$ for $2 \mathrm{~min} .{ }^{3} \mathrm{H}-\mathrm{NE}$ in the supernatant was quantified by liquid scintillation counting. Nonspecific uptake was determined in the presence of $20 \mu \mathrm{M}$ desipramine. Specific uptake was determined by subtracting nonspecific uptake from total uptake.

\section{Measurement of extracellular NE in the medial prefrontal cortex (mPFC) by in vivo microdialysis}

At the same time the osmotic pumps were implanted, rats were placed in a stereotaxic frame with the incisor bar set at $-3.3 \mathrm{~mm}$. A microdialysis guide cannula (CMA/12; CMA Microdialysis, North Chelmsford, MA), aimed at the mPFC, was implanted at coordinates $\mathrm{AP}+2.6 \mathrm{~mm}$ from Bregma, $\mathrm{ML} \pm 1.4 \mathrm{~mm}$ from midline, $\mathrm{DV}-1.7 \mathrm{~mm}$ from dura. The guide cannula was anchored to the skull and an obdurator was inserted. The wound was sutured, topical antibiotic applied, and each rat returned to its home cage. On the testing day, the obdurator was removed and a microdialysis probe, with molecular weight cutoff of $20 \mathrm{kDa}$ and $4 \mathrm{~mm}$ of active membrane, was inserted into the guide cannula; the probe extended $4 \mathrm{~mm}$ beyond the tip of the guide, centering the active membrane within the mPFC. The probe was perfused with artificial cerebrospinal fluid $\left(147 \mathrm{mM} \mathrm{NaCl}, 2.5 \mathrm{mM} \mathrm{KCl}, 1.3 \mathrm{mM} \mathrm{CaCl}_{2}, 0.9 \mathrm{mM} \mathrm{MgCl}\right.$; $\mathrm{pH}$ 7.4) at a flow rate of $1.0 \mu \mathrm{l} / \mathrm{min}$. After a $2 \mathrm{~h}$ equilibration period, four $30 \mathrm{~min}$ samples $(30 \mu \mathrm{l})$ were collected into tubes containing $2.5 \mu \mathrm{l}$ of stabilizing solution $(0.2 \mu \mathrm{M}$ EDTA, $0.2 \mu \mathrm{M}$ ascorbic acid, $0.2 \mathrm{M}$ perchloric acid). NE in the microdialysis samples was measured by high- 
performance liquid chromatography (HPLC) with coulometric detection (Coulochem2, ESA Inc., East Chelmsford, MA). The amount of NE in each sample was quantified against a calibration curve run daily, ranging from 0 to $25 \mathrm{pg}$, with a detection limit of 0.5 pg.

\section{Measurement of plasma and brain desipramine and desmethyl-desipramine}

The measurement of desipramine and its primary metabolite desmethyl-desipramine was carried out using a modification of a method described previously (Argenti and D’Mello, 1994). Plasma and brain were collected for analysis and stored at $-70^{\circ} \mathrm{C}$ until assay. To $500 \mu 1$ of plasma (either sample or blank standard) were added $100 \mu 1$ of internal standard solution (imipramine $200 \mathrm{ng} / \mathrm{ml}$ ) followed by $100 \mu \mathrm{l}$ of ammonium hydroxide. The plasma was then extracted with $1 \mathrm{ml}$ l-butanol (20\%) in hexane (pH 11) for $15 \mathrm{~min}$ on a reciprocating shaker. After separation of the phases by centrifugation at $2,500 \mathrm{xg}$ at $25^{\circ} \mathrm{C}$ for $3 \mathrm{~min}$, the organic layer was transferred to fresh glass culture tubes and evaporated to dryness with nitrogen gas at $34^{\circ} \mathrm{C}$. Each sample was reconstituted with $100 \mu 1$ mobile phase (70:30 0.025 $\mathrm{M} \mathrm{KH}_{2} \mathrm{PO}_{4}$ :acetonitrile).

Half of the brain was homogenized in $8 \mathrm{ml}$ carbonate buffer $\left(0.1 \mathrm{M} \mathrm{NaCO}_{3}, \mathrm{pH} 12\right)$. Aliquots $(2 \mathrm{ml})$ of homogenates were transferred to glass tubes and $2 \mu \mathrm{g}$ internal standard (imipramine) was added along with $3 \mathrm{ml}$ l-butanol (20\%) n-hexane to both samples and blank brain standards. The mixture was shaken for $15 \mathrm{~min}$ and centrifuged at 2,500 $\mathrm{x} g$ at $25^{\circ} \mathrm{C}$ for $3 \mathrm{~min}$. The organic phase was transferred to a glass tube and the extraction was repeated again. The organic phase was evaporated by nitrogen gas and reconstituted to a $100 \mu 1$ volume with mobile phase. 
Chromatography was conducted using a reversed-phase column (Waters Symmetry Shield RP $\mathrm{C}_{18} 4.6 \mathrm{~mm}$ x $150 \mathrm{~mm}$, Milford, MA) and a $50 \mu 1$ injector loop. The column temperature was ambient and the flow rate was set at $1.2 \mathrm{ml} / \mathrm{min}$. The fluorescence of the eluent was monitored at an excitation wavelength of $260 \mathrm{~nm}$ with an emission wavelength of $360 \mathrm{~nm}$. For desipramine and desmethyl-desipramine determinations, recovery during extraction exceeded $90 \%$ and the lower limit of quantification was $25 \mathrm{ng}$.

\section{Measurement of $\beta$-adrenergic receptor density}

$\beta$-Adrenergic receptor density was determined as described previously (O'Donnell, 1990). The right cerebral cortex was homogenized in $2 \mathrm{mM} \mathrm{N}$-2-hydroxyethylpiperazine-N'-2-ethanesulfonic acid (HEPES) and $1 \mathrm{mM}$ ethylenediamine tetra-acetic acid (EDTA) buffer (pH 7.75) for $15 \mathrm{sec}$ using a Polytron homogenizer. The homogenate was centrifuged at $40,000 \times \mathrm{g}$ for $20 \mathrm{~min}$. The supernatant was removed and the wash procedure was repeated 4 times. The final pellet was suspended in SHM buffer (10 mM HEPES, $150 \mathrm{mM} \mathrm{NaCl}, 10 \mathrm{mM} \mathrm{MgCl}$; $\mathrm{pH}$ 7.75). Saturation experiments were carried out to determine the density of the $\beta-1$ and $\beta-2$ adrenergic receptors. Membrane suspensions were incubated in triplicate at $37^{\circ} \mathrm{C}$ for $30 \mathrm{~min}$ with ${ }^{125} \mathrm{I}$-pindolol $(50-1000$ pM) alone, ${ }^{125}$ I-pindolol and $100 \mathrm{nM}$ CGP20712A (to block binding of IPIN to $\beta-1$ adrenergic receptors), or ${ }^{125}$ I-pindolol plus $100 \mu \mathrm{M}$ isoproterenol (to define nonspecific binding). The reaction was stopped by the addition of $6 \mathrm{ml}$ of ice-cold SHM, and the samples were filtered over a vacuum through Schleicher and Schuell No. 25 glass fiber filters. The filters were washed twice with $3 \mathrm{ml}$ of ice-cold SHM buffer and counted for radioactivity using a gamma counter at an efficiency of $75 \%$. 


\section{Statistical analysis}

The data were analyzed by one-way analyses of variance (ANOVA) followed by Tukey's or Bonferroni's post-hoc tests. Data are presented as means \pm SEM and differences are considered statistically significant when $\mathrm{p}$ values are less than 0.05 . 


\subsection{Results}

\section{Effects of repeated desipramine treatment on NET expression and behavior in the}

\section{forced-swim test}

The relationship between the effects of chronic desipramine treatment on NET expression and its effects on behavior in the forced-swim test, a preclinical test predictive of antidepressant activity, was examined. Treatment of rats with desipramine for 14 days reduced NET expression in a dose-dependent manner, as indicated by a reduction of the specific binding of ${ }^{3} \mathrm{H}$-nisoxetine to the NET in preparations of cerebral cortex $\left(\mathrm{F}_{(3,16)}=4.33, \mathrm{p}<0.05\right.$; Figure 2.1A) and hippocampus $\left(\mathrm{F}_{(3,16)}=4.34, \mathrm{p}<0.05\right.$; Fig. 2.1A). Down-regulation of the NET also was demonstrated using SDS-PAGE/immunoblotting of preparations of cerebral cortex $\left(\mathrm{F}_{(3,16)}=4.75, \mathrm{p}<0.05\right.$; Fig. 2.1B) and hippocampus $\left(\mathrm{F}_{(3,15)}=13.10, \mathrm{p}<0.001\right.$; Fig. 2.1B). Importantly, this NET down-regulation was observed two days after discontinuation of chronic desipramine treatment, a time when plasma and brain concentrations of desipramine and desmethyl-desipramine were undetectable (i.e., below the 25 ng detection limit of the assay). By comparison, one hour after acute treatment with $10 \mathrm{mg} / \mathrm{kg}$ desipramine, which causes similar effects on forcedswim behavior, plasma concentrations (mean \pm S.D.) were $0.5 \pm 0.3$ (desipramine) and $0.09 \pm 0.02$ (desmethyl-desipramine) $\mu \mathrm{g} / \mathrm{ml}$ and brain concentrations were $3.4 \pm 0.1$ (desipramine) and $0.09 \pm 0.03$ (desmethyl-desipramine) $\mu \mathrm{g} / \mathrm{g}$ protein. In parallel with the down-regulation of the NET, chronic desipramine also produced a dose-dependent reduction in the duration of immobility in the forced-swim test $\left(\mathrm{F}_{(3,18)}=91.23, \mathrm{p}<0.001\right.$; Fig. 2.1C). This was evident two days after discontinuation of chronic desipramine treatment and paralleled the reduction of NET expression (Fig. 2.1B). This treatment 
also reduced the $B_{\max }$ for ${ }^{125}$ I-pindolol binding to $\beta$ - 1 adrenergic receptors in cerebral cortex (control: $73.3 \pm 4.6$; two days post-desipramine treatment: $40.7 \pm 3.4 \mathrm{fmol} / \mathrm{mg}$ protein; $\mathrm{n}=5$ /group; $\mathrm{p}<0.01) ; \beta$-2 adrenergic receptor density was unchanged.

\section{Recovery of NET expression and behavioral effects following discontinuation of repeated desipramine treatment}

Chronic treatment with desipramine reduced NET expression and produced a persistent antidepressant-like effect in the forced-swim test. Experiments were carried out to examine the relationship between changes in NET expression and behavior. Rats were treated chronically with $15 \mathrm{mg} / \mathrm{kg} /$ day desipramine for 14 days and subjected to the forced-swim test 2,5 , or 8 days after the end of desipramine treatment (i.e., removal of the osmotic pumps). Rats then were killed and brains regions reserved for assessment of NET expression and function; NET expression was determined using ${ }^{3} \mathrm{H}$-nisoxetine binding and Western blotting and NET activity by measurement of ${ }^{3} \mathrm{H}-\mathrm{NE}$ uptake in vitro.

A significant reduction of NET binding sites, measured by ${ }^{3} \mathrm{H}$-nisoxetine binding, was evident two days after the discontinuation of chronic desipramine treatment in the cerebral cortex $\left(\mathrm{F}_{(3,19)}=8.59, \mathrm{p}<0.001\right.$; Fig. 2.2A) and hippocampus $\left(\mathrm{F}_{(3,19)}=3.22, \mathrm{p}<\right.$ 0.05; Fig. 2.2A). The NET binding sites were partially recovered five days, and fully recovered eight days, post-treatment. Consistently, decreased expression of NET also was observed by SDS-PAGE/immunoblotting two days after the discontinuation of chronic desipramine treatment in the cerebral cortex $\left(\mathrm{F}_{(3,12)}=6.98, \mathrm{p}<0.01 ;\right.$ Fig. 2.2B $)$ and hippocampus $\left(\mathrm{F}_{(3,12)}=4.26, \mathrm{p}<0.05 ; \mathrm{Fig} .2 .2 \mathrm{~B}\right)$. The down-regulation of the NET 
protein expression was partially reversed five days, and completely recovered eight days, post-treatment. The time-course of NET expression and activity were paralleled by behavioral effects in the forced-swim test. Rats tested two days following the end of chronic desipramine treatment displayed a reduced duration of immobility in the forcedswim test $\left(\mathrm{F}_{(3,18)}=27.15, \mathrm{p}<0.001 ;\right.$ Fig. 2.2C). This antidepressant-like effect was partially reversed five days and completely disappeared eight days post-treatment.

The NET activity, determined by measurement of uptake of ${ }^{3} \mathrm{H}-\mathrm{NE}$ into cerebral cortical and hippocampal slices in vitro, exhibited a pattern similar to NET expression. NE uptake was significantly reduced two days after the end of chronic desipramine treatment and returned to control levels by eight days post-treatment in both cerebral cortical $\left(\mathrm{F}_{(4,19)}=3.92, \mathrm{p}<0.05\right.$; Fig. 2.2D) and hippocampal slices $\left(\mathrm{F}_{(4,21)}=26.35, \mathrm{p}<\right.$ 0.001; Fig. 2.2D).

\section{Extracellular NE concentration in $\mathrm{mPFC}$ after chronic desipramine treatment}

Overall, the results described above indicate that repeated desipramine treatment reduced NET expression in cerebral cortex and hippocampus, resulting in a persistent antidepressant-like effect on behavior that was not dependent on the presence of desipramine. Such a reduction in NET expression and function would be expected to result in enhanced noradrenergic neurotransmission in the brain since the primary method of inactivation, i.e., reuptake, would be impaired. To examine this, the extracellular concentration of $\mathrm{NE}$ was measured in the $\mathrm{mPFC}$ by in vivo microdialysis. A representative photomicrograph of a cresyl violet-stained section in which the microdialysis probe track was localized to $\mathrm{mPFC}$ is shown in (Figure 2.3A). It was found 
that the basal NE concentration was increased more than two-fold two days after the discontinuation of repeated desipramine treatment $\left(\mathrm{F}_{(3,50)}=20.14, \mathrm{p}<0.001\right.$; Fig. 2.3B). The extracellular NE concentration returned to control values by five days post-treatment. This period of enhanced noradrenergic neurotransmission was consistent with that of reduced NET expression and function, as well as the persistent effects in the forced-swim test (see above). Also, consistent with persistently increased extracellular NE concentration during chronic desipramine treatment, the density of $\beta-1$ adrenergic

receptors in cerebral cortex, determined by ${ }^{125} \mathrm{I}$-pindolol (200 pM) binding, was reduced two days following the end of the repeated-treatment regimen (control: $29.8 \pm 1.7$; two days post-desipramine: $12.8 \pm 1.8 \mathrm{fmol} / \mathrm{mg}$ protein; $\mathrm{n}=5$ /group; $\mathrm{p}<0.01$ ); $\beta$-1 receptor density was not different from control levels five and eight days post-treatment $(27.2 \pm$ 1.9 and $30.8 \pm 3.2 \mathrm{fmol} / \mathrm{mg}$ protein, respectively; $\mathrm{n}=5 /$ group).

\section{Effect of catecholamine depletion on the persistent effects of desipramine treatment in the forced-swim test}

In order to determine whether enhanced noradrenergic neurotransmission was necessary for the persistent antidepressant effect in the forced-swim test, a NE depletion approach was utilized, similar to that used to assess the role of noradrenergic neurotransmission in the clinical actions of desipramine (Miller et al., 1996). Two days after the end of chronic desipramine treatment, when the NET expression was reduced and noradrenergic neurotransmission increased, rats were treated with the AMPT, an inhibitor of tyrosine hydroxylase, the rate-limiting enzyme for NE biosynthesis. AMPT $(150 \mathrm{mg} / \mathrm{kg}$ or $300 \mathrm{mg} / \mathrm{kg}$, i.p.) was administrated $4 \mathrm{~h}$ before the forced-swim test to rats 
that had been treated chronically with vehicle or desipramine. AMPT treatment resulted in a dose-dependent loss of the persistent, antidepressant-like effect of chronic desipramine in the forced-swim test $\left(\mathrm{F}_{(5,35)}=17.64, \mathrm{p}<0.001\right.$; Fig. 2.4A). An acute dose of $150 \mathrm{mg} / \mathrm{kg}$ AMPT was effective in reversing the actions of chronic desipramine treatment; this dose of AMPT did not affect behavior in the forced-swim when administered alone. Administration of $300 \mathrm{mg} / \mathrm{kg}$ AMPT also reversed the persistent behavioral effect of desipramine, but when administered alone it produced a depressantlike effect on forced-swim behavior $\left(\mathrm{F}_{(5,35)}=17.64, \mathrm{p}<0.05\right.$; Fig. 2.4A). 


\subsection{Discussion}

The present results show a relationship between desipramine-induced downregulation of the NET and antidepressant effects on behavior. These exhibit similar doseresponse and time-of-recovery relationships. Importantly, the down-regulation of the NET results in antidepressant effects on behavior, even when there is no drug present to inhibit NE transport. Consistent with this, NET knockout mice show a similar antidepressant-like effect in forced-swim and tail-suspension tests, due to reduced clearance rates of $\mathrm{NE}(\mathrm{Xu}$ et al., 2000). It has been suggested that the functional consequence of down-regulation of monoamine transporters is greater than pharmacological inhibition (Klimek et al., 1997) due to its noncompetitive nature versus the competitive nature of pharmacological inhibition. The results of the microdialysis experiment indicate that reduced NET expression does result in increased extracellular concentrations of NE, indicative of enhanced noradrenergic neurotransmission, similar to what is observed when the NET is inhibited acutely by desipramine (Lapiz et al., 2007a).

Clinical actions of antidepressants develop gradually over weeks of treatment (Frazer and Benmansour, 2002; Katz et al., 1996; Katz et al., 2004), leading to the suggestion that neuroadaptive processes underlie the long-term behavioral effects. In the present study, it was found that the expression and activity of NET were significantly reduced by repeated desipramine treatment after a two-day washout, when plasma and brain antidepressant drug concentrations were not detectable. The density of postsynaptic $\beta-1$ adrenergic receptors also was decreased two days after chronic administration of 15 $\mathrm{mg} / \mathrm{kg} /$ day desipramine for 14 days, consistent with previous findings (Ordway et al., 1988). Desipramine-induced reduction in immobility is associated with decreased $\beta-1$ 
adrenergic receptors; both effects are blocked by co-administration of $\beta-1$ adrenergic receptors antagonists (Kitada et al., 1986; Mancinelli et al., 1991). Both $\beta-1$ adrenergic receptor and NET expression were significantly reduced two days after chronic desipramine treatment, and recovered after 8 days of withdrawal, suggesting that regulation of both NET and $\beta-1$ adrenergic receptors is involved in adaptive mechanisms for noradrenergic neurons. The increased synaptic NE concentration that results from NET down-regulation likely contributes to the down-regulation of $\beta-1$ adrenergic receptors (Ordway et al., 1988). Repeated desipramine treatment causes other neuronal changes that may contribute to antidepressant activity, including increased ${ }^{3} \mathrm{H}-\mathrm{GTP}$ binding to $\mathrm{G}_{\mathrm{s}}$ protein coupled to $\beta-1$ adrenergic receptors (Yamamoto et al., 1990), increased CREB mRNA expression (Nibuya et al., 1996), induction of BDNF expression (Nibuya et al., 1996), and increased neurogenesis in the dentate gyrus and hippocampus (Santarelli et al., 2003; Kodama et al., 2004; Chen at al. 2006; Sairanen et al., 2005).

The mechanism underlying desipramine-induced down-regulation of the NET has not been fully determined. In addition to being observed in vivo (Zhu et al., 2002; Weinshenker et al., 2002), it also has been shown in vitro in cell lines expressing the NET. Using Western blotting, NET expression in SK-N-BE(2)M17 cells was shown to be decreased by $3-14$ days of exposure to desipramine (Zhu et al., 1998). This suggests that desipramine-induced NET regulation is, at least in part, a direct effect and not secondary to an increase in the extracellular concentration of NE. In vitro, both the NET and serotonin transporter (SERT) have been shown to be regulated via a PKC- (PKC) dependent pathway (Apparsundaram et al., 1998a,b; Jayanthi et al., 2005). Desipramine and other NE reuptake inhibitors may stimulate some specific factors in the PKC 
pathway and trigger a signal transduction cascade activating protein kinase C. Activation of PKC by $\beta$-PMA down-regulates and internalizes membrane-associated NET (Jayanthi et al., 2004). The NET-PP2A-Ar complex and the NET-syntaxin 1A complex have been shown to be involved in the PKC-mediated process (Sung et al., 2005; Sung and Blakely, 2007). It has been reported that inhibition of $\mathrm{IP}_{3}$ receptors by 2 -aminoethoxydiphenyl borate and xestospongin $\mathrm{C}$ reduces the $\mathrm{V}_{\max }$ of NET, as well as NET expression (Amano et al., 2006). Given that inhibition of $\mathrm{IP}_{3}$ receptors simultaneously results in PKC inhibition, it appears that the regulation of the NET is under the control of calcium/PKCmediated mechanisms. However, this has not been demonstrated in vivo. Such a demonstration might suggest novel means to produce NET down-regulation and antidepressant effects on behavior.

Whether the down-regulation of NET is mediated by altered NET gene transcription has been a point of investigation. Previous studies using HEK-293 and SK-N-BE(2)M17 cells have shown that desipramine-induced reduction of NET expression primarily is due to translocation or increased degradation of the NET, but have not ruled out altered transcription (Zhu et al., 1998; Zhu et al., 2002). However, in vivo, it was found that NET mRNA expression in the locus ceruleus is elevated after chronic desipramine treatment (Szot et al., 1993). Further, it was found that the mRNA expression of another monoamine transporter, the SERT, in the raphe nucleus is unchanged following chronic treatment with the SRI paroxetine (Benmansour et al., 1999).

While the present study focused on NET expression and the effects of desipramine, it is likely that similar mechanisms are involved in the long-term effects of SRIs. Repeated treatment with drugs from this pharmacological class reduces SERT expression and 
increases serotonergic neurotransmission. Using quantitative autoradiography, a marked reduction of ${ }^{3} \mathrm{H}$-cyano-imipramine binding to the SERT is observed after chronic paroxetine or sertraline treatment. Similarly, using ${ }^{3} \mathrm{H}$-citalopram homogenate binding, SERT binding sites in the rat prefrontal cortex are reduced after chronic paroxetine or sertraline treatment (Gould et al., 2006). Accordingly, the SERT reuptake activity (i.e., clearance) in the CA3 region of hippocampus is reduced after chronic treatment with SRIs such as paroxetine and sertraline; desipramine does not affect SERT function (Benmansour et al., 2002). The extracellular serotonin concentration, measured by in vivo microdialysis, is elevated in the hippocampus and caudate nucleus in the awake monkey after 3-day fluoxetine treatment (Smith et al., 2000). However, to date, it has not been reported whether enhanced, persistent down-regulation of the SERT results in antidepressant effects on behavior, even when drug is not present. Dual norepinephrine and serotonin reuptake inhibitors, which may produce persistent effects on both noradrenergic and serotonergic neurotransmission, may possess greater efficacy and a more rapid onset of action (Millan, 2006).

Among the adaptive changes that may underlie the long-term effects of antidepressant treatment, NET and SERT regulation fit with the clinical data to a considerable degree. From a functional perspective, the direction of the long-term change in transporter expression following antidepressant treatment is the same as that seen with acute treatment with an antidepressant. In both cases, there is a reduction in transporter function and enhanced monoaminergic neurotransmission. By contrast, changes in monoaminergic receptor expression often are homeostatic, i.e., in opposition to the effect of acute antidepressant treatment (Ordway et al., 1991). Clinically, in 
untreated patients, it has been reported that reducing catecholamine activity with AMPT or serotonergic activity with tryptophan depletion has no obvious effects on symptoms of depression, indicating that monoamine deficiency itself is insufficient to cause symptoms of depression (Miller et al., 1996b). However, catecholamine depletion by AMPT results in depression relapse in the patients treated chronically with NE reuptake inhibitors such as desipramine, but not SRIs (Miller et al., 1996a; Bremner et al., 2003). By contrast, inhibition of serotonin synthesis with para-chlorophenylalanine or a tryptophan-free amino acid drink reverses symptom remission caused by SRIs, but not NE reuptake inhibitors (Miller et al., 1996a; Salomon et al., 1993).

It was found, consistent with these clinical findings, that inhibition of catecholamine synthesis with AMPT reversed the persistent antidepressant-like effect of desipramine in the forced-swim test. Changes in both noradrenergic and dopaminergic neurotransmission may contribute to this effect of AMPT (O'Donnell and Seiden, 1984). A specific role for noradrenergic neurotransmission is suggested by the finding that NEdeficient mice fail to respond to the behavioral effects of the NE reuptake inhibitor desipramine. Restoration of NE by 1-threo-3,4-dihydroxyphenylserine (1-DOPS) reinstates the behavioral effects of desipramine in these mice (Cryan et al., 2004). Overall, the preclinical and clinical data suggest that enhanced monoaminergic neurotransmission is necessary, but not sufficient, for producing antidepressant effects, at least for those drugs that act via inhibition of reuptake. A schema describing pharmacological mechanisms thought to underlie the effects of desipramine is shown (Fig. 4B). Following acute treatment, desipramine inhibits the NET, reducing NE uptake, which results in an increased extracellular NE concentration and an antidepressant-like 
behavioral response. Two days following chronic desipramine treatment, when the plasma and brain levels of desipramine and its major active metabolite are not detectable, NET expression and function are reduced, resulting in enhanced noradrenergic neurotransmission and an antidepressant response. However, treatment with AMPT at this time reduces noradrenergic neurotransmission, resulting in a loss of the antidepressant-like response, consistent with clinical findings (Miller et al., 1996a).

Overall, the present results demonstrate a relationship between desipramine-induced down-regulation of the NET and antidepressant-like effects on behavior. NET downregulation, which was evident for at least two days following discontinuation of treatment, persisted even in the absence of detectable levels of desipramine or its major metabolite in plasma or brain. NET down-regulation resulted in reduced NE uptake, measured in vitro, and enhanced noradrenergic neurotransmission, measured in the mPFC in vivo. Neuroimaging studies have consistently implicated the mPFC in depression, and in the response to antidepressant treatment (Dreyets, 2000). Also consistent with clinical data, it was found that the antidepressant-like effect that resulted from NET downregulation depended on the enhanced noradrenergic neurotransmission since it was lost when NE synthesis was inhibited. The present data provide support for the idea that NET down-regulation may contribute to the long-term therapeutic effects of some antidepressant drugs. Understanding the mechanism of NET regulation in vivo, which in vitro data suggest is due more to altered internalization and degradation than altered transcription, may suggest novel targets for therapeutic intervention in the treatment of depression. 

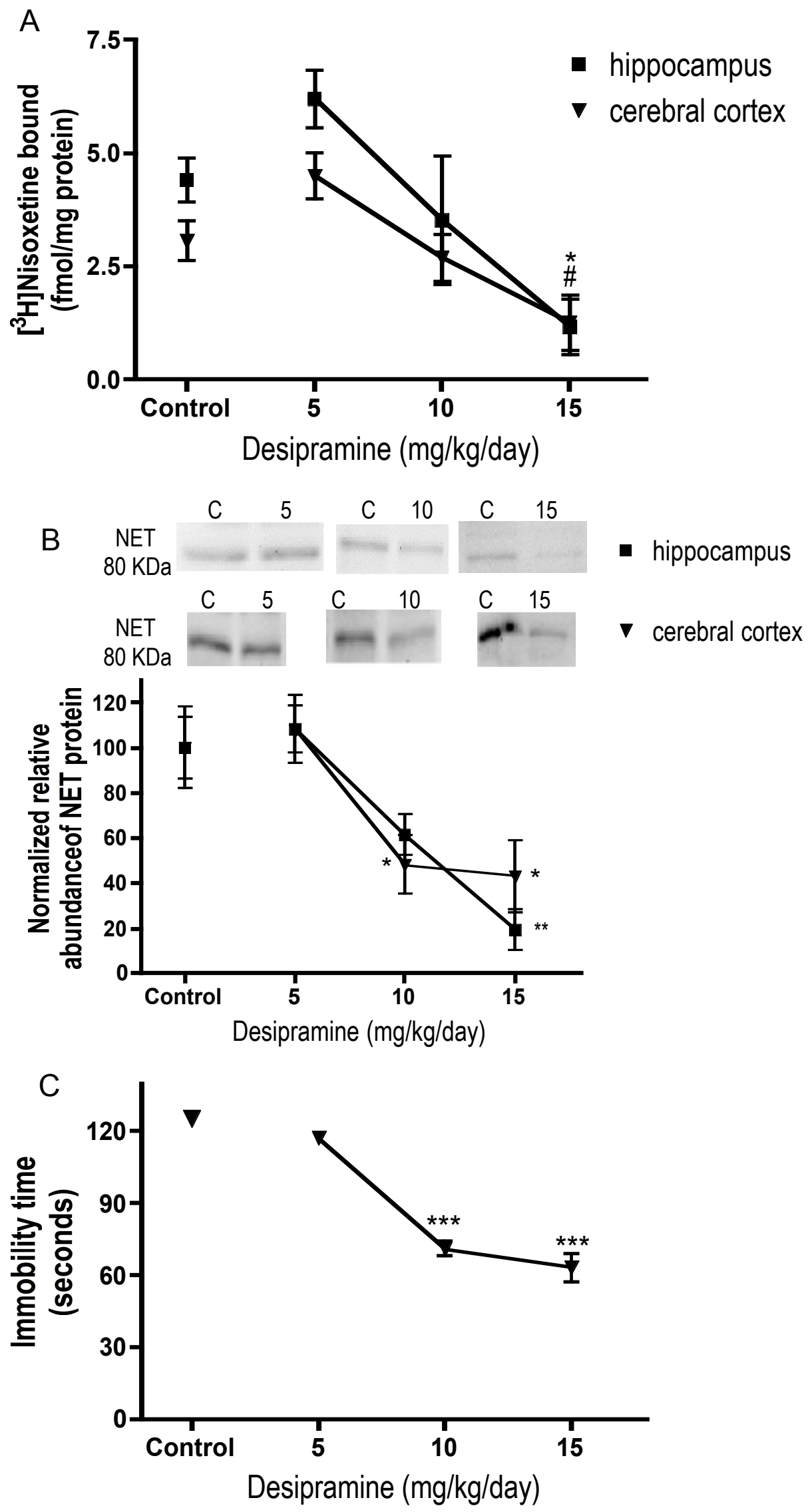
Figure 2.1 Dose-response functions were determined for the ability of chronic desipramine treatment to reduce NET expression in the cerebral cortex and hippocampus, determined by ${ }^{3} \mathrm{H}$-nisoxetine binding (A) and SDS-PAGE /immunoblotting with antisera against the NET (B), and to reduce immobility time in the forced-swim test (C). All measures were determined two days after the end of the chronic treatment period, when brain and plasma concentrations of desipramine and its metabolite desmethyldesipramine were not detectable (i.e., below the $25 \mathrm{ng}$ detection limit of the assay). Data shown are means \pm SEM of 5-6 rats per group. ${ }^{*} \mathrm{p}<0.05,{ }^{*} \mathrm{p}<0.01, * * * \mathrm{p}<0.001 \mathrm{vs}$ control. 

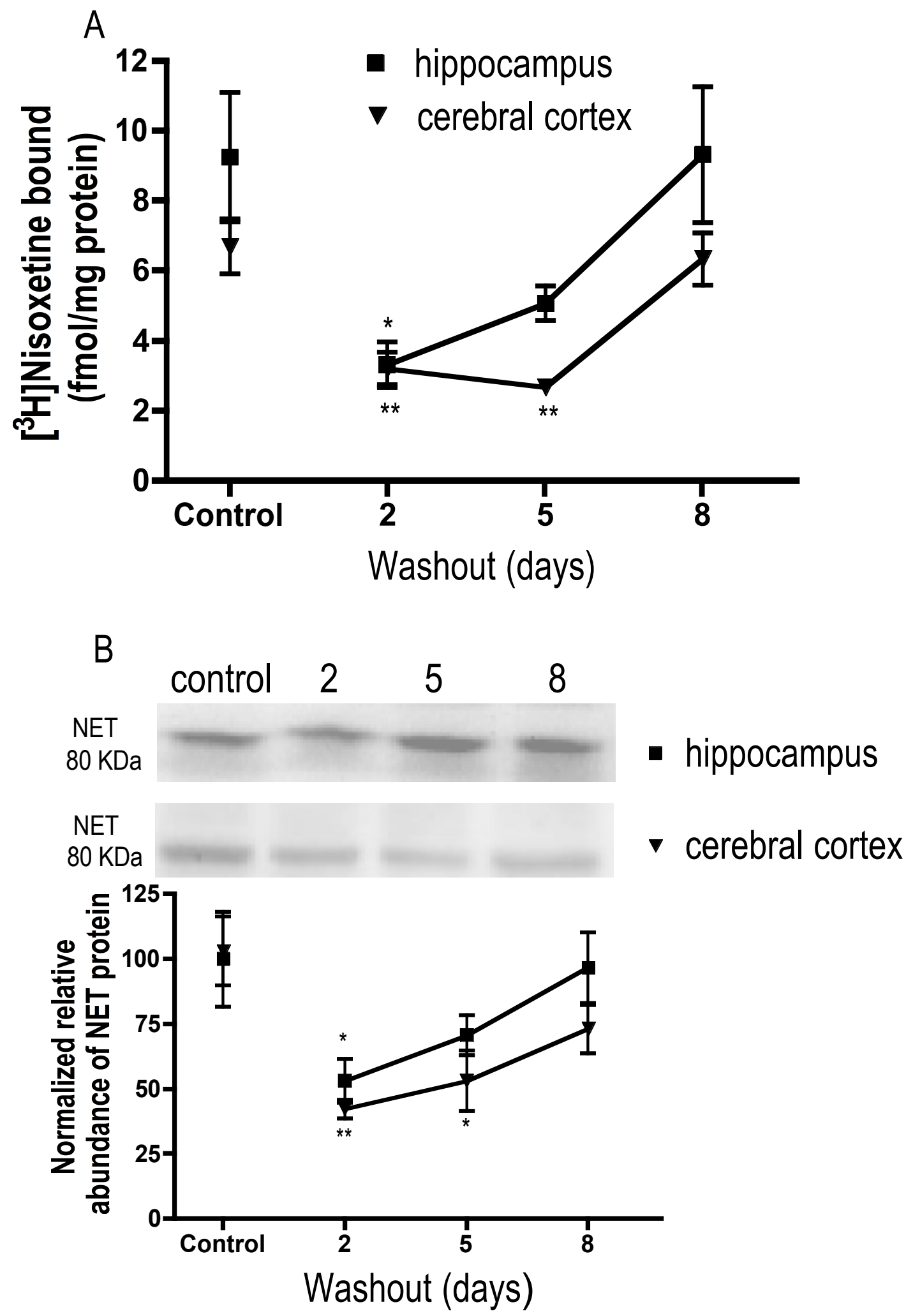


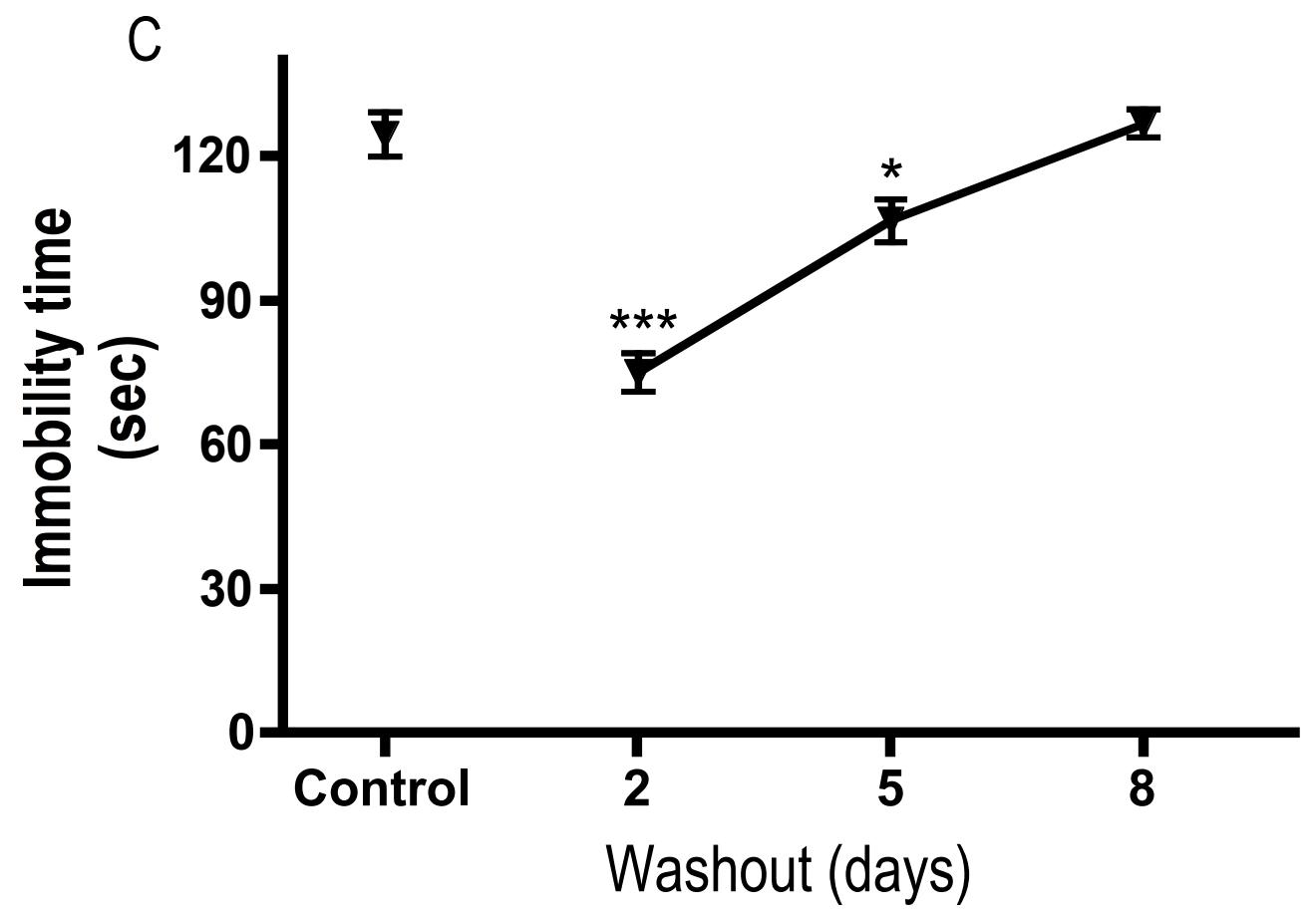

D

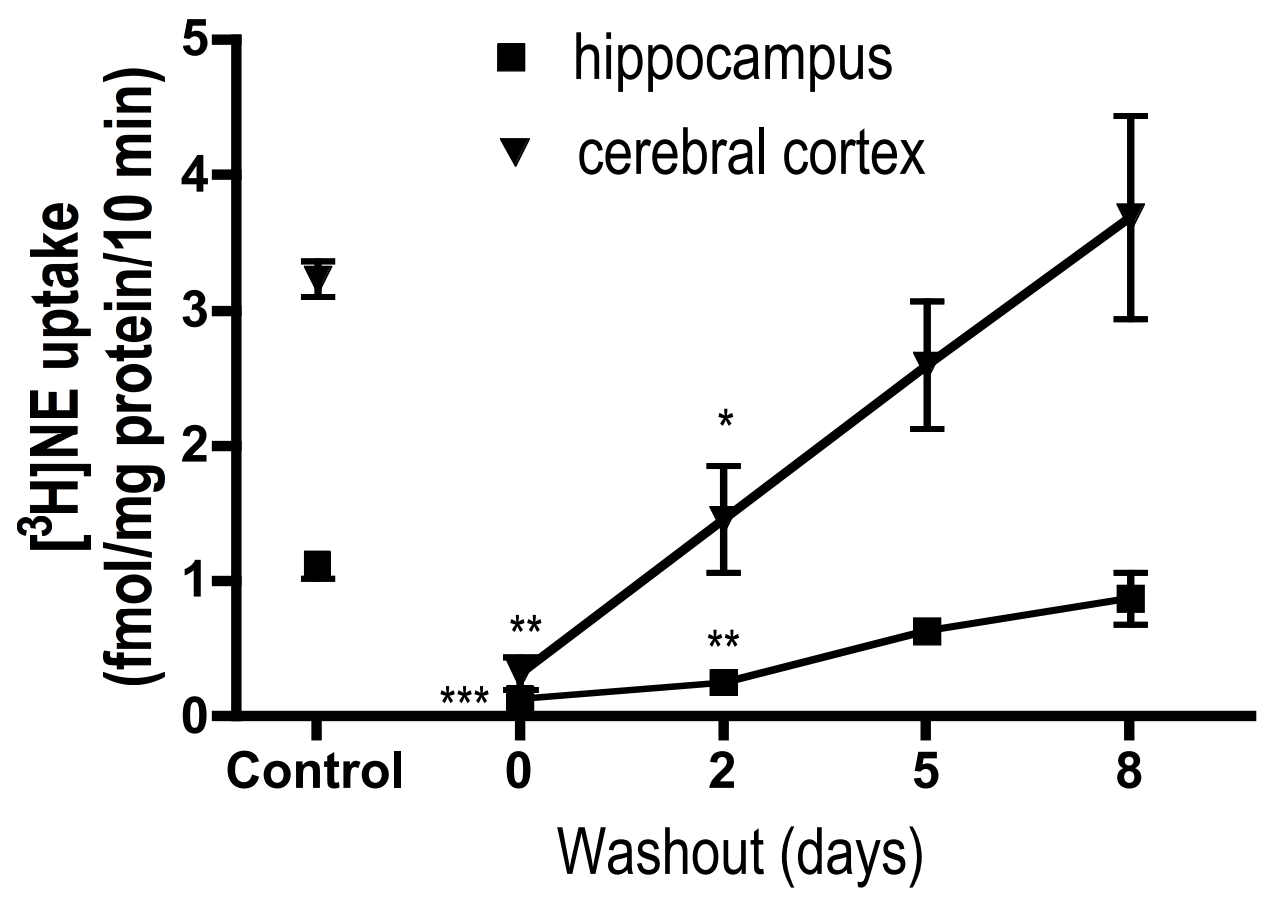


Figure 2.2 The recovery time-course of chronic desipramine on NET expression in the cerebral cortex and hippocampus, measured by ${ }^{3} \mathrm{H}$-nisoxetine binding (A) and SDSPAGE/immunoblotting with antisera against the NET (B). The persistent antidepressantlike effect in the forced-swim test was evident two days after the end of the chronic treatment period, but dissipated by eight days (C). The uptake of ${ }^{3} \mathrm{H}-\mathrm{NE}$ into tissue slices, which reflects the activity of the NET, was reduced two days after discontinuation of desipramine treatment, and returned to the control level after five to eight days (D). Data shown are means \pm SEM of $5-10$ rats per group. ${ }^{*} \mathrm{p}<0.05 ; * * \mathrm{p}<0.01 ; * * * \mathrm{p}<0.001$ vs. control. 

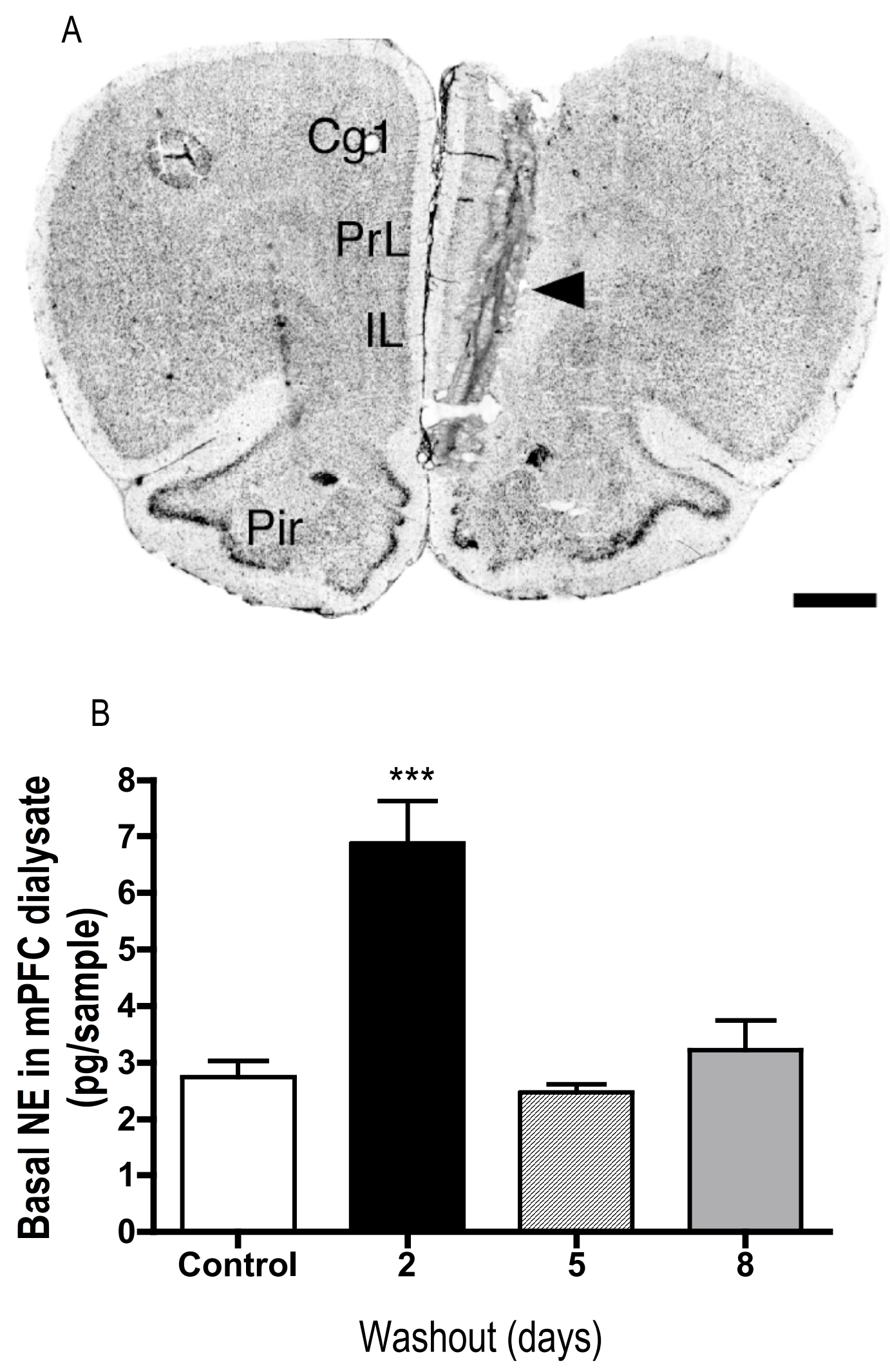
Figure 2.3 Representative photomicrograph of a cresyl violet-stained section, corresponding to Plate 9 in the atlas of Paxinos and Watson (1998), showing the microdialysis probe track in $\mathrm{mPFC}$ on the right (arrow). Brain regions are labeled on the left side for clarity. The guide cannula extended into the lower part of $\mathrm{Cg} 1$, and the $4 \mathrm{~mm}$ active probe track extended from the uppermost part of area PrL to just below area IL, thus including both major components of rat mPFC. Abbreviations: $\mathrm{Cg} 1$, cingulate cortex, region 1; IL, infralimbic cortex; Pir, piriform cortex; PrL, prelimbic cortex (A). Chronic $15 \mathrm{mg} / \mathrm{kg} /$ day desipramine treatment with 2 days washout significantly elevated the tonic baseline of NE in mPFC, measured by in vivo microdialysis (B). Data shown are means \pm SEM of $11-12$ rats per group. ${ }^{* * *} \mathrm{p}<0.001$ 


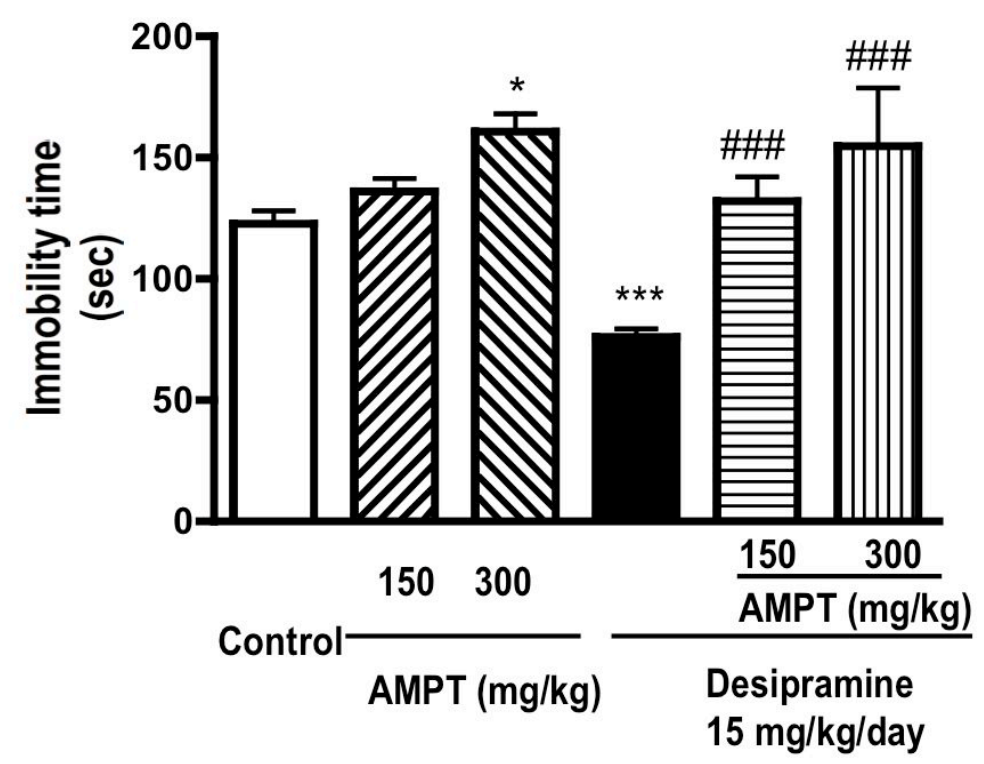

B
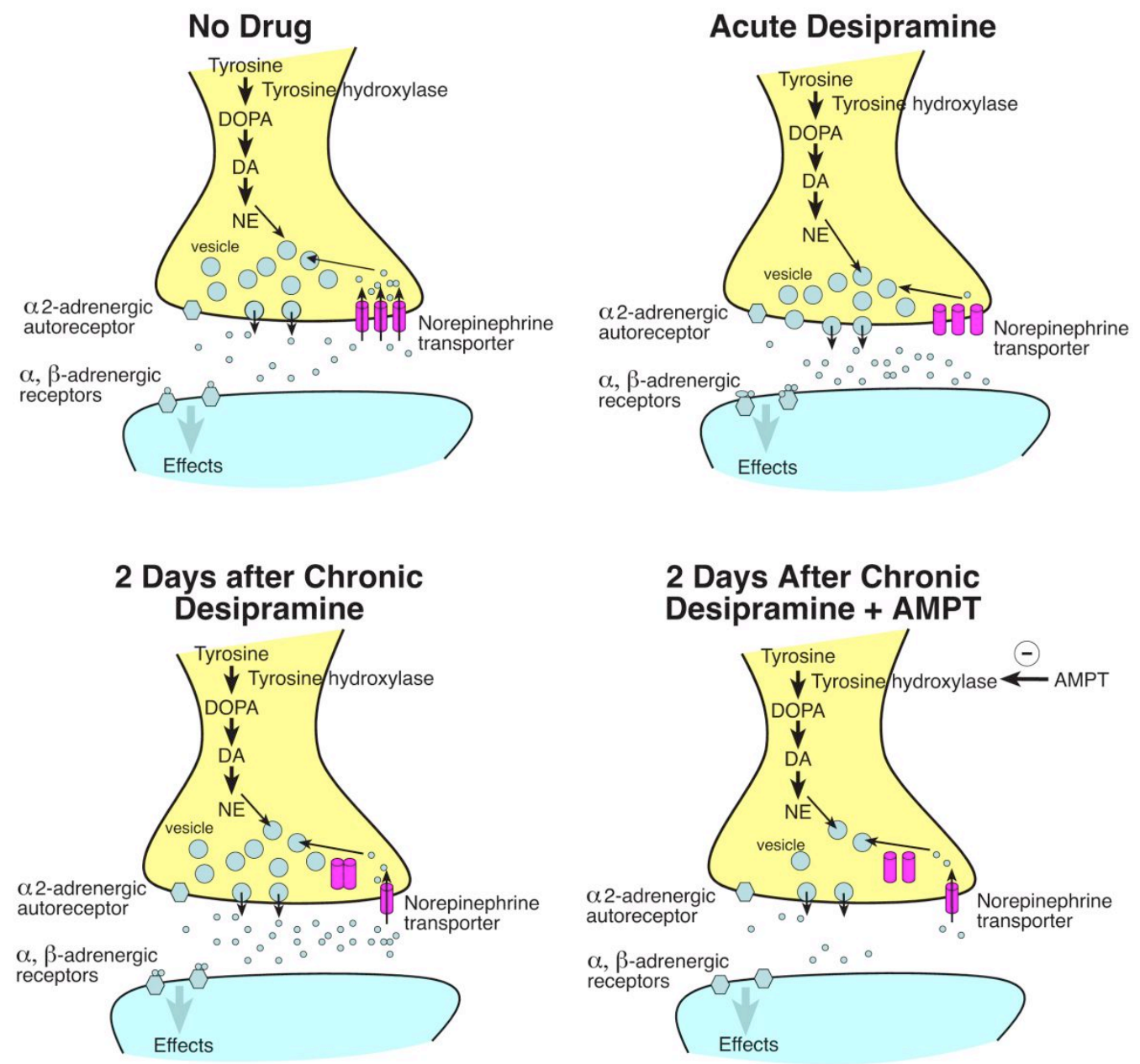
Figure 2.4 To examine whether enhanced noradrenergic neurotransmission was necessary for the persistent antidepressant-like effect in the forced-swim test, AMPT, an inhibitor of tyrosine hydroxylase, was administered two days after the end of the chronic desipramine treatment regimen. AMPT reversed the antidepressant-like effect in the forced-swim test, even at a dose where it did not affect behavior on its own (A). The changes in noradrenergic neurotransmission after acute and chronic desipramine treatment are demonstrated in this diagram (B). The membrane NET is blocked by acute desipramine treatment, resulting in an increased synaptic NE concentration. Two days after completion of chronic desipramine treatment, when the plasma and brain concentrations of desipramine and its major active metabolite are not detectable, the membrane NET is down-regulated. Under this condition, the increase of synaptic NE and antidepressant effect on behavior result not only from the direct blocking of NET by the desipramine, but also from reduced NET expression and function. Inhibition of NE synthesis with AMPT reverses the increase in neurotransmission, resulting in a loss of antidepressant efficacy, even though the NET is down-regulated. Data shown are means \pm SEM of 5-7 rats per group. ${ }^{*} \mathrm{p}<0.05, * * * \mathrm{p}<0.001$ vs. control; ${ }^{\# \#} \mathrm{p}<0.001$ vs. desipramine alone. 


\section{CHAPTER THREE}

\section{Association of changes in norepinephrine and serotonin transporter expression with the long-term behavioral effects of antidepressant drug treatment}

This chapter is identical to a manuscript, which was submitted to Neuropsychopharmacology in July 2008. 


\subsection{Abstract}

Previous work has shown that repeated desipramine treatment causes downregulation of the norepinephrine transporter (NET), accompanied by persistent antidepressant-like effects on behavior. The present study examined whether this mechanism generalizes to other antidepressant drugs and also is evident for the serotonin transporter (SERT). Treatment of rats for 14 days with $20 \mathrm{mg} / \mathrm{kg} /$ day protriptyline or 7.5 $\mathrm{mg} / \mathrm{kg} /$ day sertraline reduced NET and SERT expression, respectively, in cerebral cortex and hippocampus; these treatments also induced a persistent antidepressant-like effect in the forced-swim test. Increased serotonergic neurotransmission likely mediated the persistent antidepressant-like behavioral effect of sertraline, since it was blocked by inhibition of serotonin synthesis with para-chlorophenylalanine; a parallel effect was observed previously for desipramine and noradrenergic neurotransmission. Treatment with $20 \mathrm{mg} / \mathrm{kg}$ /day reboxetine for 42 , but not 14 , days reduced NET expression; antidepressant-like effects on behavior were observed for both treatment durations. Treatment for 14 days with $70 \mathrm{mg} / \mathrm{kg} /$ day venlafaxine, which inhibits both the NET and SERT, or $10 \mathrm{mg} / \mathrm{kg} /$ day phenelzine, a monoamine oxidase inhibitor, produced persistent antidepressant-like effects on behavior without altering NET or SERT expression. For all drugs tested, reductions of NET and SERT protein were not accompanied by reduced NET or SERT mRNA in LC or dorsal raphe nucleus, respectively. Overall, the present results suggest an important, though not universal, role for NET and SERT regulation in the long-term behavioral effects of antidepressants. Understanding the mechanisms underlying transporter regulation in vivo may suggest novel targets for the development of antidepressant drugs. 


\subsection{Introduction}

Antidepressants, in general, enhance noradrenergic and/or serotonergic neurotransmission following acute administration (Millan, 2006). For many antidepressants, including the tricyclic antidepressants, serotonin reuptake inhibitors (SRIs), norepinephrine reuptake inhibitors (NRIs), and serotonin-norepinephrine reuptake inhibitors (SNRIs), this results from inhibition of the norepinephrine or serotonin transporters (NET, SERT), which clear the transmitters from the synapse (Beyer et al., 2002; Katz et al., 2004; Morilak and Frazer, 2004; White et al., 2005). Some drugs enhance monoaminergic neurotransmission by other mechanisms such as inhibition of monoamine oxidase (Laux et al., 1995; Lopez-Munoz et al., 2007) or antagonism of presynaptic $\alpha-2$ adrenergic receptors (Charney et al., 1986; Dickinson, 1990; Millan et al., 2000; Artigas et al., 2001). While enhanced monoaminergic neurotransmission appears to be an effect shared by antidepressants from different chemical and pharmacological classes, its relationship to antidepressant efficacy is unclear since therapeutic effects develop gradually over time with repeated treatment (Frazer and Benmansour, 2002; Nelson et al., 2004; Katz et al., 2004).

This delayed clinical activity has raised questions regarding the relevance of the acute neurochemical effects of antidepressants, including enhancement of monoaminergic neurotransmission, to their long-term effects on behavior. It is believed that enhanced monoaminergic neurotransmission is not sufficient to produce an antidepressant effect, since this neurochemical effect is manifested early, prior to development of a clear, clinical effect. However, enhanced monoaminergic activity appears to be necessary for clinical activity. This is evident from the finding that 
inhibition of synthetic enzymes for norepinephrine or serotonin results in a rapid return of symptoms in depressed patients who have been treated successfully with desipramine or fluoxetine, respectively (Charney, 1998; Miller et al., 1996a). Recent work has implicated antidepressant-induced down-regulation of NET and SERT in the brain as a mechanism that may contribute to the long-term pharmacological effects of antidepressant drugs (Hirano et al., 2005a; Thakker et al., 2005; Zhao et al., 2008). Reduced NET or SERT expression would increase monoaminergic neurotransmission, even in the absence of pharmacological inhibition of the transporters.

In a recent study, it was found that repeated treatment with desipramine, which is relatively selective for inhibition of the NET relative to the SERT, reduces the expression of the NET in cerebral cortex and hippocampus in a dose-dependent manner (Zhao et al., 2008). This was evidenced by reduced binding of ${ }^{3} \mathrm{H}$-nisoxetine and by SDSPAGE/immunoblotting using NET-specific antisera. The reduced expression results in reduced uptake of ${ }^{3} \mathrm{H}$-norepinephrine into tissue slices in vitro and increased extracellular norepinephrine concentration in the prefrontal cortex measured in vivo using microdialysis. At all desipramine treatment conditions when the NET was found to be down-regulated, an antidepressant-like effect on behavior was evident in the forced-swim test. Importantly, NET down-regulation and behavioral effects were observed even when brain and plasma levels of desipramine and its major, active metabolite desmethyldesipramine were not detectable. Finally, as is observed in the clinical setting (Lam et al., 2001; Miller et al., 1996a), the persistent antidepressant-like effect of desipramine in the forced-swim test was lost when tyrosine hydroxylase was inhibited with alpha-methyl-p-tyrosine (AMPT; Zhao et al., 2008). 
Other studies have reported that repeated treatment with antidepressant drugs reduces the expression of the NET in the brain (Benmansour et al., 2004; Wong et al., 2000). Similarly, some antidepressants, including SRIs, have been reported to reduce the expression of the SERT (Benmansour et al., 1999; Benmansour et al., 2002; Gould et al., 2003; Hirano et al., 2005a; Hirano et al., 2005b; Gould et al., 2006), resulting in enhanced serotonergic neurotransmission. Antidepressant-induced down-regulation of the NET and SERT has been observed with cell lines in vitro (Zhu and Ordway, 1997; Zhu et al., 1998; Horschitz et al., 2001; Zhu, 2005; Iceta et al., 2007). This suggests that the down-regulation may result from a direct effect of the drugs on the transporter and is not secondary to increased extracellular concentrations of the transmitter. Thus, NET and SERT down-regulation may be effects caused by reuptake inhibitors and not by drugs that increase monoaminergic neurotransmission by other mechanisms, such as inhibition of monoamine oxidase.

While it appears that NET and SERT down-regulation with chronic treatment is an effect shared by a number of antidepressant drugs that inhibit monoamine reuptake, it is not clear to what extent this action contributes to the long-term behavioral effects of antidepressants from different pharmacological classes; to date, this relationship has only been investigated for desipramine. The present study examined the effects of the antidepressants protriptyline, reboxetine, sertraline, venlafaxine, and phenelzine on the NET and SERT and assessed whether changes in their expression resulted in antidepressant-like effects on behavior, similar to what has been observed with desipramine (Zhao et al., 2008). Protriptyline, a tricyclic antidepressant, produces neurochemical and behavioral effects similar to those of desipramine (Crissman and 
O'Donnell, 2002; O'Donnell et al., 2005). Reboxetine is an NRI that exhibits somewhat greater selectivity for the NET vs. the SERT compared to desipramine and protriptyline (Scates and Doraiswamy, 2000; Wong et al., 2000; Iversen, 2006). Sertraline is an SRI and is active in a number of antidepressant models (Benmansour et al., 1999; Benmansour et al., 2002). Venlafaxine, although classified as an SNRI, exhibits markedly greater potency for inhibition of the SERT than the NET (Iversen, 2006). Phenelzine, a monoamine oxidase inhibitor, does not interact directly with the NET or SERT, but increases monoaminergic neurotransmission and has antidepressant activity (Thase et al., 1995). Overall, the present study shows that down-regulation of the NET or SERT is produced by some antidepressants that interact with the transporters and that this effect contributes to their long-term behavioral effects; however, persistent antidepressant-like effects on behavior can, in some cases, be observed even when NET or SERT expression is not altered. 


\subsection{Materials and Methods}

\section{Animals}

Male Sprague-Dawley rats (Harlan, Indianapolis, IN), weighing 300-350g, were housed 2 per cage in a temperature-controlled room $\left(22-23^{\circ} \mathrm{C}\right)$ with a 12 -h on/12-h off light cycle (lights on at 6:00 AM). Food and water were freely provided. Blind observations were used throughout all behavioral testing, which was carried out from 1:00 PM - 5:00 PM in a quiet room. All procedures were reviewed and approved by the Animal Care and Use Committee of West Virginia University Health Sciences Center, and are consistent with the NIH "Guidelines for the Care and Use of Laboratory Animals" (NIH publication No. 80-23, revised 1996).

\section{Drugs administration}

Rats were anesthetized with ketamine $(100 \mathrm{mg} / \mathrm{kg})$ and xylazine $(10 \mathrm{mg} / \mathrm{kg})$ and implanted subcutaneously with osmotic minipumps (model 2ML2 or 2ML4, Alzet Corporation, Palo Alto, CA) preloaded with either vehicle (50\% saline, $40 \%$ DMSO, and $10 \%$ ethanol), protriptyline (Sigma-Aldrich, St Louis, MO), reboxetine (provided by Institut de Recherches Servier, Croissy/Seine, France), sertraline (Tocris, Ellisville, MO) or venlafaxine (Sigma-Aldrich, St Louis, MO) at concentrations that delivered 10 or 20 (protriptyline), 20 (reboxetine), 7.5 (sertraline), or 70 (venlafaxine) $\mathrm{mg} / \mathrm{kg} /$ day of the free base. Minipumps were removed, under anesthesia, 14 days later. However, for some rats treated with reboxetine, minipumps were removed 21 days after implantation and new minipumps were implanted, providing 42 days of drug administration. A dose of 10 $\mathrm{mg} / \mathrm{kg} /$ day (i.p.) of the irreversible monoamine oxidase inhibitor phenelzine was 
administrated for 14 days. Doses of each of the drugs used were chosen based on previous reports of neuropharmacological activity (Ordway et al., 1991; Gould et al., 2006).

Rats were tested for antidepressant-like behavior in the forced-swim test and locomotor activity in the open-field test 2 days after pump removal or the last phenelzine treatment; this minimized acute drug effects. However, the behavioral tests for one group treated with $10 \mathrm{mg} / \mathrm{kg}$ /day protriptyline were performed 1 day after the removal of pumps. Following the completion of the behavioral tests, rats were sacrificed by decapitation, their brains removed, and cerebral cortex and hippocampus dissected for measurement of NET and SERT using ${ }^{3} \mathrm{H}$-nisoxetine or ${ }^{3} \mathrm{H}$-citalopram binding and SDSPAGE/immunoblotting with specific antisera. Also, locus coeruleus and raphe nucleus were punched from surrounding tissue for real-time PCR measurement of NET and SERT mRNA.

\section{Forced-swim test}

The forced-swim test was carried out as described previously (Porsolt et al., 1977; Zhang et al., 2006). Plexiglas cylinders (40 $\mathrm{cm}$ high and $18 \mathrm{~cm}$ in diameter) were filled with water $\left(30 \mathrm{~cm}\right.$ depth, $\left.22-23^{\circ} \mathrm{C}\right)$; at this depth, rats could not touch the bottom of the cylinder with their tails or hind limbs. On day 1 (i.e., 1 day after cessation of antidepressant treatment), the rats were pre-tested for $15 \mathrm{~min}$ to develop an immobility posture after initial escape-oriented movements (Cryan et al., 2002). On day 2 (2 days after cessation of chronic antidepressant treatment), rats were subjected to the 5-min forced-swim test and immobility time was recorded; immobility was defined as floating 
on the surface of the water with the only movement being that required to keep the head above water. Some rats treated with $10 \mathrm{mg} / \mathrm{kg} /$ day protriptyline were subjected to 5 -min forced-swim testing one day after the end of the antidepressant treatment regimen, with the 15-min pre-test on the last day of drug treatment. Finally, in some tests, rats were administered the tryptophan hydroxylase inhibitor $p$-chlorophenylalanine (PCPA, 300 $\mathrm{mg} / \mathrm{kg}$, i.p; Sigma-Aldrich, St Louis, MO) twice daily for three consecutive days, with the last dose given $18 \mathrm{~h}$ before 5-min forced-swim test. This was done to determine whether reduced serotonergic neurotransmission blocked the antidepressant-like effect observed in the forced-swim test following down regulation of the SERT; this paralleled previous experiments examining the effects of reduced noradrenergic neurotransmission on persistent antidepressant-like behavior observed following desipramine-induced downregulation of the NET (Zhao et al., 2008).

To ensure that any changes in immobility in the forced-swim test were not secondary to increased locomotor activity, rats were observed in the open field test (Zhang et al., 2008). The floor of the open-field apparatus was divided into nine identical squares. Rats were placed individually in the center and allowed to explore for $5 \mathrm{~min}$; the number of line crossings (with all four paws crossing a line) and rears were recorded. None of the treatments increased locomotor activity, so these data are not shown.

\section{SDS-PAGE/Immunoblotting of SERT and NET protein in the rat brain}

Cerebral cortex and hippocampus were homogenized in TEVP buffer (10 mM Tris base, $5 \mathrm{mM} \mathrm{NaF}, 1 \mathrm{mM} \mathrm{Na} \mathrm{VO}_{4}, 1 \mathrm{mM}$ EDTA, 1 mM EGTA, 320 mM sucrose; $\mathrm{pH}$ 7.4) with a glass homogenizer and centrifuged at $1,000 \times \mathrm{g}$ for $20 \mathrm{~min}$ at $4^{\circ} \mathrm{C}$. The 
supernatant was centrifuged at $20,000 \times \mathrm{g}$ for $30 \mathrm{~min}$ to obtain a crude synaptosomal fraction (Lin et al., 1998; Wyszynski et al., 1998; Dunah et al., 2001). The pellets were re-suspended and solubilized with RIPA buffer $(50 \mathrm{mM}$ Tris, $150 \mathrm{mM} \mathrm{NaCl}, 2 \%$ IGEPAL CA-630, 0.5\% sodium deoxycholate, $0.1 \%$ SDS, and 0.1\% Triton X-100; $\mathrm{pH}$ 8.0) containing protease inhibitors (Roche, Indianapolis, IN). Protein content of membrane lysate was measured using the bicinchoninic acid assay (Smith, 1985; Pierce, Rockford, IL). Equal amounts of protein from both control and treated rats were mixed with 2X Laemmli sample buffer (Bio-Rad, Hercules, CA) and boiled at $100^{\circ} \mathrm{C}$ for $3 \mathrm{~min}$. Samples were loaded onto $8 \%$ polyacrylamide gels for electrophoresis and, after separation, transferred to nitrocellulose membranes. The membranes were blocked in TBST buffer containing $5 \%$ nonfat milk for $2 \mathrm{~h}$ at room temperature, washed with TBST buffer, and incubated overnight at $4^{\circ} \mathrm{C}$ with a specific, rabbit polyclonal antibody generated against a unique 22 amino acid peptide sequence mapping to the first extracellular domain of the NET (Chemicon, Temecula, CA; Zhao et al., 2008) or a peptide fragment of the C-terminus of the SERT (Santa Cruz, Santa Cruz, CA; Xie et al., 2006). After washing with TBST, membranes were incubated for $1 \mathrm{~h}$ at room temperature with horseradish peroxidase-conjugated goat anti-rabbit immunoglobulin $\mathrm{G}$ (Pierce, Rockford, IL). The labeled protein bands were detected by chemiluminescence imaging (Bio-Rad, Hercules, CA) and quantified by densitometry using an NIH image analysis program, and normalized to actin. Comparisons of treatment effects were carried out within single gels/immunoblots. 


\section{${ }^{3} \mathrm{H}-$ Nisoxetine binding assay}

${ }^{3} \mathrm{H}-\mathrm{Nisoxetine}$ binding to the NET was carried out as described previously (TejaniButt et al., 1990; Bryan-Lluka et al., 2001). One-half of the cerebral cortex or hippocampus was homogenized in $5 \mathrm{ml}$ of ice-cold binding buffer (50 mM Tris base, 120 $\mathrm{mM} \mathrm{NaCl}, 5 \mathrm{mM} \mathrm{KCl}$; pH 7.4) using a Polytron (Brinkman Instruments, Westbury, NY) and then centrifuged at $36,000 \times \mathrm{g}$ for $10 \mathrm{~min}$ at $4^{\circ} \mathrm{C}$. The supernatant was discarded, the pellet re-suspended in ice-cold binding buffer, centrifuged at $36,000 \times \mathrm{g}$ for $10 \mathrm{~min}$ at $4^{\circ}$ $\mathrm{C}$, and the pellet re-suspended in binding buffer to obtain a protein concentration of 1 $\mathrm{mg} / \mathrm{ml}$ as assayed using the bicinchoninic acid method (Smith, 1985; Pierce, Rockford, IL). Triplicate tubes containing $100 \mu \mathrm{l}$ incubation buffer (total binding) or $100 \mu \mathrm{l}$ desipramine (final concentration $50 \mu \mathrm{M}$; non-specific binding), $100 \mu 1$ tissue sample, and $50 \mu \mathrm{l}{ }^{3} \mathrm{H}$-nisoxetine (final concentration $5 \mathrm{nM} ; 72 \mathrm{Ci} / \mathrm{mmol}$, PerkinElmer, Boston, MA) were incubated in a shaking ice bath for $4 \mathrm{~h}$. Non-specific binding (i.e., in the presence of $50 \mu \mathrm{M}$ desipramine) was approximately $10 \%$ of total binding. Bound ${ }^{3} \mathrm{H}$-nisoxetine was captured by rapid filtration through glass fiber filters (GF/B Brandel, Gaithersburg, MD) that were pre-soaked in 5\% polyethyleneimine under vacuum with a cell harvester (Brandel, Gaithersburg, MD). Filters were washed twice with ice-cold binding buffer and radioactivity determined by liquid scintillation counting.

\section{${ }^{3} \mathrm{H}$-citalopram binding assay}

${ }^{3} \mathrm{H}$-Citalopram binding to the SERT was performed as described previously (D’Amato et al., 1987; Gould et al., 2006). One-half of the cerebral cortex or hippocampus was homogenized in $5 \mathrm{ml}$ of ice-cold binding buffer (50 mM Tris base, 120 
mM NaCl, 5 mM KCl; pH 7.4) using a Polytron (Brinkman Instruments, Westbury, NY) and then centrifuged at $36,000 \times \mathrm{g}$ for $10 \mathrm{~min}$ at $4^{\circ} \mathrm{C}$. The supernatant was discarded, the pellet re-suspended in ice-cold binding buffer, centrifuged at $36,000 \times \mathrm{g}$ for $10 \mathrm{~min}$ at $4^{\circ}$ $\mathrm{C}$, and the pellet re-suspended in binding buffer to obtain a protein concentration of 1 $\mathrm{mg} / \mathrm{ml}$ as assayed using the bicinchoninic acid method (Smith, 1985; Pierce, Rockford, IL). Triplicate tubes containing $100 \mu \mathrm{l}$ incubation buffer (total binding) or $100 \mu \mathrm{l}$ fluoxetine (final concentration $50 \mu \mathrm{M}$; non-specific binding), $100 \mu 1$ tissue sample, and $50 \mu 1{ }^{3} \mathrm{H}$-citalopram (final concentration $5 \mathrm{nM} ; 79 \mathrm{Ci} / \mathrm{mmol}$, PerkinElmer, Boston, MA) were incubated for $1 \mathrm{~h}$ with shaking at room temperature. Non-specific binding (i.e., in the presence of $50 \mu \mathrm{M}$ fluoxetine) was approximately $10 \%$ of total binding. Bound ${ }^{3} \mathrm{H}-$ citalopram was captured by rapid filtration through glass fiber filters (GF/B Brandel, Gaithersburg, MD) that were pre-soaked in 5\% polyethyleneimine under vacuum with a cell harvester (Brandel, Gaithersburg, MD). Filters were washed twice with ice-cold binding buffer and radioactivity determined by liquid scintillation counting.

\section{Measurement of NET and SERT mRNA by quantitative real-time PCR}

Locus coeruleus (for NET mRNA) and dorsal and median raphe nucleus (for SERT mRNA) were punched from the rat brain (Chamas et al., 1999; Chamas et al., 2004; Paxinos and Watson, 1998; Zhu et al., 2002). Total RNA was extracted using the Trizol reagent (Invitrogen, Carlsbad, CA) and was kept in RNAlater buffer (Ambion, Austin, TX) and stored at $-80^{\circ}$ C. Total RNA concentration was determined by spectrophotometry and adjusted to $0.5 \mu \mathrm{g} / \mu \mathrm{l}$. The quality of the RNA was verified using $1 \%$ denaturing agarose gel electrophoresis. Contaminating genomic DNA was 
eliminated by incubating with DNase mixture (Qiagen, Valencia, CA) at room temperature for 20 min. RNA was reverse transcribed to cDNA with high capacity cDNA archive kit (Applied Biosystems, Foster City, CA). The cDNA was subjected to real-time PCR using TaqMan universal PCR Master Mix and ABI 7300 real-time PCR system (Applied Biosystems, Foster City, CA). Specific primers and probes were purchased from pre-designed, pre-optimized TaqMan Gene Expression Assays (Applied Biosystems, Foster City, CA). Quantities of NET and SERT mRNA were normalized to the 18s rRNA. Analysis was performed using ABI-7300 system SDS software.

\section{Statistical analysis}

The data were analyzed by one-way analyses of variance (ANOVA) followed by Tukey's or Bonferroni's post hoc tests. When simple, paired comparisons between two groups were conducted, two-tailed Student's t-tests were used. Data are presented as

means \pm SEM and differences are considered statistically significant when $p$ values are less than 0.05 . 


\subsection{Results}

The neurochemical and behavioral effects of repeated antidepressant treatment were assessed 2 days after the end of the treatment period (i.e., osmotic minipump removal or discontinuation of phenelzine injections), except for some tests with protriptyline (see below). This permitted assessment of persistent effects under conditions when brain and plasma concentrations would be minimized (Zhao et al., 2008). None of the treatments increased locomotor activity, which could confound interpretation of results in the forced-swim tests; however, one day following treatment with protriptyline, locomotor activity was reduced (i.e., line crosses in the open-field test, to $65 \%$ of control; data not shown).

\section{Effects of protriptyline}

The relationship between the effect of chronic protriptyline treatment on NET expression and its effect on behavior in the forced-swim test was examined. Treatment of rats with $20 \mathrm{mg} / \mathrm{kg}$ /day protriptyline for 14 days, with a 2-day washout period, reduced NET expression, as indicated by a reduction of the binding of ${ }^{3} \mathrm{H}$-nisoxetine to the NET in preparations of cerebral cortex $\left(\mathrm{F}_{(4,21)}=5.75, \mathrm{p}<0.01\right.$; Fig. 3.1A) and hippocampus $\left(F_{(4,21)}=7.43, p<0.001\right.$; Fig. 3.1A). Down-regulation of the NET also was demonstrated using SDS-PAGE/immunoblotting of preparations of cerebral cortex $\left(\mathrm{F}_{(2,12)}=12.19, \mathrm{p}<\right.$ 0.001; Fig. 3.1B) and hippocampus $\left(\mathrm{F}_{(2,12)}=13.81, \mathrm{p}<0.001\right.$; Fig. 3.1B). Downregulation of NET expression was not observed 2 days following the end of treatment with $10 \mathrm{mg} / \mathrm{kg} /$ day protriptyline for 14 days, but was seen 1 day following this treatment (Fig. 3.1A). 
A persistent antidepressant-like effect in the forced-swim test was evident 2 days after discontinuation of 14-day treatment with $20 \mathrm{mg} / \mathrm{kg} /$ day protriptyline or 1 day after discontinuation of 14-day treatment with $10 \mathrm{mg} / \mathrm{kg}$ /day protriptyline $\left(\mathrm{F}_{(4,25)}=10.00, \mathrm{p}<\right.$ 0.001; Fig. 3.1C); this paralleled the protriptyline-induced down-regulation of the NET. No antidepressant-like effect on behavior was observed 2 days after chronic protriptyline treatment at a dose of $10 \mathrm{mg} / \mathrm{kg} /$ day (Fig. 3.1C), consistent with the lack of NET downregulation at this treatment condition.

In order to determine whether the down-regulation of the NET resulted from a change in gene transcription, NET mRNA expression in the locus coeruleus was measured by quantitative RT-PCR. The normalized, relative NET mRNA expression was not changed 2 days following the end of chronic treatment with $20 \mathrm{mg} / \mathrm{kg} /$ day protriptyline or 1 day following the end of chronic treatment with $10 \mathrm{mg} / \mathrm{kg} /$ day protriptyline $\left(\mathrm{F}_{(2,27)}=2.14, \mathrm{p}>\right.$ 0.05; Table 3.1). Similarly, repeated treatment with $15 \mathrm{mg} / \mathrm{kg} /$ day desipramine, which reduces NET protein expression (Zhao et al., 2008), also did not reduce NET mRNA in locus coeruleus ( $\mathrm{p}>0.05$; Table 3.1$)$.

\section{Effects of reboxetine}

The relationship between the effect of chronic reboxetine treatment on NET expression and its effect on behavior in the forced-swim test was examined. Treatment of rats with $20 \mathrm{mg} / \mathrm{kg}$ /day reboxetine for 6 weeks, with a 2-day washout, reduced NET

expression, as indicated by a reduction of the specific binding of ${ }^{3} \mathrm{H}$-nisoxetine to the NET in preparations of cerebral cortex $\left(\mathrm{F}_{(2,12)}=23.00 ; \mathrm{p}<0.0001\right.$; Fig. 3.2A) and hippocampus $\left(\mathrm{F}_{(2,12)}=3.78 ; \mathrm{p}<0.05\right.$; Fig. 3.2A); however, treatment for two weeks did 
not alter NET expression significantly. By contrast, SERT expression (i.e., ${ }^{3} \mathrm{H}-$ citalopram binding) was not altered by reboxetine treatment, either in preparations of cerebral cortex $\left(\mathrm{F}_{(2,14)}=1.67 ; \mathrm{p}>0.05\right.$; Fig. 3.2B $)$ or hippocampus $\left(\mathrm{F}_{(2,16)}=0.68 ; \mathrm{p}>0.05\right.$; Fig. 3.2B).

Down-regulation of the NET by six-week chronic reboxetine treatment also was demonstrated using SDS-PAGE/immunoblotting of preparations of cerebral cortex $\left(\mathrm{F}_{(2,13)}\right.$ $=5.99 ; \mathrm{p}<0.05$; Fig. 3.2C) and hippocampus $\left(\mathrm{F}_{(2,16)}=2.94 ; \mathrm{p}<0.05\right.$; Fig. 3.2C). By contrast, this treatment did not alter SERT expression, measured by immunoblotting, in either cerebral cortex or hippocampus (Fig. 3.2D). Interestingly, repeated treatment with $15 \mathrm{mg} / \mathrm{kg}$ desipramine for 14 days reduced SERT expression in cerebral cortex and hippocampus as evidenced using ${ }^{3} \mathrm{H}$-citalopram binding (40 - 50\% reduction; data not shown).

In parallel with the down-regulation of the NET, chronic treatment with reboxetine for 6 weeks also produced a reduction in the duration of immobility in the forced-swim test, indicative of an antidepressant-like effect $\left(\mathrm{F}_{(2,15)}=34.01 ; \mathrm{p}<0.001 ;\right.$ Fig. 3.2E). Although the 2-week reboxetine treatment did not reduce NET expression in cerebral cortex or hippocampus, an antidepressant-like effect still was observed in the forcedswim test following this treatment (Fig. 3.2E).

In order to determine whether the down-regulation of NET resulted from a change in NET gene transcription, NET mRNA expression in the locus coeruleus and SERT mRNA expression in the dorsal and medial raphe nucleus were measured using quantitative RTPCR. The normalized, relative NET mRNA expression in the locus coeruleus was elevated, about 3 -fold, 2 days after discontinuation of chronic reboxetine treatment $(\mathrm{p}<$ 
0.001; Table 3.1). The normalized, relative SERT mRNA expression in the dorsal and medial raphe nucleus was increased about 2.5-fold $(\mathrm{p}<0.01$; Table 3.1).

\section{Effects of sertraline}

Given the apparent relationship between the down-regulation of the NET by chronic treatment with NRIs and persistent antidepressant-like effects in the forced-swim test, it was of interest to also examine the relationship between changes in SRI-induced SERT expression and behavior. Rats were treated chronically with $7.5 \mathrm{mg} / \mathrm{kg} /$ day sertraline for 14 days and subjected to the forced-swim test 2 days after the end of sertraline treatment (i.e. removal of the osmotic pumps), and SERT expression was determined in several brain regions using ${ }^{3} \mathrm{H}$-citalopram binding and Western blotting. Further, to determine whether enhanced serotonergic neurotransmission was necessary for the persistent antidepressant effect in the forced-swim test, a serotonin depletion approach was utilized, similar to that used to assess the role of serotonergic neurotransmission in the clinical actions of sertraline (Miller et al., 1996b). Rats were treated with PCPA, an inhibitor of tryptophan hydroxylase, the rate-limiting enzyme for serotonin biosynthesis. PCPA (300 $\mathrm{mg} / \mathrm{kg}$, i.p.) was administrated twice daily for three consecutive days with the last dose given $18 \mathrm{~h}$ before behavioral test (O'Leary et al., 2007) to rats that had been treated chronically with vehicle or sertraline.

A significant reduction of SERT binding sites, measured using ${ }^{3} \mathrm{H}$-citalopram, was evident 2 days after the discontinuation of chronic sertraline treatment in the cerebral cortex $\left(\mathrm{F}_{(3,18)}=8.17, \mathrm{p}<0.01 ;\right.$ Fig. 3.3A $)$ and hippocampus $\left(\mathrm{F}_{(3,18)}=10.06, \mathrm{p}<0.001 ;\right.$ Fig. 3.3A). By contrast, NET expression (i.e., ${ }^{3} \mathrm{H}$-nisoxetine binding) was not altered by 
sertraline treatment, either in preparations of cerebral cortex $(p>0.05$; Fig. 3.3B) or hippocampus ( $\mathrm{p}>0.05$; Fig. 3.3B).

The down-regulation of the SERT also was demonstrated using SDSPAGE/immunoblotting of preparations of cerebral cortex $\left(\mathrm{F}_{(3,16)}=6.94, \mathrm{p}<0.01\right.$; Fig. 3.3C) and hippocampus $\left(\mathrm{F}_{(3,16)}=14.37, \mathrm{p}<0.001\right.$; Fig. 3.3C). By contrast, this treatment did not alter NET expression, measured by immunoblotting, in either cerebral cortex or hippocampus (Fig. 3.3D).

In parallel with the down-regulation of the SERT, chronic sertraline treatment also produced an antidepressant-like effect in the forced-swim test, demonstrated by a reduction of immobility time $\left(\mathrm{F}_{(3,19)}=19.57, \mathrm{p}<0.001\right.$; Fig. 3.3E). Three-day, twice daily treatment with $300 \mathrm{mg} / \mathrm{kg} /$ day PCPA, to reduce serotonin neurotransmission, reversed the behavioral actions of chronic sertraline treatment, demonstrated by the increased immobility time and reduced latency to immobility (Fig. 3.3E); PCPA, when administered alone, did not affect behavior in the forced-swim test (Fig. 3.3E), nor did it alter SERT expression (Fig. 3.3C).

There was a significant effect of sertraline administration on normalized, relative SERT mRNA expression in the dorsal and median raphe nucleus $\left(\mathrm{F}_{(3,18)}=28.5, \mathrm{p}<0.001\right.$; Table 3.1). Post hoc tests revealed that while chronic sertraline treatment did not change the SERT mRNA expression, a significant decrease in SERT mRNA expression was found in the groups treated with PCPA alone or in combination with chronic sertraline (Table 3.1). 


\section{Effects of venlafaxine}

Given that venlafaxine inhibits both the NET and SERT, i.e. it is an SNRI, it was of interest to explore the relationship between venlafaxine-induced changes in NET and SERT expression and behavior. Rats were treated chronically with $70 \mathrm{mg} / \mathrm{kg} /$ day venlafaxine for 14 days and subjected to the forced-swim test 2 days after the end of venlafaxine treatment. NET and SERT binding sites were determined in several brain regions using ${ }^{3} \mathrm{H}$-nisoxetine and ${ }^{3} \mathrm{H}$-citalopram binding. NET and SERT protein expression was determined by Western blotting. Treatment of $70 \mathrm{mg} / \mathrm{kg} /$ day venlafaxine did not alter NET (Fig. 3.4A) or SERT binding sites (Fig. 3.4B) in cerebral cortex and hippocampus. Consistently, NET and SERT protein expression in cerebral cortex and hippocampus was not changed after chronic venlafaxine treatment (Fig. 3.4C, 3.4D). However, in spite of the lack of any change in NET or SERT expression, an antidepressant-like effect in the forced-swim test was observed two days after the end of the chronic venlafaxine treatment period $(\mathrm{p}<0.001$; Fig. 3.4E).

\section{Effects of phenelzine}

To determine whether enhanced monoaminergic neurotransmission, independent of NET or SERT inhibition, was sufficient to alter expression of the transporters, the effects

of the monoamine oxidase inhibitor phenelzine were determined. Rats were treated with $10 \mathrm{mg} / \mathrm{kg} /$ day phenelzine (i.p.) for 14 days and subjected to the forced-swim test 2 days after the end of the treatment period. NET and SERT expression was then assessed in cerebral cortex and hippocampus. 
Phenelzine treatment did not alter NET or SERT expression in cerebral cortex or hippocampus, measured by ${ }^{3} \mathrm{H}$-nisoxetine and ${ }^{3} \mathrm{H}$-citalopram binding (Fig. 3.5A, 3.5B) and SDS-PAGE/immunoblotting (Fig. 3.5C, 3.5D). However, a significant decrease in immobility time in the forced-swim test was observed following chronic phenelzine treatment $(\mathrm{p}<0.001$; Fig. 3.5E). 


\subsection{Discussion}

In a previous study, the relationship between desipramine-induced down-regulation of the NET and antidepressant effects on behavior was observed (Zhao et al., 2008). The down-regulation of the NET is associated with antidepressant effects on behavior, even when there is no detectable drug present to inhibit norepinephrine reuptake. Desipramine-induced down-regulation of the NET and the development of persistent antidepressant-like effects on behavior develop gradually with repeated treatment, consistent with the development of the clinical response to antidepressants (Frazer et al., 2002; Katz et al., 1996, 2004; Gelenberg and Chesen, 2000). This suggests that neural adaptation resulting in enhanced monoaminergic neurotransmission may be a key mechanism mediating antidepressant actions. Consistent with this, it was found that inhibition of catecholamine synthesis with AMPT reverses the persistent antidepressantlike effect in the forced-swim test (Zhao et al., 2008); similar effects have been observed in depressed patients treated with desipramine (Charney, 1998; Miller et al., 1996a). The results of the present study demonstrated that NET down-regulation appears to be important for the actions of protriptyline and reboxetine, two other antidepressants that interact with the NET. Further, SERT down-regulation contributes to the long-term behavioral effects of the SRI sertraline.

NET expression, measured by ${ }^{3} \mathrm{H}$-nisoxetine binding and SDSPAGE/immunoblotting, was reduced after 14 days of treatment with protriptyline or 42 days of treatment of reboxetine, similar to the effect observed after repeated treatment with desipramine (Zhao et al., 2008). $\beta$-1 adrenergic receptor density also is reduced after chronic desipramine, protriptyline, or reboxetine treatment (Ordway et al., 1991; Gould et 
al., 2003). This suggests that NET down-regulation results in increased noradrenergic neurotransmission; this has been verified experimentally for desipramine and reboxetine treatment using in vivo microdialysis (Page and Lucki, 2002; Lapiz et al., 2007; Zhao et al., 2008).

NET down-regulation in response to NRI treatment, in addition to being observed in vivo (Zhu et al., 2002; Weinshenker et al., 2002; Zhao et al., 2008), also has been shown in vitro in cell lines expressing the NET. NET expression in SK-N-BE(2)M17 cells is decreased following 3 - 14 days of exposure to desipramine (Zhu et al., 1998). Chronic desipramine-induced NET down-regulation also was observed with PC12 and human neuroblastoma cells (Zhu and Ordway, 1997; Zhu et al., 2005), as well as HEK-293 cells transfected with the NET (Zhu et al., 1998). Because these cells lack synaptic innervation, these findings suggest that desipramine-induced NET regulation is, at least in part, a direct effect of occupation of the NET, and not secondary to an increase in the extracellular concentration of NE. Consistent with this interpretation, it was found that chronic treatment with the monoamine oxidase inhibitor phenelzine, which increases noradrenergic neurotransmission, does not down-regulate the NET. However, it did produce antidepressant-like effects in the forced-swim test.

In the present study, it was found that repeated treatment with the SRI sertraline reduced SERT expression, measured using ${ }^{3} \mathrm{H}$-citalopram binding and SDSPAGE/immunoblotting. Previously, it has been found that SERT density in the CA3 region of the hippocampus, assessed by quantitative autoradiography with ${ }^{3} \mathrm{H}$ cyanoimipramine, is decreased by $80-90 \%$ by chronic sertraline or paroxetine treatment (Benmansour, et al., 1999). After 15 days of sertraline treatment, SERT binding sites are 
reduced by $80 \%$, accompanied by a marked reduction of serotonin clearance (Benmansour et al., 2002). SERT density in the dentate gyrus, lateral nucleus of the amygdala, and dorsal raphe, measured by ${ }^{3} \mathrm{H}$-cyanoimipramine binding, is significantly reduced after chronic paroxetine treatment (Gould et al., 2003). Similarly, using ${ }^{3} \mathrm{H}-$ citalopram homogenate binding, SERT binding sites in the rat prefrontal cortex are reduced after chronic paroxetine or sertraline treatment (Gould et al., 2006). SERT expression in mouse brain regions is reduced after chronic paroxetine treatment; this effect persists for $120 \mathrm{~h}$ after 21 days of treatment (Hirano et al., 2005b). In humans, it has been reported that treatment with $40 \mathrm{mg} /$ day citalopram for 8 days reduces SERT binding sites in the diencephalon and brainstem (Kugaya et al., 2003). To date, it had not been determined whether persistent down-regulation of the SERT resulted in the antidepressant effects on behavior. In the present study, it was found that two days following discontinuation of sertraline treatment, when SERT expression was reduced in cerebral cortex and hippocampus, a persistent antidepressant-like effect in the forcedswim test was observed.

In HEK cells expressing the SERT, its binding sites are reduced after a 3-day incubation with $500 \mathrm{nM}$ citalopram; this is accompanied by decreased maximal transporter activity $\left(\mathrm{V}_{\max }\right)$ and an unchanged $\mathrm{K}_{\mathrm{m}}$ value (Horschitz et al., 2001). In vitro, down-regulation of SERT is associated with protein kinase C (PKC) activation-induced phosphorylation of specific amino acid residues, which triggers translocation of SERT from membrane to cytoplasm (Jayanthi et al., 2004; Sung et al., 2005; Sung et al., 2007; Amano et al., 2006). Qian et al. (1997) and Lau et al. (2008) also have shown that stimulation of PKC causes internalization of cell-surface SERT protein. 
While treatment with the NRI reboxetine reduced NET expression without altering the SERT, consistent with its reported selectivity (Wong et al., 2000; Millan et al., 2001; Versiani et al., 1999), desipramine treatment reduced expression of both the NET and the SERT. This may result from a lack of selectivity for desipramine for the NET at the dose tested (Iversen, 2006) or may be due to the effects of desipramine's primary, active metabolite desmethyldesipramine, which reaches concentrations similar to the parent compound (Kozisek et al., 2007). In preparations of rat brain, desmethyldesipramine exhibits 12-fold greater affinity for the SERT compared with the NET; desmethyldesipramine's affinity for the SERT is similar to desipramine's for the NET (Deupree et al., 2007). Thus, immediately after desipramine administration, when the desipramine concentration is much higher than that of desmethyldesipramine, the pharmacological effect of desipramine might be associated primarily with the NET, while later as the concentration of the longer-lived metabolite desmethyldesipramine increases, both SERT and NET may be involved.

Among the adaptive changes that may underlie the long-term effects of antidepressant treatment, NET and SERT regulation fit with the clinical data to a considerable degree. From a functional perspective, the direction of the long-term change in transporter expression following antidepressant treatment is the same as that seen with acute treatment with an antidepressant. In both cases, there is a reduction in transporter function and enhanced monoaminergic neurotransmission. By contrast, changes in monoaminergic receptor expression often are homeostatic, i.e., in opposition to the effect of acute antidepressant treatment (Ordway et al., 1991). Preclinically, AMPT partially prevents the acute desipramine response, while a combination of AMPT and reserpine 
completely prevents the behavioral effects of acute desipramine (O’Leary et al., 2007); this suggests that disruption of both catecholamine synthesis and vesicular storage and release are required to completely block desipramine's effects. PCPA, a tryptophan hydroxylase inhibitor (Koe and Weissman, 1966), completely reverses the antidepressant-like effect produced by acute treatment with the SRIs fluoxetine and citalopram (Page et al., 1999; O'Leary et al., 2007). Clinically, in untreated patients, it has been reported that reducing catecholamine activity with AMPT or serotonergic activity with tryptophan depletion has no obvious effects on symptoms of depression, indicating that monoamine deficiency itself is insufficient to cause symptoms of depression (Miller et al., 1996b). However, catecholamine depletion by AMPT results in the return of symptoms of depression in depressed patients treated chronically with NRIs such as desipramine, but not SRIs (Miller et al., 1996a; Miller et al., 1996b; Bremner et al., 2003). By contrast, inhibition of serotonin synthesis with PCPA or a tryptophan-free amino acid drink reverses symptom remission caused by SRIs, but not NRIs (Miller et al., 1996b; Salomon et al., 1993).

Consistent with these clinical data, it has been found in an earlier study that inhibition of catecholamine synthesis with AMPT reverses the persistent antidepressant-like effect of desipramine in the forced-swim test (Zhao et al., 2008); changes in both noradrenergic and dopaminergic neurotransmission may contribute to this effect of AMPT (O'Donnell and Seiden, 1984). A role for noradrenergic neurotransmission is suggested by the finding that NE-deficient mice fail to respond to the behavioral effects of the NRI desipramine. Restoration of noradrenergic function by 1-threo-3,4dihydroxyphenylserine (1-DOPS) reinstates the behavioral effects of desipramine in these 
mice (Cryan et al., 2004). In the present study, it was found that inhibition of serotonin synthesis with PCPA reversed the persistent antidepressant-like effect of sertraline in the forced-swim test. Overall, the preclinical and clinical data suggest that enhanced monoaminergic neurotransmission is necessary, but not sufficient, for producing antidepressant effects, at least for those drugs that act via inhibition of reuptake.

Whether the down-regulation of the NET or SERT is mediated by altered gene transcription has been a point of investigation. Previous studies using HEK-293 and SKN-BE(2)M17 cells have shown that desipramine-induced reduction of NET expression primarily is due to translocation or increased degradation of the NET, but have not ruled out altered transcription (Zhu et al., 1998; Zhu et al., 2002). However, in vivo, it is found that NET mRNA expression in the locus coeruleus is elevated after chronic desipramine treatment (Szot et al., 1993). Further, it is found that the SERT mRNA expression in the raphe nucleus is unchanged following chronic treatment with SRIs (Benmansour et al., 1999; Abumaria et al., 2007). Lopez et al. (1994) found that the SERT mRNA level is increased after chronic antidepressant treatment, while Lesch et al. (1993) reported a decreased SERT mRNA level. In vitro, the expression of NET mRNA in human enterocyte-like cell line Caco-2 (Iceta et al., 2007) and SERT-expressing HEK293 cells (Lau et al., 2008) is unaltered after chronic SRIs treatment. In the present study, it was found that NET mRNA expression in the rat locus coeruleus was unchanged after chronic desipramine or protriptyline treatment, while it was elevated 3-fold after the 6-week reboxetine treatment regimen. Given that the change in NET protein expression produced by these drugs is reduced, i.e., in the opposite direction, it is unlikely that chronic antidepressant-induced down-regulation of the NET is regulated at the 
transcriptional level. In fact, exposure to reboxetine for six weeks might trigger a compensatory increase in transcription. Changes in SERT mRNA also do not appear to account for sertraline-induced changes in SERT protein expression. However, while sertraline treatment alone did not alter SERT mRNA, PCPA alone or in combination with sertraline reduced it. Interestingly, SERT mRNA expression in the raphe nucleus was increased after the six-week reboxetine treatment; the mechanism mediating this effect and its functional significance are unclear.

It seems that down-regulation of NET or SERT is not the only mechanism mediating persistent antidepressant-like behavioral effects. Treatment of rats with $20 \mathrm{mg} / \mathrm{kg} / \mathrm{day}$ reboxetine for two weeks did not reduce the NET expression but did produce an antidepressant-like effect in the forced-swim test 2 days after the end of the treatment period. Further, 2-week treatment with $70 \mathrm{mg} / \mathrm{kg} /$ day venlafaxine treatment failed to decrease the NET or SERT expression but still produced a persistent antidepressant-like effect in the forced-swim test. It also was reported that NET and SERT binding sites, measured using quantitative autoradiography with ${ }^{3} \mathrm{H}$-citalopram, are not reduced in the CA3 region of hippocampus after treatment for 21 days with 15 or $70 \mathrm{mg} / \mathrm{kg} / \mathrm{day}$ venlafaxine (Gould et al., 2006). Similarly, chronic treatment with amitriptyline, a tricyclic antidepressant that inhibits both the NET and SERT, also fails to reduce SERT and NET binding sites (Owens et al., 1997). The inability of venlafaxine to downregulate the NET or SERT following chronic treatment is not due to a lack of efficacy, since treatment with $70 \mathrm{mg} / \mathrm{kg} /$ day causes a down-regulation of $\beta-1$ adrenergic receptors in the same rats in which no down-regulation of the transporters is observed (Gould et al., 2006). Also, chronic venlafaxine produces a dose-dependent attenuation of the 
hypothermic response of rats to acute treatment with 8-OH-DPAT, a serotonin-1A receptor agonist, similar to the effects produced by sertraline and citalopram (Hensler et al., 2003; Rossi et al., 2005). The reason why chronic reboxetine and venlafaxine failed to down-regulate NET or SERT but still showed antidepressant-like behavioral effects is not known. It is possible that differential stimulation of heteroreceptors (Chiang and Aston-Jones, 1993; Mongeau et al., 1993), distinct interactions with P450 isoenzymes (Cadieux, 1999; Tanaka, 1999), different binding affinities for the transporters (Lenox and Frazer, 2002), and details regarding the nature and location of binding to the NET or SERT (Larsen et al., 2004; Schmid et al., 2001) may account for the observed differences among the effects of the antidepressants tested.

Overall, the present results demonstrate a relationship between antidepressantinduced changes in NET and SERT expression and the development of persistent antidepressant-like effects on behavior. Also, consistent with clinical data, it was found that the antidepressant-like effect that resulted from SERT down-regulation depended on the enhanced serotonergic neurotransmission, since it was lost when serotonin synthesis was inhibited. A similar dependence of desipramine-induced NET down-regulation on enhanced noradrenergic neurotransmission was demonstrated previously (Zhao et al., 2008). The present data provide support for the idea that the down-regulation of NET and SERT may contribute to the long-term therapeutic effects of antidepressant drugs. The mechanism of NET and SERT regulation appears to be due more to altered internalization and degradation than altered transcription. Understanding the molecular mechanisms mediating NET and SERT regulation in vivo might suggest novel targets for therapeutic intervention in the treatment of depression. 
Table 3.1 Effects of chronic antidepressant treatment on NET mRNA expression in the locus coeruleus and SERT mRNA expression in the raphe nucleus

\begin{tabular}{|c|c|c|}
\hline $\begin{array}{l}\text { Antidepressants } \\
\text { (mg/kg/day) }\end{array}$ & $\begin{array}{l}\text { Normalized NET mRNA } \\
\text { level in locus ceruleus }\end{array}$ & $\begin{array}{l}\text { Normalized SERT mRNA } \\
\text { level in raphe nuclei }\end{array}$ \\
\hline \multicolumn{3}{|l|}{ Protriptyline } \\
\hline Control & $1.41 \pm 0.26$ & N.D. \\
\hline 20 & $1.80 \pm 0.33$ & N.D. \\
\hline 10 & $1.73 \pm 0.17$ & N.D. \\
\hline \multicolumn{3}{|l|}{ Desipramine } \\
\hline Control & $1.59 \pm 0.54$ & N.D. \\
\hline 15 & $2.42 \pm 0.40$ & N.D. \\
\hline \multicolumn{3}{|l|}{ Reboxetine } \\
\hline Control & $1.08 \pm 0.14$ & $1.04 \pm 0.09$ \\
\hline 20 & $3.14 \pm 0.69 * * *$ & $2.61 \pm 0.73 * *$ \\
\hline \multicolumn{3}{|l|}{ Sertraline } \\
\hline Control & N.D. & $1.24 \pm 0.34$ \\
\hline PCPA & N.D. & $0.19 \pm 0.04 * * *$ \\
\hline 7.5 & N.D. & $1.47 \pm 0.33$ \\
\hline $\mathrm{PCPA}+7.5$ & N.D. & $0.42 \pm 0.22 * * *$ \\
\hline
\end{tabular}

Rats were treated chronically with antidepressants via osmotic pumps. NET and SERT mRNA were determined by the real-time PCR 2 days after discontinuation of chronic treatment (1 day post-treatment for $10 \mathrm{mg} / \mathrm{kg}$ protriptyline). Values shown are ratios relative to $18 \mathrm{~S}$ rRNA (mean $\pm \mathrm{SEM} ; \mathrm{n}=5 /$ group). $* \mathrm{p}<0.05, * * \mathrm{p}<0.01, * * * \mathrm{p}<$ 0.001. N.D., not determined. 
A

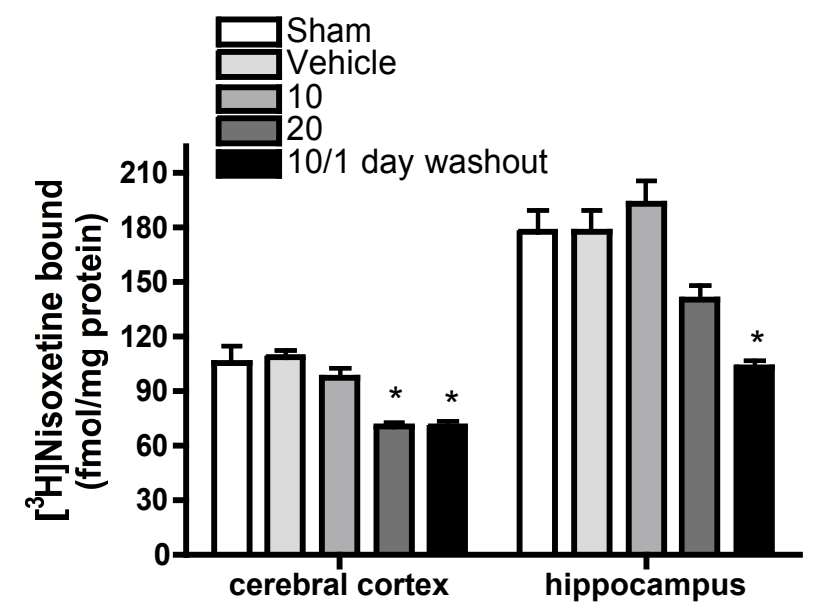

C

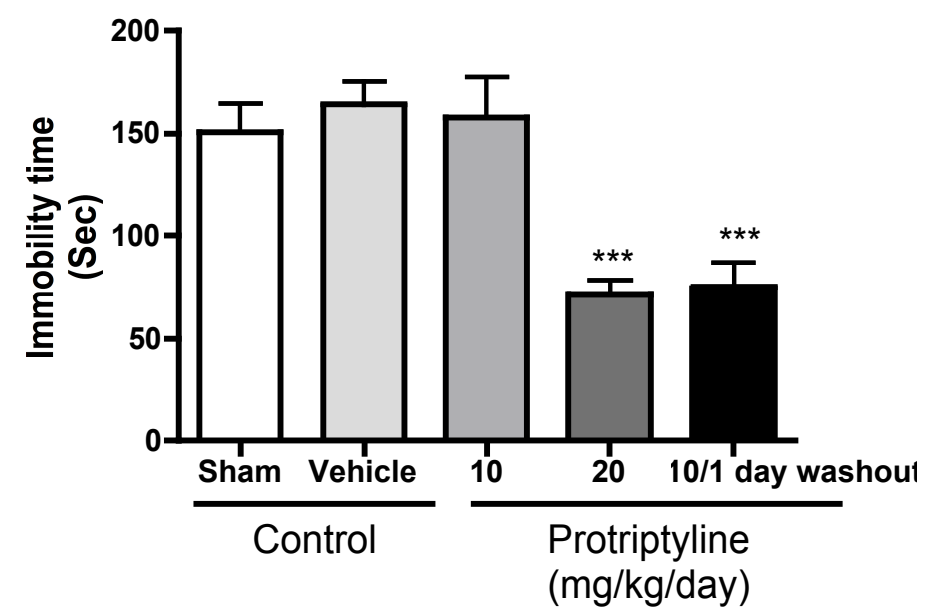

B
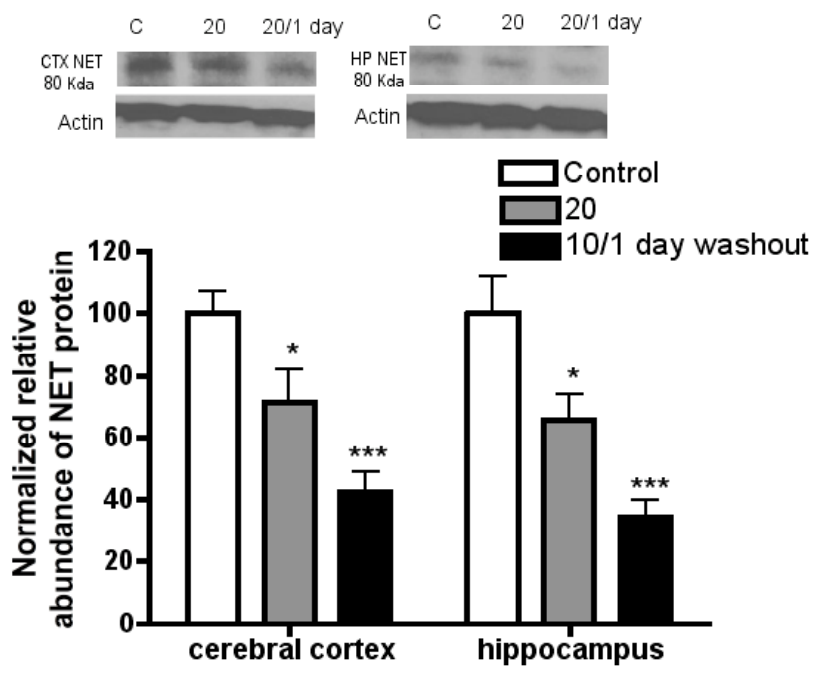

Figure 3.1 The effects of chronic protriptyline were determined for the ability to reduce NET expression in the cerebral cortex and hippocampus, determined by ${ }^{3} \mathrm{H}$-nisoxetine binding (A) and SDS-PAGE/immunoblotting (B), and to reduce immobility time in the forced-swim test (C). All measures were determined two days after the end of the chronic treatment period except one group $(10 \mathrm{mg} / \mathrm{kg} /$ day with 1 day washout). Data shown are means \pm SEM of 5-8 rats per group. ${ }^{*} \mathrm{p}<0.05 ; * * * \mathrm{p}<0.001$ vs. control. 
A

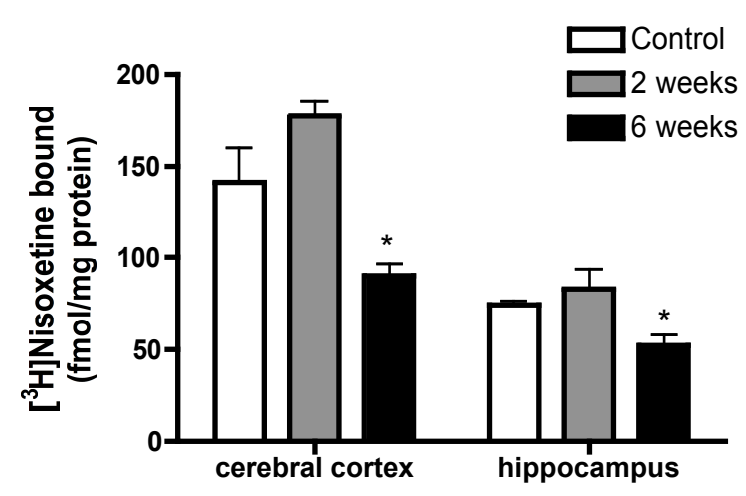

C
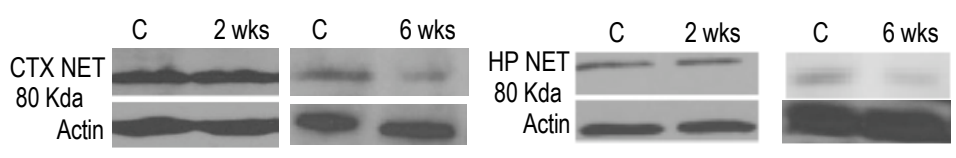

Control

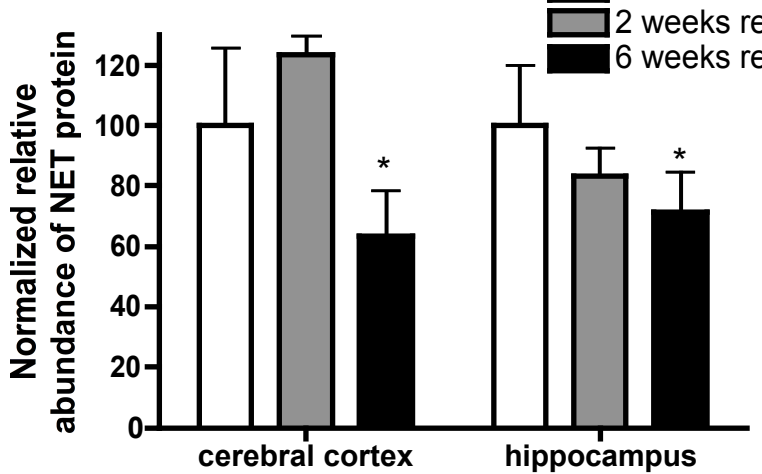

E

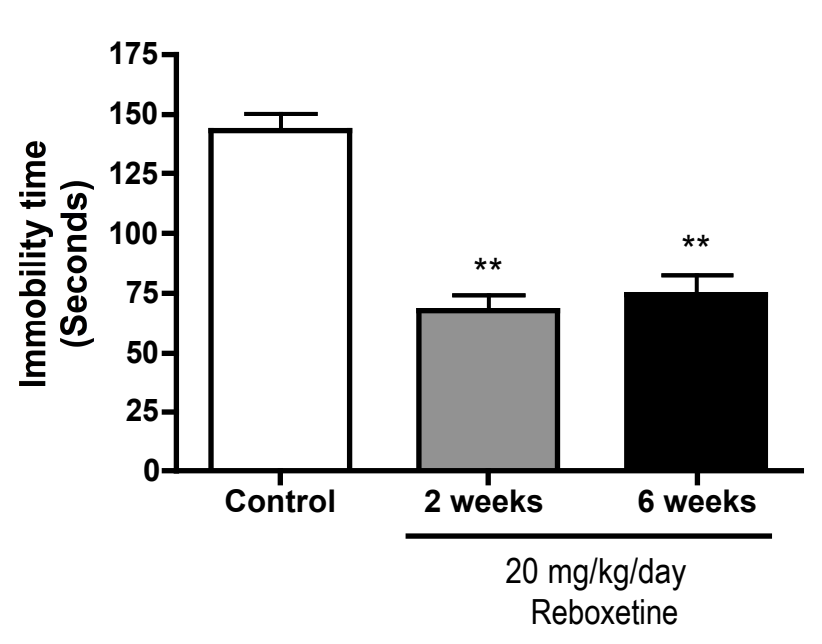

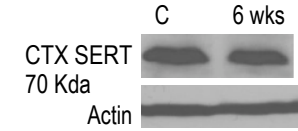

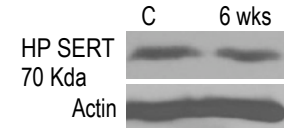

B $\square$ 2 weeks reboxetine

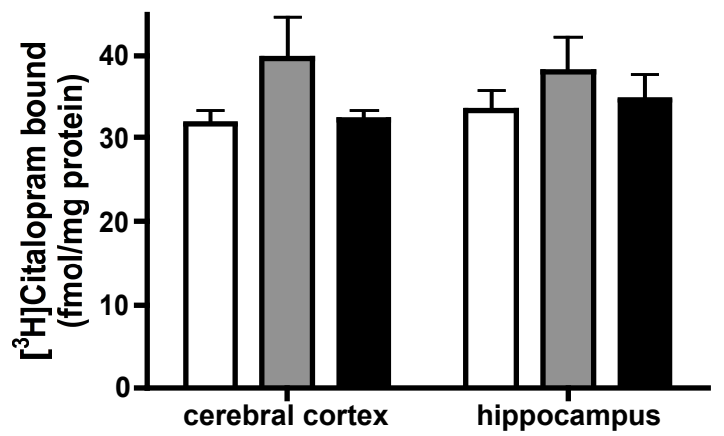

D

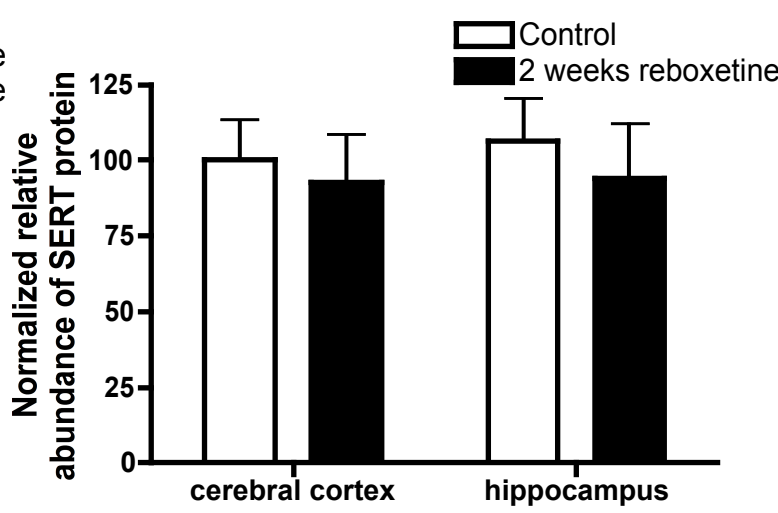


Figure 3.2 The effect of 6 -week reboxetine $(20 \mathrm{mg} / \mathrm{kg} /$ day $)$ on NET and SERT expression in the cerebral cortex and hippocampus was determined using ${ }^{3} \mathrm{H}$-nisoxetine and ${ }^{3} \mathrm{H}$-citalopram binding, respectively. 6-week reboxetine treatment significantly reduced NET binding sites in both cerebral cortex and hippocampus, but not SERT binding sites (A, B). The NET protein expression in the cerebral cortex and hippocampus determined by SDS-PAGE/immunoblotting with antisera against the NET was significantly reduced only after 6-week treatment, but not after 2-week treatment (C). The persistent antidepressant-like effect in the forced-swim test was still evident two days after the end of the chronic treatment period (D). Data shown are means \pm SEM of 5-6 rats per group. ${ }^{*} \mathrm{p}<0.05 ; * * \mathrm{p}<0.01$ vs. control. 


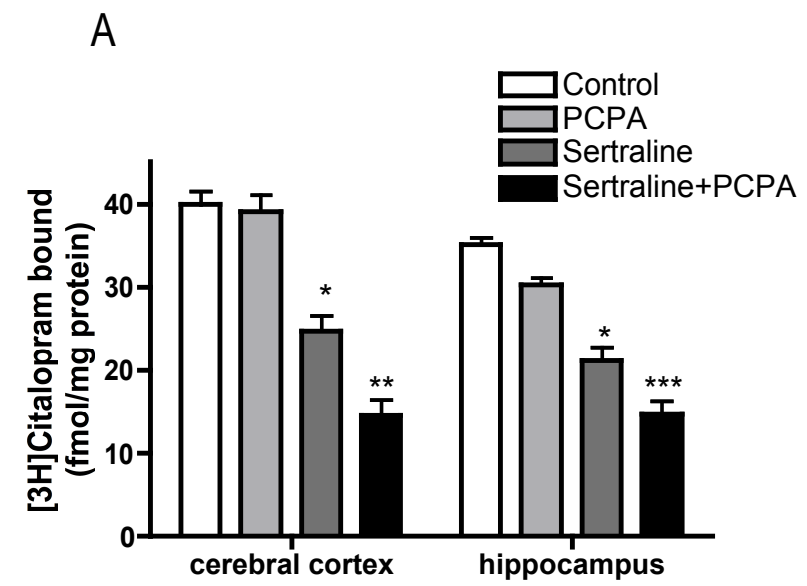

B ${ }^{\text {Control }}$

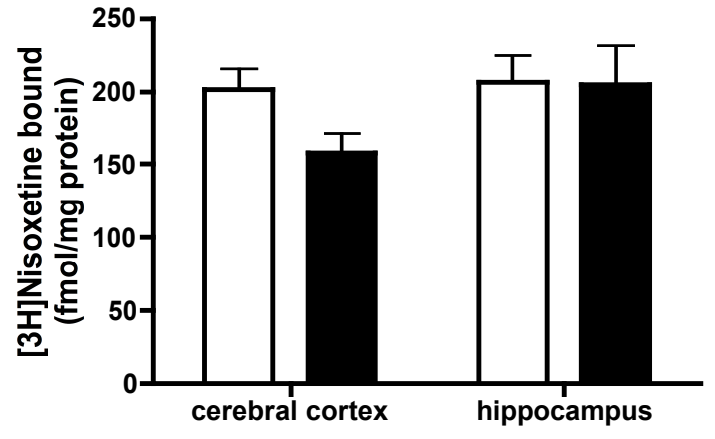

C
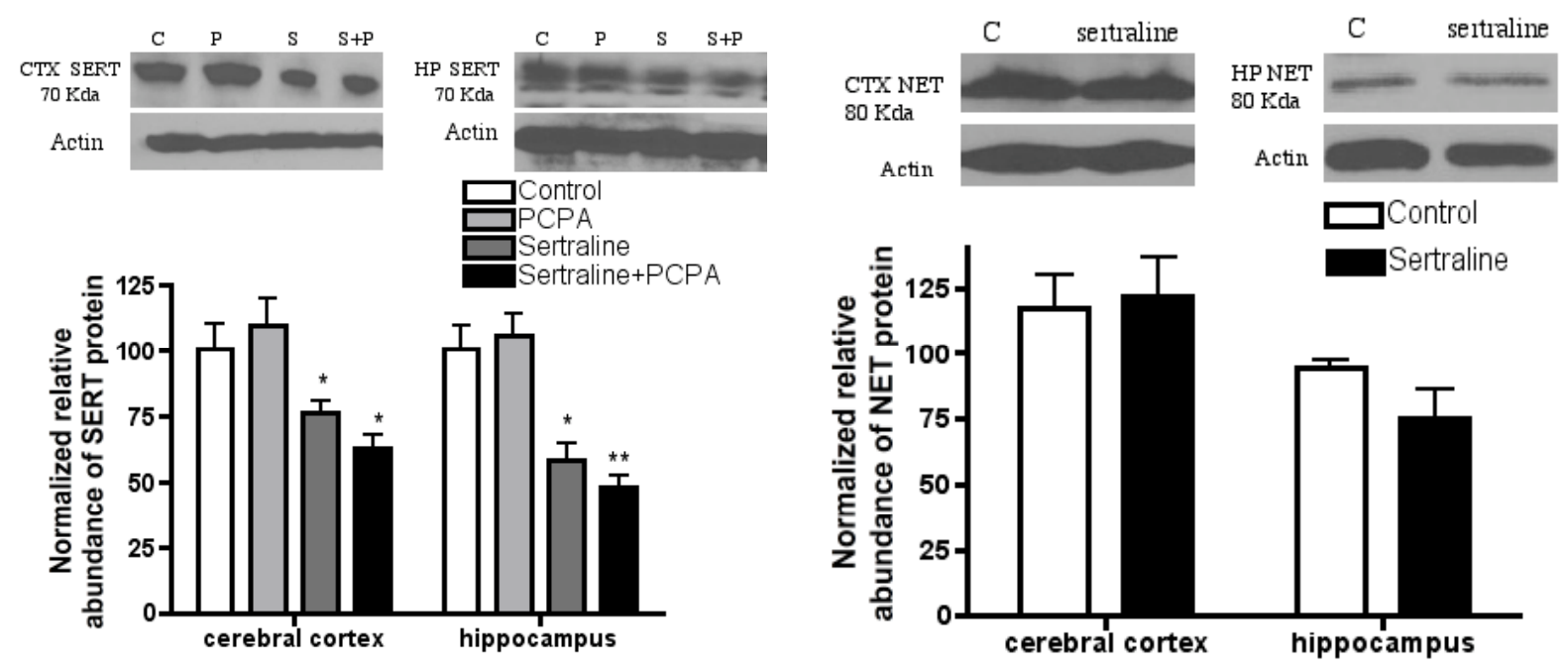

E

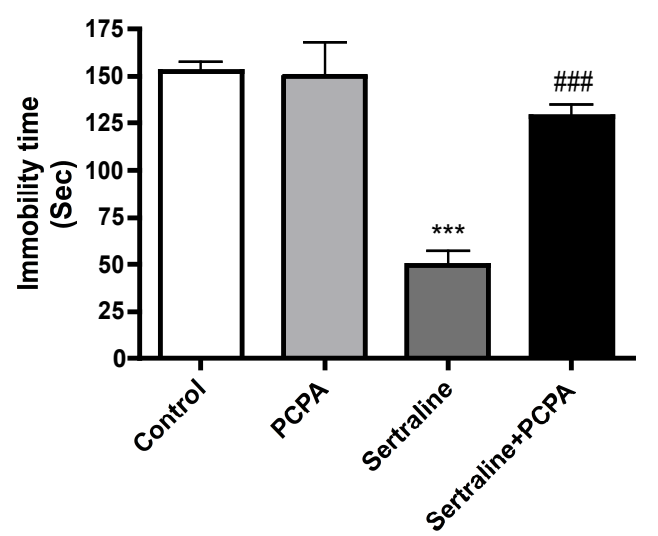


Figure 3.3 The SERT expression in the cerebral cortex and hippocampus measured by ${ }^{3} \mathrm{H}$-citalopram binding (A) and SDS-PAGE/immunoblotting (C) displayed significant reduction after 2-week sertraline treatment. The NET expression in the cerebral cortex and hippocampus determined by ${ }^{3} \mathrm{H}$-nisoxetine binding (B) and SDSPAGE/immunoblotting (D) was not altered by chronic sertraline treatment. To examine whether enhanced serotonergic neurotransmission was necessary for the persistent antidepressant-like effect in the forced-swim test, PCPA, an inhibitor of tryptophan hydroxylase, was administered (300 mg/kg, IP) twice daily for three consecutive days with last dose given $18 \mathrm{~h}$ before the forced-swim test. PCPA reversed the sertralineinduced antidepressant-like effect in the forced-swim test, even at a dose where it did not affect behavior on its own (E). Data shown are means \pm SEM of 5-8 rats per group. ${ }^{*} \mathrm{p}<$ $0.05 ;{ }^{*} \mathrm{p}<0.01 ; * * * \mathrm{p}<0.001$ vs. control; ${ }^{\# \#} \mathrm{p}<0.01 ;{ }^{\# \#} \mathrm{p}<0.001$ vs. sertraline alone. 
A

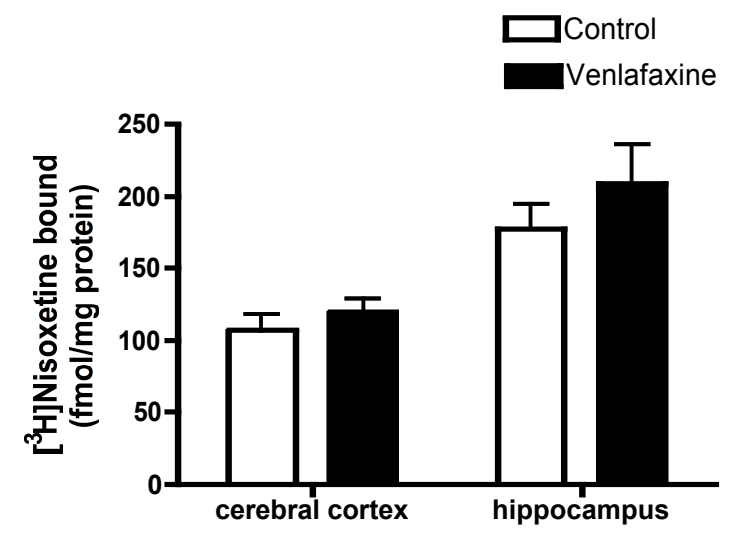

C
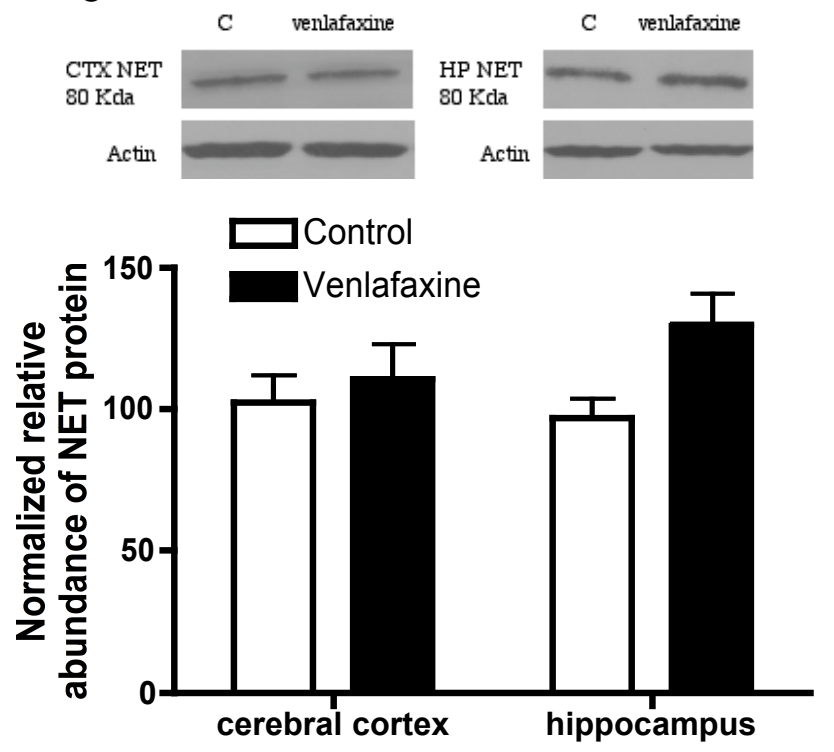

E

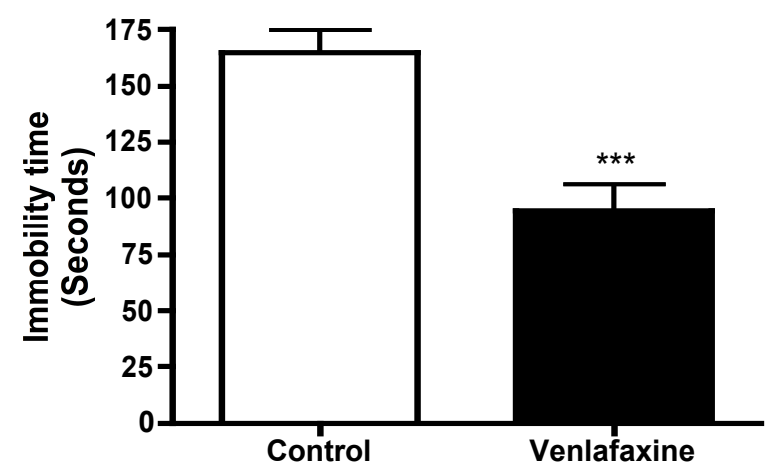

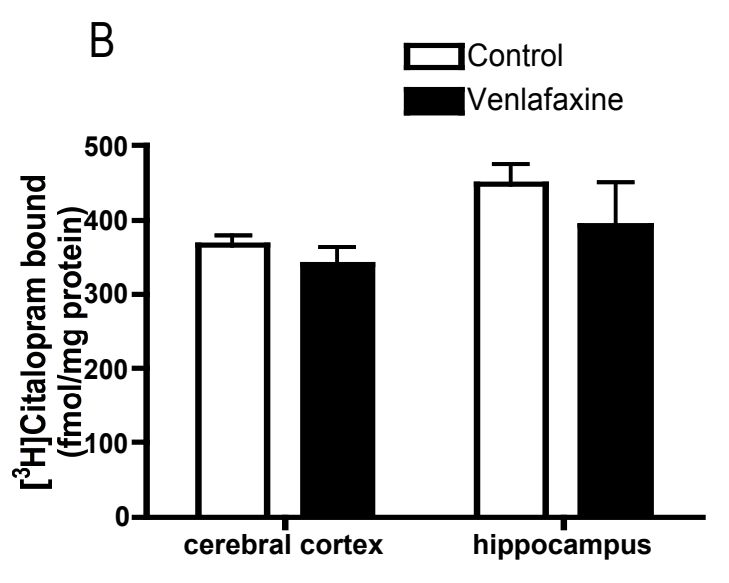
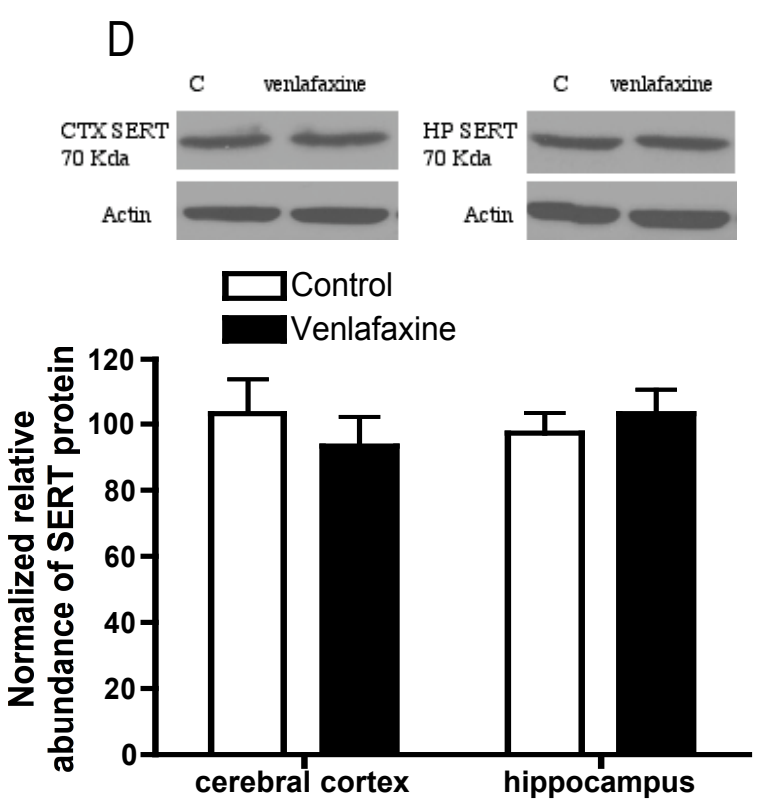
Figure 3.4 The effect of 2 -week of venlafaxine $(70 \mathrm{mg} / \mathrm{kg} /$ day $)$ on NET and SERT expression in the cerebral cortex and hippocampus was determined using ${ }^{3} \mathrm{H}$-nisoxetine and ${ }^{3} \mathrm{H}$-citalopram binding, respectively. 2 -week venlafaxine treatment did not reduce NET and SERT binding sites in both cerebral cortex and hippocampus (A, B). The NET and SERT protein expression in the cerebral cortex and hippocampus determined by SDS-PAGE/immunoblotting with antisera against the NET and SERT was not changed after chronic treatment $(C, D)$. However, the persistent antidepressant-like effect in the forced-swim test was still evident two days after the end of the chronic treatment period (D) even though neither NET nor SERT protein expression was down-regulated. Data shown are means \pm SEM of 5-6 rats per group. $* * * p<0.001$ vs. control. 
A

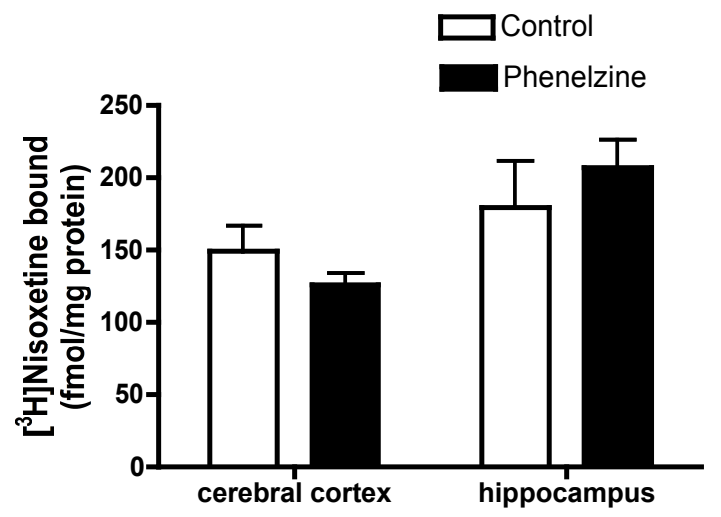

C

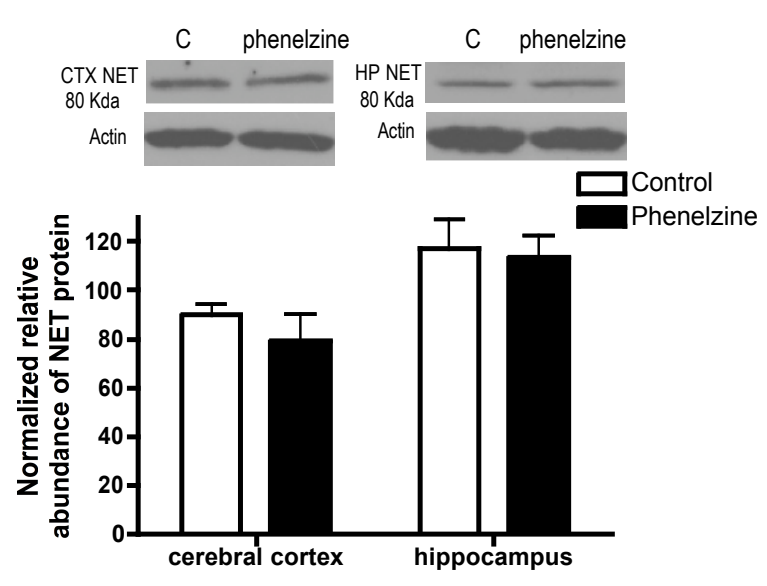

E

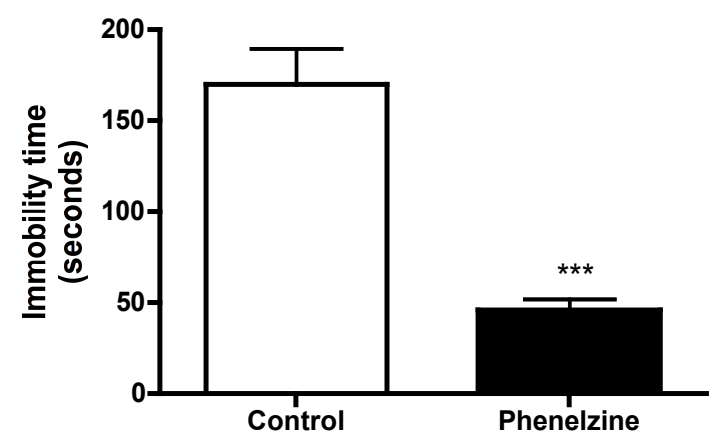

B

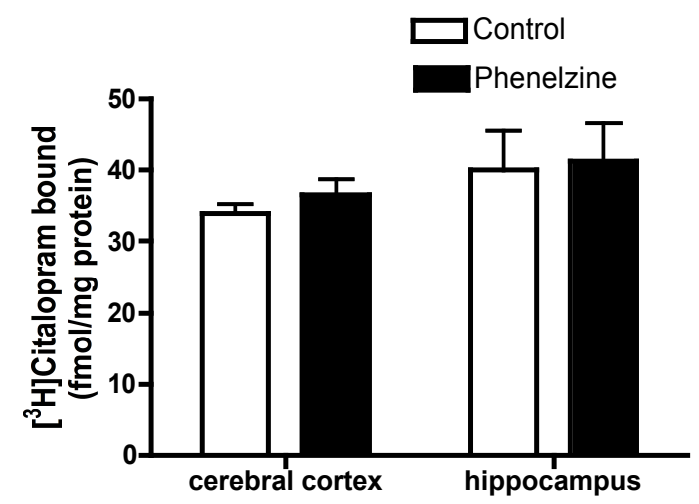

D

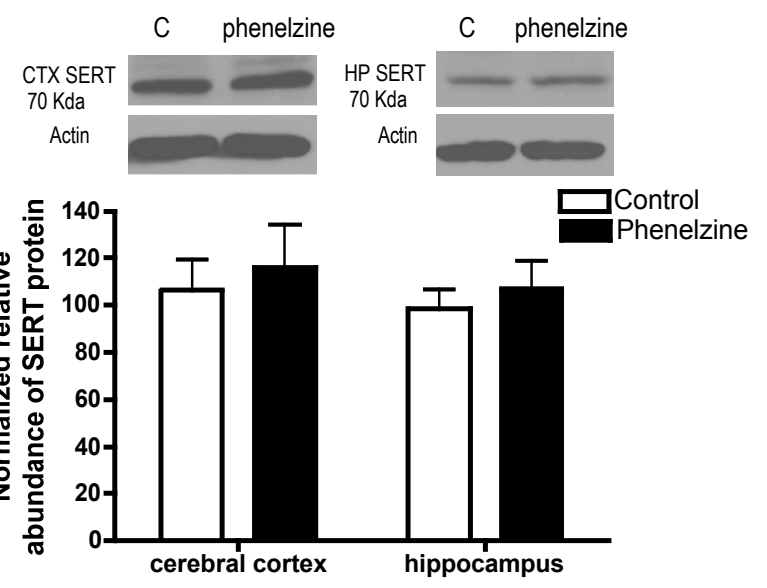


Figure 3.5 The NET and SERT binding sites in the cerebral cortex and hippocampus measured by 3H-nisoxetine (A) and 3H-citalopram binding (B) didn't change after 14day phenelzine treatment. The NET and SERT protein expression in the cerebral cortex (C) and hippocampus (D) determined by SDS-PAGE/immunoblotting displayed also no change after 14-day phenelzine treatment. The persistent antidepressant-like effect was still observed in the forced-swim test 2 days after discontinuation of 14-day phenelzine treatment $(\mathrm{E})$. Data shown are means \pm SEM of 5-6 rats per group. ***p $<0.001$ vs. control. 


\section{CHAPTER FOUR}

Role of PKC in NET activity in cerebral cortical slices and antidepressant-like effects on behavior 


\subsection{Abstract}

The results of studies using cell culture models have suggested a role for protein kinase $\mathrm{C}$ (PKC) in norepinephrine transporter (NET) regulation; experiments were carried out to begin to assess the importance of this mechanism in brain tissue, as well to determine its importance in mediation of antidepressant effects on behavior. The PKC activators $\beta$ PMA and bryostatin-1 reduced norepinephrine uptake in cortical slices in vitro; this was due to decreased $\mathrm{V}_{\max }$ and unchanged $\mathrm{K}_{\mathrm{m}}$ values. Reduced norepinephrine uptake also was observed following incubation with the PP1/2A inhibitor calyculin $\mathrm{A}$ and the $\mathrm{IP}_{3}$ receptor antagonist 2-APB. It also was found that i.v. or ICV administration of $\beta$-PMA or ICV administration of bryostatin-1 produced antidepressant-like effect on forced-swim behavior. The effect of $\beta$-PMA on forced-swim behavior was reversed by coadministration of 1-(5-isoquinolinesulfonyl)-2-methylpiperazine (H-7), a protein kinase $\mathrm{C}$ inhibitor. The present results suggest a role for PKC signaling in NET regulation in the rat brain and indicate that modulation of PKC activity by changes in $\mathrm{IP}_{3}$ and $\mathrm{PP} 1 / 2 \mathrm{~A}$ function may contribute in the mediation of antidepressant effects on behavior. Since NET regulation appears be involved in the development of antidepressant effects on behavior, mechanisms involving PKC may offer novel targets for producing antidepressant actions. 


\subsection{Introduction}

The NET, a target for certain antidepressants, is important in regulation of synaptic NE concentrations; the NET mediates reuptake of NE into the presynaptic terminal, which is the primary method of inactivation (Schomig et al., 1989). Chronic treatment with antidepressants that inhibit the NET, e.g. desipramine and reboxetine, downregulates NET expression and enhances synaptic NE levels, resulting in persistent antidepressant behavioral effects (Zhao et al., 2008). The time-course of down-regulation of NET is consistent with clinical observations and provides a plausible mechanism to explain the delayed onset of action of antidepressants in patients with major depressive illness (Benmansour et al., 2002; Katz et al., 2004); it also is consistent with data that suggest that enhanced monoaminergic neurotransmission is necessary for antidepressant effectiveness (Miller et al., 1996a; Miller et al., 1996b). The molecular mechanisms underling chronic antidepressants-induced down-regulation of the NET, particularly in vivo, have not been fully elucidated; however, the PKC signaling pathway does appear to be involved (Jayanthi et al., 2004; Jayanthi et al., 2006).

The NET is phosphorylated by $\mathrm{PKC}$, affecting its cellular localization and function (Jayanthi et al., 2006). $\beta$-PMA, a PKC activator, reduces NET activity and surface expression in HEK-293 and LLC-PK1 cells stably transfected with the human NET (Apparsundaram et al., 1998a; Apparsundaram et al., 1998b), as well as in rat placental trophoblasts (Jayanthi et al., 2004). Reduced NET activity is characterized by a decrease in the maximum transport velocity $\left(\mathrm{V}_{\max }\right)$ with little or no change in substrate affinity $\left(\mathrm{K}_{\mathrm{m}}\right)$. This reduction in activity is mediated primarily by the internalization of surface NET protein (Jayanthi et al., 2004). Site-directed mutagenesis reveals that threonine-258 
and serine-259 residues of the human NET are PKC phosphorylation sites that control transporter internalization (Jayanthi et al., 2006). NET activity also is reduced by the protein phosphatase 1 and 2A (PP1/2A) inhibitors okadaic acid and calyculin A, which prevent de-phosphorylation of the PKC sites (Bauman et al., 2000).

The PKC activator bryostatin-1 has been suggested to be a novel antidepressant, based on preclinical data (Sun and Alkon, 2005). Antidepressant effects caused by PKC activation could be mediated by phosphorylation of a number of different proteins, given the high expression of this enzyme in the brain (Saito et al., 1988). PKC activation facilitates synaptic neurotransmission and induces rapid morphological plasticity (Pilpel and Segal, 2004), especially in the hippocampus, which has been implicated in depression and its pharmacotherapy (Drevets, 2001; Liotti and Mayberg, 2001). Some behavioral effects of PKC activation may be mediated via the regulation of NET and SERT cell surface expression, which has been demonstrated in vitro. If this also occurs in vivo, it could result in reduced monoamine transporter function and increased monoaminergic neurotransmission (Jayanthi et al., 2005).

Most studies examining PKC-induced down-regulation of NET expression and activity have been carried out in vitro using a variety of cell lines; it is of interest to examine this mechanism in brain and to assess possible behavioral relevance. The results of the present study addressing this issue indicate that PKC activation reduces NET activity both in vitro and in vivo and results in antidepressant-like effects in the forcedswim test. 


\subsection{Materials and Methods}

\section{Animals}

Male Sprague-Dawley rats (Harlan, Indianapolis, IN), weighing 300-350g, were housed 2 per cage in a temperature-controlled room $\left(22-23^{\circ} \mathrm{C}\right)$ with a $12-\mathrm{h}$ on $/ 12-\mathrm{h}$ off light cycle (lights on at 6:00 AM). Food and water were freely provided. Blind observations were used for all behavioral testing, which was carried out from 1:00 PM 5:00 PM in a quiet room. All procedures were reviewed and approved by the Animal Care and Use Committee of West Virginia University Health Sciences Center, and are consistent with the NIH "Guidelines for the Care and Use of Laboratory Animals" (NIH publication No. 80-23, revised 1996).

\section{Intracerebroventricular (ICV) drug administration}

ICV cannulation and drug administration were carried out as described previously (Zhang et al., 2003). All surgery was performed under aseptic conditions. Rats were anesthetized with ketamine $(100 \mathrm{mg} / \mathrm{kg})$ and xylazine $(10 \mathrm{mg} / \mathrm{kg})$ and placed in a stereotaxic apparatus (Stoelting, Wood Dale, IL). Guide cannulas (22-guage; Plastics One, Roanoke, VA) were implanted bilaterally into the lateral ventricles using the following coordinates: AP, $-0.5 \mathrm{~mm}$ from Bregma; $\mathrm{ML}, \pm 1.6 \mathrm{~mm}$ from the midline; $\mathrm{DV}$, -3.9 $\mathrm{mm}$ from dura (Paxinos and Watson, 1986). Following a recovery period of at least one week, compounds dissolved in aCSF were injected into the lateral ventricles using a syringe pump ( $1 \mu$ l over $2 \mathrm{~min})$. 


\section{Forced-swim test}

The forced-swim test was carried out as described previously (Porsolt et al., 1977; Zhang et al., 2006; Zhao et al., 2008). Plexiglas cylinders (40 cm high and $18 \mathrm{~cm}$ in diameter) were filled with water $\left(30 \mathrm{~cm}\right.$ depth, $\left.22-23^{\circ} \mathrm{C}\right)$; at this depth, rats could not touch the bottom of the cylinder with their tails or hind limbs. On day 1, the rats were pre-tested for 15 min to develop an immobility posture after initial escape-oriented movements (Cryan et al., 2002). On day 2, rats were subjected to the 5-min forced-swim test 30 min after administration of drugs; immobility time was recorded, with immobility defined as floating on the surface of the water with the only movement being that required to keep the head above water.

\section{${ }^{3} \mathrm{H}-\mathrm{NE}$ uptake assay}

Uptake assays were carried out as described previously (Apparsundaram et al., 1998; Vizi et al., 2004). Fresh rat cerebral cortex was placed in ice-cold, oxygenated $\left(95 \% \mathrm{O}_{2} /\right.$ 5\% $\mathrm{CO}_{2}$ ), Krebs-Ringer/HEPES (KRH) buffer (125 mM NaCl, $5.2 \mathrm{mM} \mathrm{KCl,} 1.2 \mathrm{mM}$ $\mathrm{CaCl}_{2}, 1.4 \mathrm{mM} \mathrm{MgSO} 4,1.2 \mathrm{mM} \mathrm{KH} \mathrm{PO}_{4}, 5 \mathrm{mM}$ glucose, $20 \mathrm{mM}$ HEPES, $0.2 \mathrm{mg} / \mathrm{ml}$ ascorbic acid, and $100 \mu \mathrm{M}$ pargyline; $\mathrm{pH}$ 7.4). Tissue was cut into $0.4 \mathrm{~mm}$ slices using a McIlwain tissue chopper (Brinkmann, Westbury, NY). Slices were separated by gentle shaking and washed with oxygenated KRH buffer. The slices were treated with $\beta$-PMA (SigmaAldrich, St. Louis, MO) or bryostatin-1 (SigmaAldrich, St. Louis, MO) for 30 min

at $37^{\circ} \mathrm{C}$. Uptake assays were performed by incubating the tissue slices with $30 \mathrm{nM}^{3} \mathrm{H}-$ NE/NE (0.03 - $3 \mathrm{uM} ; 10.9 \mathrm{Ci} / \mathrm{mmol}$, PerkinElmer, Boston, MA) for $10 \mathrm{~min}$ at $37^{\circ} \mathrm{C}$. Assays were terminated by rapid washing of slices with $0.5 \mathrm{ml}$ of ice-cold KRH buffer 
three times. Buffer was aspirated and slices were then sonicated in $10 \%$ trichloroacetic acid and centrifuged at $30,000 \times \mathrm{g}$ for $2 \mathrm{~min} .{ }^{3} \mathrm{H}-\mathrm{NE}$ in the supernatant was quantified by liquid scintillation counting. Nonspecific uptake was determined in the presence of 20 $\mu \mathrm{M}$ desipramine. Specific uptake was determined by subtracting nonspecific uptake from total uptake.

\section{Statistical analysis}

Data were analyzed by one-way analyses of variance followed by Tukey's or Bonferroni's post-hoc tests. Data are presented as means \pm SEM and differences are considered statistically significant when $\mathrm{p}$ values are less than 0.05 . 


\subsection{Results}

\section{Effects of $\beta$-PMA and bryostatin-1 on behavior in the forced-swim test}

The PKC activator $\beta$-PMA $(25-100 \mathrm{nmol} / \mathrm{kg}$, i.v.) reduced the duration of immobility $\left(\mathrm{F}_{(3,15)}=6.86, \mathrm{p}<0.01\right.$; Figure 4.1A) and increased the latency to immobility $\left(\mathrm{F}_{(3,15)}=6.99, \mathrm{p}<0.01 ;\right.$ Figure 4.1B $)$ in the forced-swim test; this antidepressant-like effect on behavior only was observed at the $100 \mathrm{nmol}$ dose. ICV administration of 20 pmol $\beta$-PMA, as well as 2 pmol bryostatin-1, another PKC activator, also reduced the time of immobility in the forced-swim test $\left(\mathrm{F}_{(2,12)}=4.58, \mathrm{p}<0.01\right.$; Figure $\left.4.1 \mathrm{C}\right)$. Coadministration of $10 \mathrm{nmol} \mathrm{H-7,} \mathrm{a} \mathrm{PKC} \mathrm{inhibitor,} \mathrm{antagonized} \mathrm{the} \mathrm{antidepressant-like}$ effects of 2 pmol, but not 20 pmol, $\beta$-PMA in the forced-swim test $\left(\mathrm{F}_{(5,18)}=11.92, \mathrm{p}<\right.$ 0.001; Figure 4.1D); H-7 alone had no effect.

\section{Effects of $\beta$-PMA and bryostatin-1 on NET activity}

${ }^{3} \mathrm{H}-\mathrm{NE}$ uptake into cerebral cortical slices was significantly reduced after treatment with $2 \mu \mathrm{M} \beta$-PMA in vitro (Figure $4.2 \mathrm{~A}, 4.2 \mathrm{~B}$ ). This was due to a reduction in the $\mathrm{V}_{\max }$ from the control value of $70.0 \pm 2.6$ to $45.1 \pm 2.5 \mathrm{fmol} / \mathrm{mg}$ protein $/ 10 \mathrm{~min}$ ( $36 \%$ reduction; $\mathrm{p}<0.05$ ), with no change in the $\mathrm{K}_{\mathrm{m}}$ value (control: $0.62 \pm 0.04 ; \beta$-PMA: $0.53 \pm 0.05$ $\mu \mathrm{M})$. Similar effects were observed following treatment of cerebral cortical slices in vitro with $0.5 \mu \mathrm{M}$ bryostatin-1. The $\mathrm{V}_{\max }$ was reduced to $49.9 \pm 2.2 \mathrm{fmol} / \mathrm{mg}$ protein $/ 10 \mathrm{~min}(29 \%$ reduction; $\mathrm{p}<0.05)$, while the $\mathrm{K}_{\mathrm{m}}$ was unchanged $(0.57 \pm 0.04 \mu \mathrm{M})$. 


\section{Effects of PP1/2A inhibitors okadaic acid and calyculin $A$ and $\mathrm{IP}_{3}$ receptor antagonist 2-aminoethoxydiphenyl borate (2-APB) on NET activity}

Treatment of cerebral cortical slices with the PP1/2A inhibitors okadaic acid (Figure 4.4A) and calyculin A (Figure 4.4B) reduced ${ }^{3} \mathrm{H}-\mathrm{NE}$ uptake in vitro. Okadaic acid produced a near-significant effect at a concentration of $10 \mu \mathrm{M}(\mathrm{p}=0.05)$, while calyculin A was effective at concentrations at $50 \mu \mathrm{M}(\mathrm{p}<0.05)$.

Treatment of cerebral cortical slices in vitro with a $50 \mu \mathrm{M}$ concentration of the $\mathrm{IP}_{3}$ receptor antagonist 2-APB reduced ${ }^{3} \mathrm{H}-\mathrm{NE}$ uptake $(\mathrm{p}<0.01$; Figure $4.4 \mathrm{C})$. 


\subsection{Discussion}

The present findings demonstrate that PKC activators $\beta$-PMA and bryostatin-1 reduce membrane NET activity in rat cerebral cortical slices. These data are consistent with previous studies carried out in cell lines which show that both NET and SERT are regulated via a PKC-dependent pathway (Apparsundaram et al., 1998b; Jayanthi et al., 2005). Chronic treatment with desipramine or other inhibitors of NE or 5-HT appear to stimulate molecular factors in the PKC pathway resulting in its activation. Activation of PKC by $\beta$-PMA down-regulates and internalizes membrane-associated NET in cell lines in vitro (Jayanthi et al., 2004). The NET-PP2A-Ar complex and the NET-syntaxin $1 \mathrm{~A}$ complex have been shown to be involved in this process (Sung et al., 2005; Sung et al., 2007).

$\beta$-PMA and bryostatin-1 also were found to produce antidepressant-like effects on behavior in the forced-swim test. Potential antidepressant-like effects of bryostatin-1 were first reported by Sun and Alkon (2005). PKC mediation of the antidepressant-like effects of $\beta$-PMA was confirmed by the finding that they were antagonized by the PKC inhibitor H7. Consistent with this interpretation, it has been reported that 4methylcatechol, a stimulator of brain-derived neurotrophic factor (BDNF) and an indirect PKC activator, produces antidepressant-like effects on behavior (Sun and Alkon, 2008).

Previous work has shown that chronic treatment of rats with desipramine reduces the expression and activity of the NET in cerebral cortex and hippocampus, resulting in enhanced noradrenergic neurotransmission in the brain and antidepressant-like effects on behavior (Zhao et al., 2008). NET, as well as SERT, down-regulation has been demonstrated following chronic treatment with a number of other antidepressant drugs. 
The down-regulation appears to be a direct effect of antidepressant interaction with the monoamine transporters and not secondary to increase synaptic concentrations of the transmitters, since this effect also is observed for cell lines in vitro (Oster et al., 1989; Zhu and Ordway, 1997; Zhu et al., 1998; Horschitz et al., 2001; Zhu, 2005; Iceta et al., 2007). Consistent with this, it has been found that the monoamine oxidase inhibitor phenelzine, which increases monoaminergic neurotransmission but does not interact with the NET or SERT, does not down regulate the transporters. Given the role of PKC in the control of NET and SERT trafficking and internalization, it is possible that antidepressant-like behavioral effects of PKC activators may be mediated, at least in part, via a reduction in cell-surface expression of the NET or SERT.

PKC isozymes, the main targets of phorbol ester tumor promoters, have important roles in cell-cycle regulation, cell survival, malignant transformation, apoptosis, synaptic plasticity, and neuronal injury (Griner and Kazanietz, 2007; Weinreb et al., 2004; Cejas et al., 2005). Three classes of PKCs (classical PKCs, novel PKCs, and atypical PKCs), encoded by nine PKC genes, have been identified (Dekker and Parker, 1994; Hug and Sarre, 1993; Jaken, 1996). Classical PKCs include PKC $\alpha$, PKC $\beta I$, PKC $\beta I I$, and PKC $\gamma$, which require calcium and diacylglycerol (DAG) for activation. Novel PKCs include PKC $\delta$, PKC, PKC $\eta$, and PKC $\theta$, which require DAG. Atypical PKCs include PKC $\zeta$ and $\mathrm{PKCl}$, which require neither calcium nor DAG. The physiological functions of the different PKC isozymes are not known at present.

Bryostatin-1, a naturally occurring macrocyclic lacton with a chemical structure distinct from phorbol esters, potently activates PKC but induces only part of the effects resulting from phorbol ester treatment. The binding of bryostatin-1 to PKC results in 
PKC activation, auto-phosphorylation, and translocation to the cell membrane. Importantly, bryostatin-1 is ineffective as a tumor promoter (Hennings et al., 1987; Ramsdell et al., 1986) and shows some favorable pharmacological profiles as an anticancer compound (Philip and Zonder, 1999; Davidson and Haygood, 1999; Farokhzad et al., 1998).

The involvement of PKC in the depression therapy has been implicated in several studies and malfunction of PKC signal transduction has been suggested to be involved in symptoms of depression (Akin et al., 2005). The involvement of PKC in antidepressant mechanisms also is suggested by the findings that PKC activation or phosphatase inhibition induces phosphorylation of the NET and SERT in vitro (Ramamoorthy et al., 1998).

It has been reported that inhibition of $\mathrm{IP}_{3}$ receptors by 2-aminoethoxydiphenyl borate and xestospongin $\mathrm{C}$ reduces the $\mathrm{V}_{\max }$ of NET as well as surface NET expression in SH-SY5Y cells (Amano et al., 2006), suggesting that the $\mathrm{IP}_{3}$ receptors $/ \mathrm{Ca}^{2+}$ system has facilitatory effects on NET activity. Given that activation of $\mathrm{IP}_{3}$ receptor-induced release of $\mathrm{Ca}^{2+}$ activates PKC and consequently reduces membrane NET activity, it seems that the regulation of the NET activity is balanced between the PLC-related signaling pathways. Another inducer of intracellular $\mathrm{Ca}^{2+}$ release, the ryanodine receptor, and an influx of extracellular $\mathrm{Ca}^{2+}$ mediated by SOC channels, does not change NET activity (Amano et al., 2006). The changes of NET activity mediated by PKC and $\mathrm{IP}_{3}$ receptors have been only demonstrated in cell lines in vitro. A demonstration of the importance of this mechanism in vivo might suggest a novel mechanism to produce NET (or SERT) down-regulation with resulting antidepressant-like effects on behavior. The activation of 
PKC signaling pathway by chronic antidepressant treatment might provide a mechanism underlying neuroadaptive changes in NET and SERT function.

Overall, the present study demonstrates a relationship between PKC activationinduced antidepressant-like effect in the forced-swim test and PKC activation-induced reduction of membrane NET activity in the rat cerebral cortical slices. This suggests the importance of future experiments to examine the means by which antidepressants alter PKC activity to affect cell surface expression of monoamine transporters and to identity molecular targets in this pathway that might provide a novel means for producing antidepressant effects on behavior. 

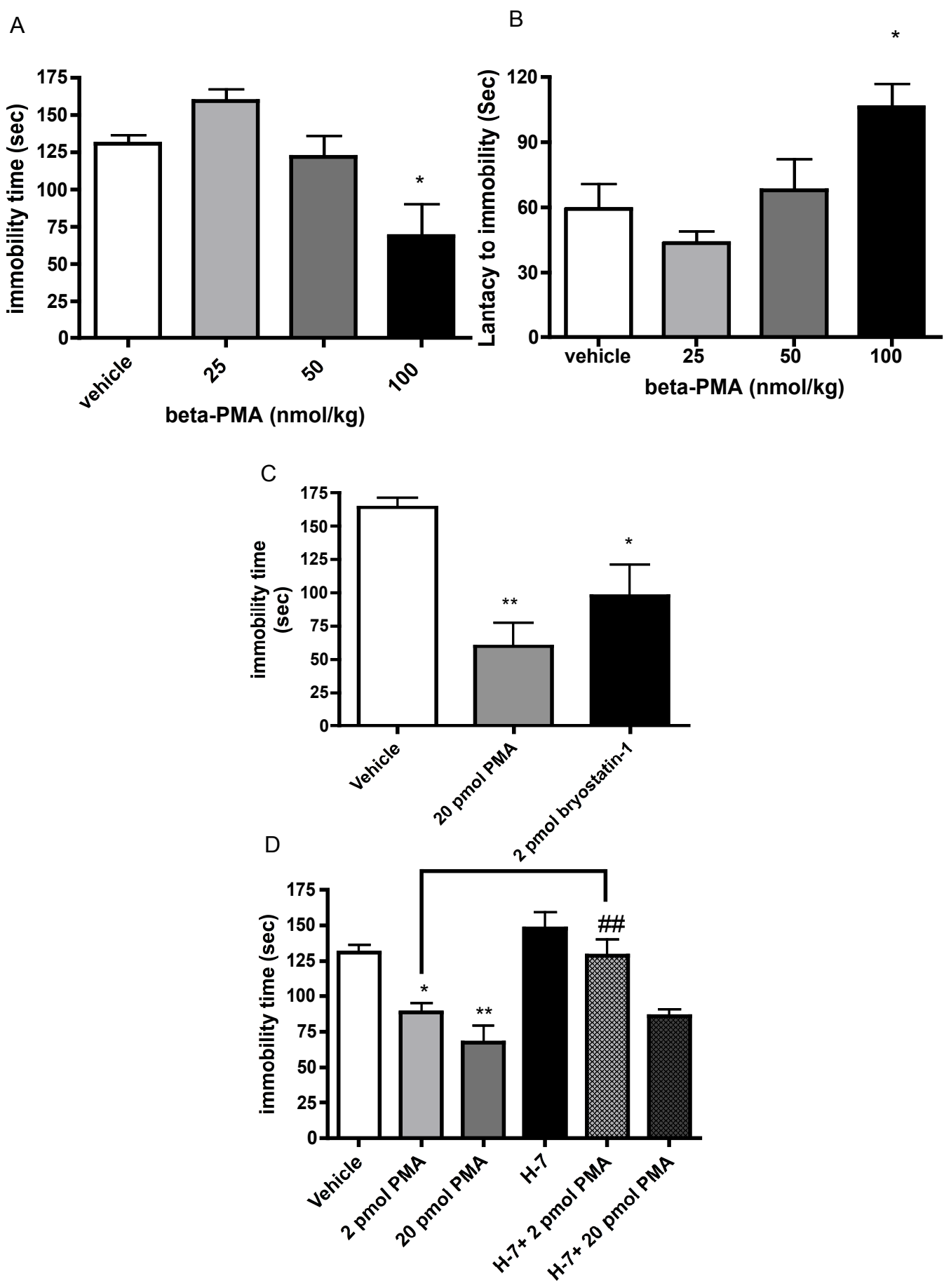
Figure 4.1 The PKC activator $\beta$-PMA produced antidepressant-like effects on forcedswim behavior. This effect was observed $3 \mathrm{~h}$ after i.v. administration of $\beta$-PMA, as indicated by reduced immobility time (A) and increased latency to immobility (B). Bilateral ICV administration of 20 pmol $\beta$-PMA and 2 pmol bryostatin-1, another PKC activator, 30 min before testing reduced also immobility time in the forced-swim test (C). Bilateral ICV administration of the PKC inhibitor H-7 (20 nmol) reversed the antidepressant-like effect of 2 pmol PMA in the forced-swim test (D). Data shown are means \pm SEM for $5-6$ rats per group. ${ }^{*} \mathrm{p}<0.05,{ }^{* *} \mathrm{p}<0.01$ vs. vehicle; ${ }^{\#} \mathrm{p}<0.01$ vs. 2 pmol PMA alone. 
A

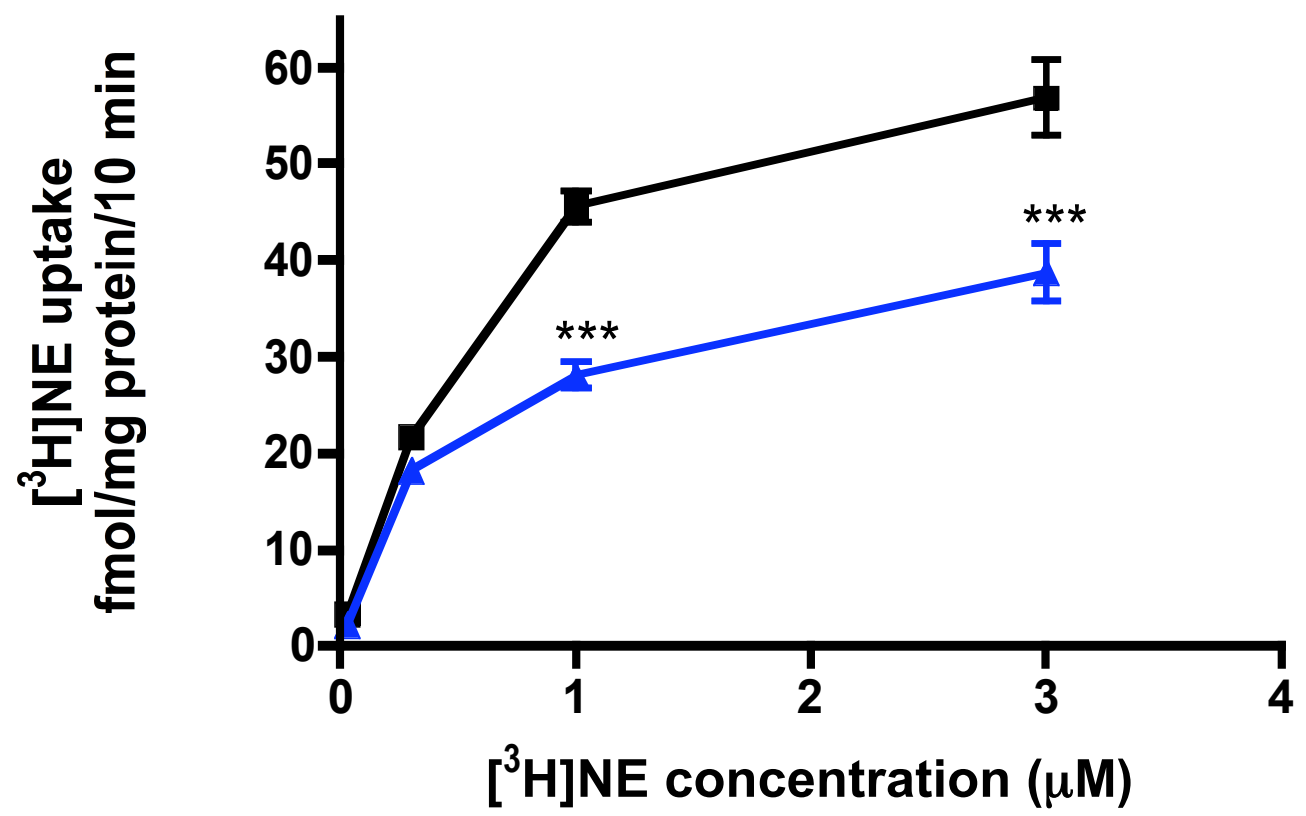

$\rightarrow$ control

$\leftarrow-2 \mu \mathrm{M} \beta$-PMA

B

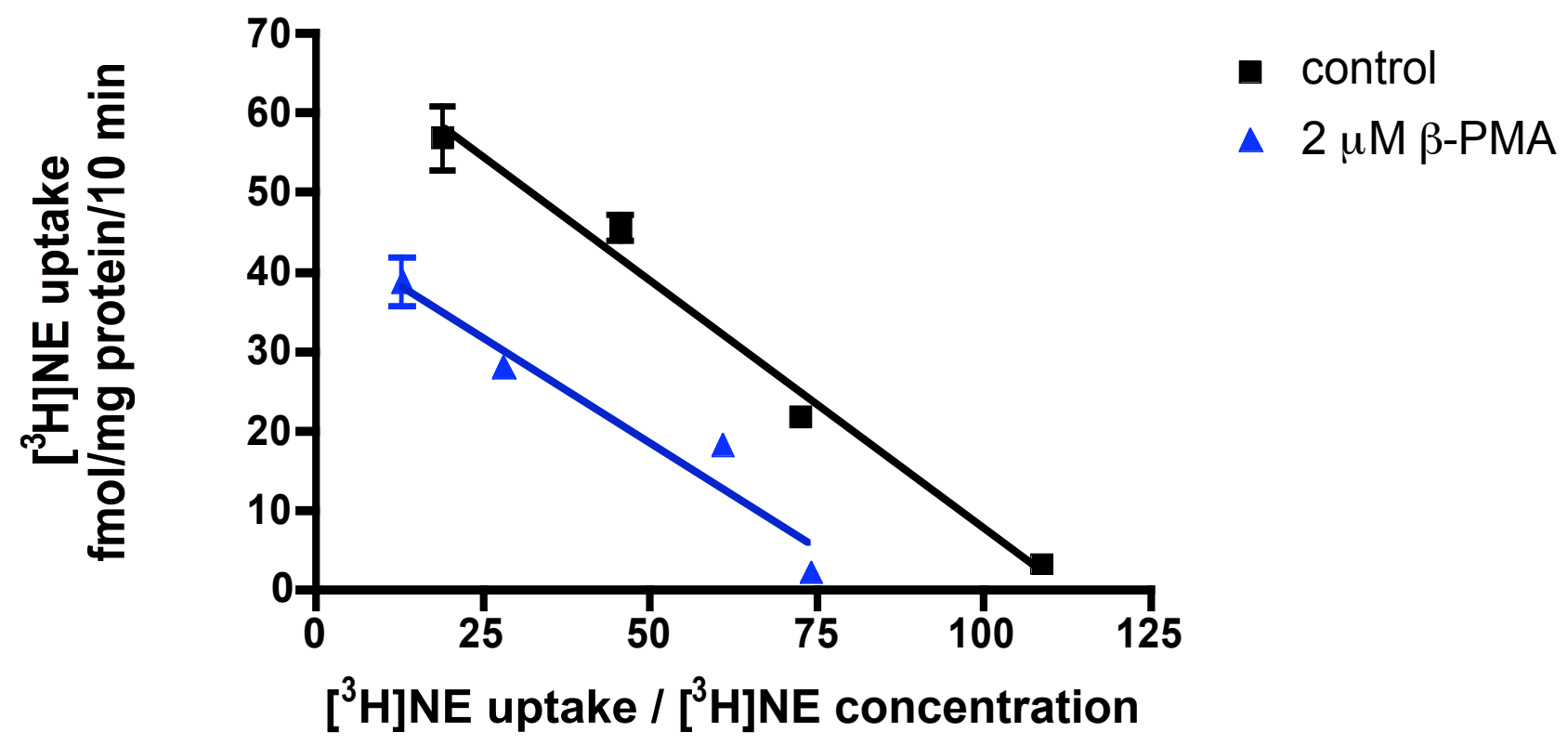


Figure 4.2 The PKC activator $\beta$-PMA reduced NET activity in cerebral cortical slices in vitro; this was due to a reduction of the $\mathrm{V}_{\max }$ and an unchanged $\mathrm{K}_{\mathrm{m}}$ value. The NET activity was determined after incubation with 4 concentrations of $\left[{ }^{3} \mathrm{H}\right] \mathrm{NE}$. Data shown are means \pm SEM of $5-6$ rats per group. ${ }^{*} \mathrm{p}<0.05, * * * \mathrm{p}<0.001$ vs. control. 


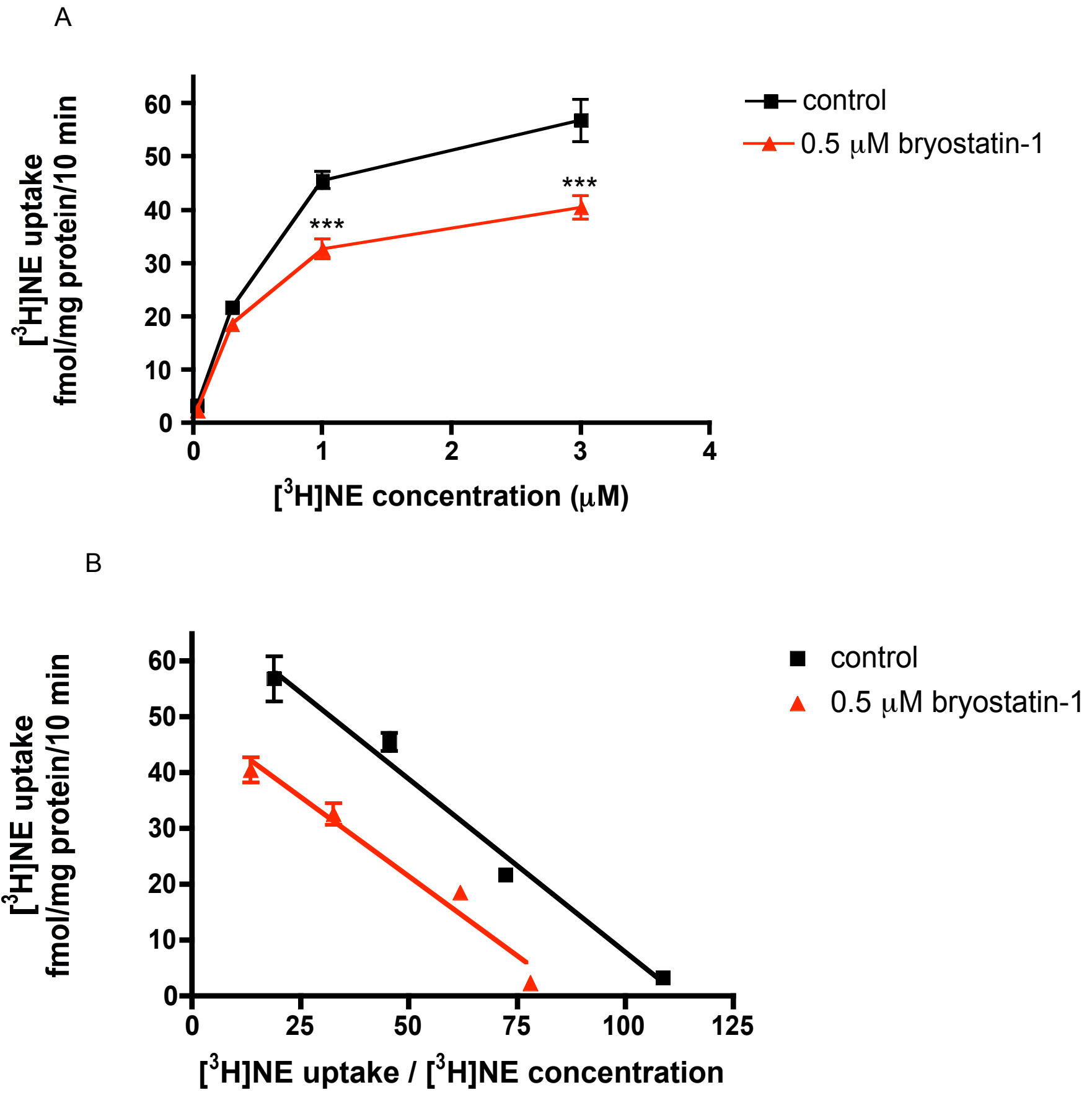


Figure 4.3 The PKC activator bryostatin-1 reduced NET activity in cerebral cortical slices; this was due to a reduction of $\mathrm{V}_{\max }$ and an unchanged $\mathrm{K}_{\mathrm{m}}$ value. The NET activity was determined after incubation with 4 concentrations of $\left[{ }^{3} \mathrm{H}\right] \mathrm{NE} / \mathrm{NE}$. Data shown are means \pm SEM of $5-6$ rats per group. $* \mathrm{p}<0.05, * * * \mathrm{p}<0.001$ vs. control. 
A

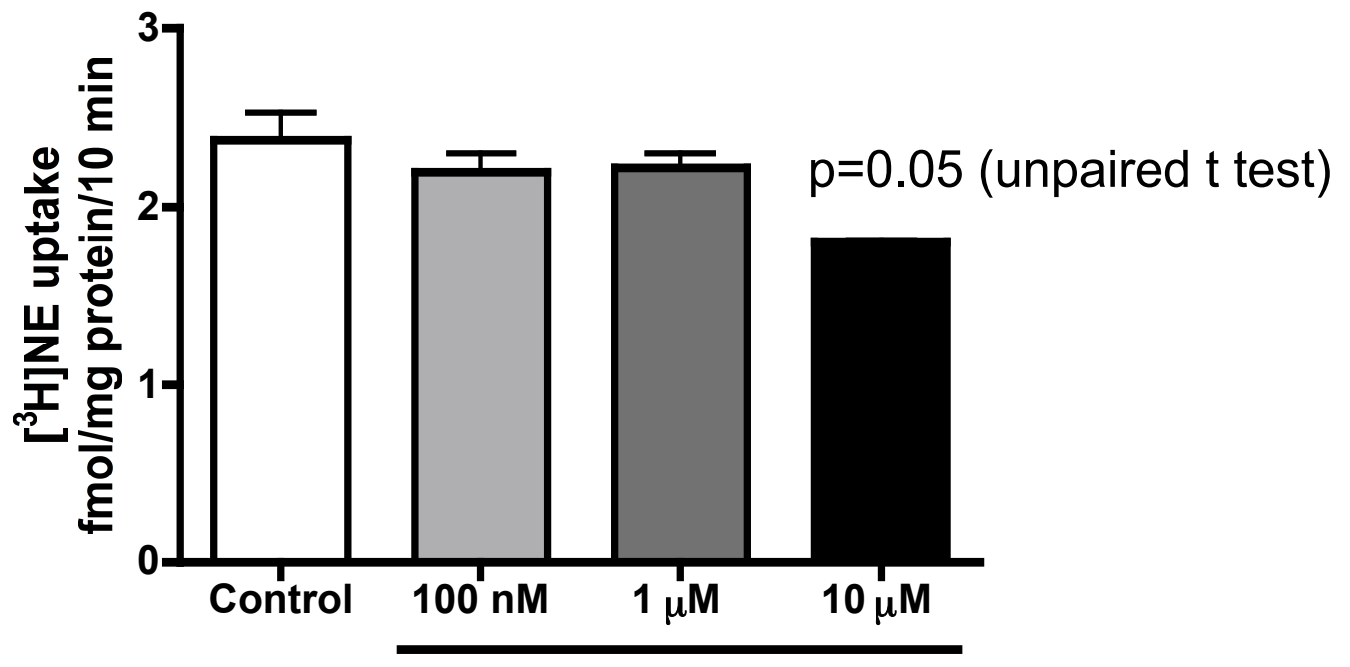

B

Okadaic acid potassium

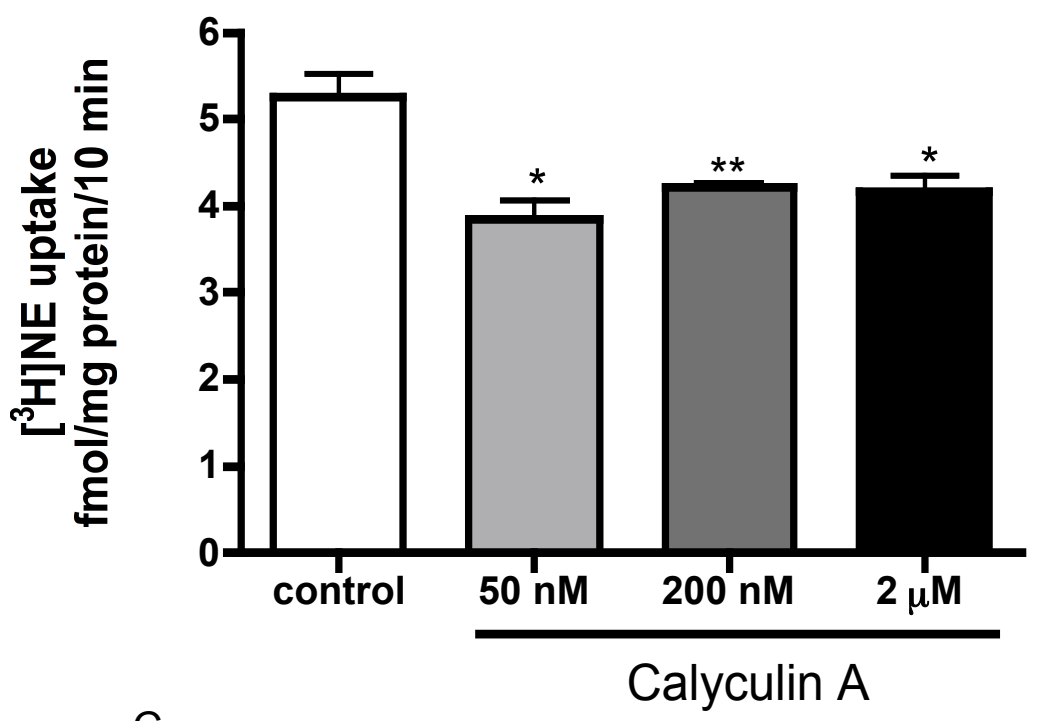

C

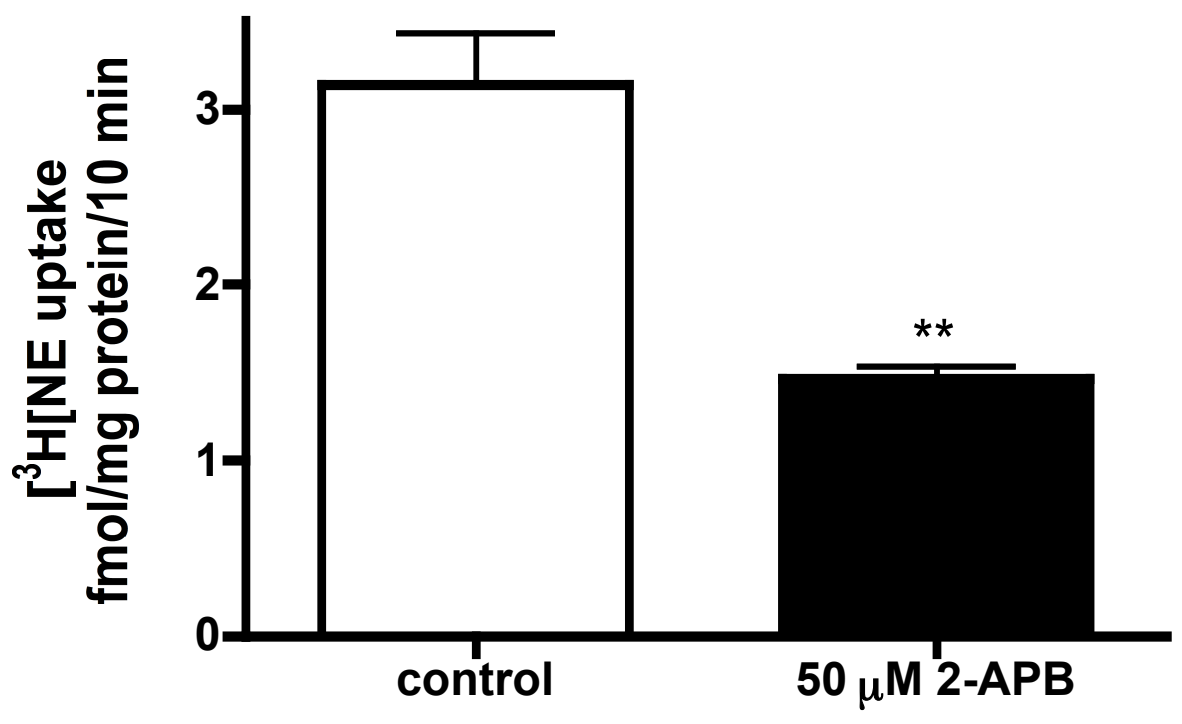


Figure 4.4 The PP1/2A inhibitors okadaic acid and calyculin A reduced NET activity in rat cerebral cortical slices, as evidenced by a reduction in the uptake of $\left[{ }^{3} \mathrm{H}\right] \mathrm{NE}$. The $\mathrm{IP}_{3}$ receptor antagonist 2-APB also reduced NET activity. Data shown are means \pm SEM of $5-6$ rats per group. $* \mathrm{p}<0.05, * * \mathrm{p}<0.01$ vs. control 


\section{Conclusions}

The present study demonstrates a relatonship between antidepressant-induced downregulation of the NET and antidepressant-like effects on behavior. This relationship also is observed for the SERT. The down-regulation of the transporters and long-term antidepressant-like behavioral effects are evidient two days following discontinuation of chronic treatment, when acute drug effects are minimized. Consitent with clinical findings, the antidepressant-like effect in the forced-swim test is reversed by inhibiton of NE or 5-HT neurotransmission, suggesting that the enhanced NE and serotonin neurontransmission is necessary, but not sufficient, to produce antidepressant-like effects on behavior. The mechanism of NET and SERT regulation by antidepressants likely is more due to altered transporter protein internalization than altered gene transcription. Further, PKC activators show some antidepressant-like effects in the forced-swim test and this is accompanied by reduced membrane NET activity in rat cerebral cortical slices. This suggests a possible PKC signaling pathway mediating NET regulation in vivo and that may be associated with antidepressant effects. Understanding molecular events that regulate NET and SERT in vivo may suggest pharmacological targets for the development of novel antidepressant drugs. 


\section{REFERENCES}

Abumaria N, Rygula R, Hiemke C, Fuchs E, Havemann-Reinecke U, Rüther E, Flügge G (2007). Effect of chronic citalopram on serotonin-related and stress-regulated genes in the dorsal raphe nucleus of the rat. Eur Neuropsychopharmacol 17:417-429.

Akin D, Manier DH, Sanders-Bush E, Shelton RC (2005). Signal transduction abnormalities in melancholic depression. Int J Neuropsychopharmacol 8:5-16.

Akiskal, H.S., 2000. Mood disorders: introduction and overview. In: Sadock, B.J. and Sadock, V.A., Editors, 2000. Comprehensive Textbook of Psychiatry, Lippincott, Williams \& Wilkins, New York pp.1284-1298.

Amano T, Aoki S, Setsuie R, Sakurai M, Wada K, Noda M (2006). Identification of a novel regulatory mechanism for norepinephrine transporter activity by the IP3 receptor. Eur J Pharmacol 536: 62-68.

Amara SG (1992). Neurotransmitter transporter. A tale of two families. Nature 360: 420421.

Apparsundaram S, Galli A., DeFelice LJ, Hartzell HC, Blakely RD (1998a). Acute regulation of norepinephrine transporter: I. Protein kinase C-linked muscarinic receptors influence transporter capacity and transporter density in SK-N-SH cells. $J$ Pharmacol Exp Ther 287: 733-743.

Apparsundaram S, Schroeter S, Giovanetti E, Blakely RD (1998b). Acute regulation of norepinephrine transport: II. PKC-modulated surface expression of human norepinephrine transporter proteins. J Pharmacol Exp Ther 287: 744-751.

Apparsundaram S, Sung U, Price RD, Blakely RD (2001). Trafficking-dependent and independent pathways of neurotransmitter transporter regulation differentially 
involving p38 mitogen-activated protein kinase revealed in studies of insulin modulation of norepinephrine transport in SK-N-SH cells. $J$ Pharmacol Exp Ther. 299: 666-677.

Arborelius L, Owens MJ, Plotsky PM, Nemeroff CB (1999). The role of corticotropinreleasing factor in depression and anxiety disorders. $J$ Endocrinol 160:1-12.

Argenti D and D'Mello P (1994). The pharmacodynamics of desipramine and desmethyldesipramine in rats. J Pharmacol Exp Ther 270: 512-519.

Artigas F, Celada P, Laruelle M, Adell A (2001). How does pindolol improve antidepressant action? Trends Pharmacol Sci 22:224-228.

Artigas F, Romero L, de Montigny C, Blier P (1996). Acceleration of the effect of selected antidepressant drugs in major depression by 5-HT1A antagonists. Trends Neurosci 19:378-383.

Ase AR, Reader TA, Hen R, Riad M, Descarries L (2001). Regional changes in density of serotonin transporter in the brain of $5-\mathrm{HT}_{1 \mathrm{~A}}$ and $5-\mathrm{HT}_{1 \mathrm{~B}}$ knockout mice, and of serotonin innervation in the 5-HT 1 B knockout. $J$ Neurochem 78: 619-630.

Ballús C. Quiros G, de Flores T, de la Torre J, Palao D. Rojo L (2000). The efficacy and tolerability of venlafaxine and paroxetine in outpatients with depressive disorder or dysthymia. Int Clin Psychopharmacol 15:43-48.

Ban TA (2001). Pharmacotherapy of depression; a historical analysis. J Neural Transm 108:7707-7716.

Bauman AL, Apparsundaram S, Ramamoorthy S, Wadzinski BE, Vaughan RA, Blakely $\mathrm{RD}$ (2000). Cocaine and antidepressant-sensitive biogenic amine transporters exist in regulated complexes with protein phosphatase 2A. J Neurosci 20:7571-7578. 
Benmansour S, Altamirano AV, Jones DJ, Sanchez TA, Gould GG, Pardon MC, Morilak DA, Frazer A (2004). Regulation of the norepinephrine transporter by chronic administration of antidepressants. Biol Psychiatry 55: 313-316.

Benmansour S, Cecchi M, Morilak DA, Gerhardt GA, Javors MA, Gould GG, Frazer A (1999). Effects of chronic antidepressant treatments on serotonin transporter function, density, and mRNA level. J Neurosci 19:10494-10501.

Benmansour S, Owens WA, Cecchi M, Morilak DA, Frazer A (2002). Serotonin clearance in vivo is altered to a greater extent by antidepressant-induced downregulation of the serotonin transporter than by acute blockade of this transporter. J Neurosci 22: 6766-6772.

Berzewdski H, Van Moffaert M, Gagiano CA (1997). Efficacy and tolerability of reboxetine compared with inmipramine in a double-blind study in patients sfuufering fromn major depression disorder. Eur Neuropsychopharmacol 7: S37-S47.

Beyer CE, Boikess S, Luo B, Dawson LA (2002). Comparison of the effects of antidepressants on norepinephrine and serotonin concentrations in the rat frontal cortex: an in-vivo microdialysis study. J Psychopharmacol 16:297-304.

Blakely RD, Berson HE, Fremeau RT Jr, Caron MG, Peek MM, Prince HK, Bradley CC (1991). Cloning and expression of a functional serotonin transporter from rat brain. Nature 354: 66-70.

Blakely RD, De Felice LJ, Hartzell HC (1994). Molecular physiology of norepinephrine and serotonin transporters. J Exp Biol 196:263-81. 
Blazer DG (2000b). Mood disorders: epidemiology. In: Sadock, B.J. and Sadock, V.A., Editors, 2000. Comprehensive Textbook of Psychiatry, Lippincott, Williams \& Wilkins, New York pp.1298-1308.

Blazer DG, Hybels CF, Simonsick EM, Hanlon JT (2000a). Marked differences in antidepressant use by race in an elderly community sample: 1986-1996. Am J Psychiatry 157: 1089-1094.

Bloom FE, Kupfer DJ (1995). Psychopharmacology: the fourth generation of progress. New York; Raven Press. 407-471.

Bonisch H, Bruss M (1994). The noradrenaline transporter of the neuronal plasma membrane. Ann N Y Acad Sci 733:193-202.

Bortolato M, Mangieri RA, Fu J, Kim JH, Arguello O, Duranti A, Tontini A, Mor M, Tarzia G, Piomelli D (2007). Antidepressant-like Activity of the Fatty Acid Amide Hydrolase Inhibitor URB597 in a Rat Model of Chronic Mild Stress. Biological Psychiatry 62:1103-1110.

Bremner JD, Vythilingam M, Ng CK, Vermetten E, Nazeer A, Oren DA, Berman RM, Charney DS (2003). Regional brain metabolic correlates of alphamethylparatyrosine-induced depressive symptoms: implications for the neural circuitry of depression. JAMA 289: 3125-3134.

Bryan-Lluka LJ, Paczkowski FA, Bonisch H (2001). Effects of short- and long-term exposure to c-AMP and c-GMP on th noradrenaline transporter. Neuropharmacology 40: 607-617. 
Bunn SJ, O’Brien KJ, Boyd TL, Powis DA (1992). Pertussis toxin inhibits noradrenaline accumulation by bovine adrenal medullary chromaffin cells. Naunyn Schmiedebergs Arch Pharmacol 346: 649-656.

Burmeister M (1999). Basic concepts in the study of disease with complex genetics. Biol Psychiatry 45: 522-532.

Cadieux RJ (1999). Antidepressant drug interactions in the elderly. Understanding the P450 system is half the battle in reducing risks. Postgrad Med 106:231-249.

Carlezon WA Jr, Mague SD, Andersen SL (2003). Enduring behavioral effects of early exposure to methylphenidate in rats. Biol Psychiatr 54: 1330-1337.

Cejas PJ, Carlson LM, Zhang J, Padmanabhan S, Kolonias D, Lindner I, Haley S, Boise LH, Lee KP (2005). Protein kinase C beta II plays an essential role in dendritic cell differentiation and autoregulates its own expression. J Biol Chem 280: 28412-28423.

Celada P, Puig M, Amargos-Bosch M, Adell A, Artigas F (2004). The therapeutic role of 5- $\mathrm{HT}_{1 \mathrm{~A}}$ and 5- $\mathrm{HT}_{2 \mathrm{~A}}$ receptors in depression. $J$ Psychiatry Neurosci 29: 252-265.

Chamas F, Serova L, Sabban EL (1999). Tryptophan hydroxylase mRNA levels are elevated by repeated immobilization stress in rat raphe nuclei but not in pineal gland. Neurosci Lett 267:157-160.

Chamas FM, Underwood MD, Arango V, Serova L, Kassir SA, Mann, JJ, Sabban EL (2004). Immobilization stress elevates tryptophan hydroxylase mRNA and protein in the rat raphe nuclei. Biol Psychiatry 55:278-283.

Charney DS (1998). Monoamine dysfunction and the pathophysiology and treatment of depression. J Clin Psychiatry 59:11-14. 
Charney DS, Price LH, Heninger GR (1986). Desipramine-yohimbine combination treatment for refractory depression. Arch Gen Psychiatry 45:1155-1161.

Chen AH, Shirayama Y, Shin KH, Neve RL, Duman RS (2001). Expression of the cAMP response element binding protein (CREB) in hippocampus produces antidepressant effect. Biol Psychiatry 49: 753-762.

Chen H, Pandey GN, Dwivedi Y (2006). Hippocampal cell proliferation regulation by repeated stress and antidepressants. Neuroreport 17: 863-867.

Chiang C, Aston-Jones G (1993). A 5-hydroxytryptamine 2 agonist augments gammaaminobutyric acid and excitatory amino acid inputs to noradrenergic locus coeruleus neurons. Neuroscience 54:409-420.

Chung HJ, Steinberg JP, Huganir RL, Linden DJ (2003). Requirement of AMPA receptor GluR2 phosphorylation for cerebellar long-term depression. Science 300: 1751-1775.

Clerc GE, Ruimy P, Verdeau-Pailles J (1994). A double-blind comparison of venlafaxine and fluoxetine in patients hospitalized for major depression and melancholia. Int Clin Psychopharmacol 9:139-143.

Cremers TI, Spoelstra EN, de Boer P, Bosker FJ, Mork A, den Boer JA, Westerink BH, Wikstrom HV (2000). Desensitisation of 5-HT autoreceptors upon pharmacokinetically monitored chronic treatment with citalopram. Eur J Pharmacol 397:351-357.

Crissman AM, O'Donnell JM (2002). Effects of antidepressants in rats trained to discriminate centrally administered isoproterenol. J Pharmacol Exp Ther 302:606611. 
Cryan JF, Markou A, Lucki L (2002). Assessing antidepressant activity in rodents: recent developments and future needs. Trends Pharmacol Sci 23:238-245.

Cryan JF, O'Leary OF, Jin SH, Friedland JC, Ouyang M, Hirsch BR, Page ME, Dalvi A, Thomas ST, Lucki I (2004). Norepinephrine-deficient mice lack responses to antidepressant drugs, including selective serotonin reuptake inhibitors. Proc Natl Acad Sci (USA) 101: 8186-8191.

D’Amato RJ, Largent BL, Snowman AM, Snyder SH (1987). Selective labeling of serotonin uptake sites in rat brain by $\left[{ }^{3} \mathrm{H}\right]$ citalopram contrasted to labeling of multiple sites by $\left[{ }^{3} \mathrm{H}\right]$ imipramine. J Pharmacol Exp Ther 242:364-371.

Davidson SK, Haygood MG (1999). Identification of sibling species of the bryozoan Bugula neritina that produce different anticancer bryostatins and harbor distinct strains of the bacterial symbiont "Candidatus Endobugula sertula". Biol Bull 196:273280.

Davidson SK, Haygood MG (1999). Identification of sibling species of the bryozoan Bugula neritina that produce different anticancer bryostatins and harbor distinct strains of the bacterial symbiont "Candidatus Endobugula sertula". Biol Bull 196:273280.

Dekker LV, Parker PJ (1994). Protein kinase C - a question of specificity. Trends Biochem Sci 19: 73-77.

Deupree JD, Montgomery MD, Bylund DB (2007). Pharmacological properties of the active metabolites of the antidepressants desipramine and citalopram. Eur $J$ Pharmacol 576:55-60. 
Dhir A and Kulkami SK (2007). Effect of addition of yohimbine (Alpha-2-receptor antagonist) to the antidepressant activity of fluoxetine or venlafaxine in th mouse forced swim test. Pharmacology 80: 239-243.

Dickinson SL (1990). Alpha2-adrenoceptor antagonism and depression. Drug News Perspect 4:197-203.

Dierick M, Ravizza L, Realini R (1996). A double-blind comparison of venlafaxine and fluoxetine for treatment of major depression in outpatients. Prog Neuropsychopharmacol Biol Psychiatry 20:57-71.

Drevets WC (2000). Functional anatomical abnormalities in limbic and prefrontal cortical structures in major depression. Prog Brain Res 126: 413-431.

Drevets WC (2001). Neuroimaging and neuropathological studies of depression: implications for th cognitive-emotional features of mood disorders. Curr Opion Neurobiol 11: 240-249.

Dunah AW, Standaert DG (2001). Dopamine D1 receptor-dependent trafficking of striatal NMDA glutamate receptors to the posysynaptic membrane. $J$ Neurosci 21 : $5546-5558$.

Duncan GE, Paul IA, Breese GR (1993). Neuroanatomical differences in the rate of betaadrenergic receptor adaptation after repeated treatment with imipramine. Psychopharmacol Bull 29: 401-407.

Eison AS, Eison MS, Torrente DP, Wright RN, Yocca FD (1990). Nefazodone: Preclinical pharmacology of a new antidepressant. Psychopharm Bull 26:311-315.

Farokhzad OC, Mun EC, Sicklick JK, Smith JA, Matthews JB (1998). Effects of bryostatin 1, a novel anticancer agent, on intestinal transport and barrier function: role 
Fava M, Kendler KS (2000). Major depressive disorder. Neuron 28: 335-341.

Figlewicz DP, Bentson K, Ocrant I (1993a). The effect of insulin on norepinephrine uptake by PC12 cells. Brain Res Bull 32:425-431.

Figlewicz DP, Szot P, Israel PA, Payne C, Dorsa DM (1993b). Insulin reduces norepinephrine transporter mRNA in vivo in rat locus coeruleus. Brain Res 602:161164.

Fisher AS, Stewart RJ, Yan T, Hunt SP, Stanford SC (2007). Disruption of noradrenergic transmission and the behavioral response to a novel environment in NK1R-/- mice. Eur J Neurosci 25:1195-204.

Fleischhacker WW, Hinterhuber H, Bauer H, Pflug B, Berner P, Simhandl C, Wolf R, Gerlach W, Jaklitsch H, Sastre-y-Hernández M (1992). A multicenter double-blind study of three different doses of the new cAMP-phosphodiesterase inhibitor rolipram in patients with major depressive disorder. Neuropsychobiology 26:59-64.

Frazer A (2000). Norepinephrine involvement in antidepressant action. J Clin Psychiatry S10: $25-30$.

Frazer A (2001). Serotonergic and noradrenergic reuptake inhibitors: prediction of clinical effects from in vitro potencies. J Clin Psychiatry 62:16-23.

Frazer A, Benmansour S (2002). Delayed pharmacological effects of antidepressants. Mol Psychiatry 7: S23-28.

Frazer A, Conway P (1984). Pharmacologic mechanisms of action of antidepressant. Psychiatr Clin North Am 7: 575-586.

Froger N, Gardier AM, Moratalla R, Alberti I, Lena I, Boni C, de Felipe C, Rupniak, NMJ, Hunt SP, Jacquot C, Hamon M, Lanfumey L (2001). 5-HT HA $_{\text {A }}$ autoreceptor 
adaptive changes in substance $\mathrm{P}$ (NK1) receptor knock-out mice mimic antidepressant-induced desensitisation. J Neurosci 21: 8188-8197.

Garcia AS, Barrera G, Burke TF, Ma S, Hensler JG, Morilak DA (2004). Autoreceptormediated inhibition of norepinephrine release in rat medial prefrontal cortex is maintained after chronic desipramine treatment. J Neurochem 91: 683-693.

Geffen LB, Livett BG (1971). Synaptic vesicles in sympathetic neurons. Physiol Rev 51:98-157.

Gelenberg AJ, Chesen CL (2000). How fast are antidepressants? J Clin Psychiatry 61: $712-721$

Gould GG, Altamirano AV, Javors MA, Frazer A (2006). A comparison of the chronic treatment effects of venlafaxine and other antidepressants on serotonin and norepinephrine transporters. Biol Psychiatry 59:408-414.

Gould GG, Pardon MC, Morilak DA, Frazer A (2003). Regulatory effects of reboxetine treatment alone, or following paroxetine treatment, on brain noradrenergic and serotonergic systems. Neuropsychopharmacology 28:1633-1641.

Griebel G, Perrault G, Soubrie P (2001). Effects of SR48968, a selective non-peptide NK2 receptor antagonist on emotional processes in rodents. Psychopharmacology 158:241-251.

Grinerl EM, Kazanietzl MG (2007). Protein kinase C and other diacylglycerol effectors in cancer. Nature Reviews Cancer 7: 281-294.

Grosshans DR, Browning MD (2001). Protein kinase C activation induces tyrosine phosphorylation of the NR2A and NR2B subunits of the NMDA receptor. $J$ Neurochem 76:737-744. 
Hamilton M (1960). A rating scale for depression. J Neurol Neurosurg Psychiatry 25: 5662.

Hamiton M (1967). Development of a rating scale for primary depressive illness. $\mathrm{Br} J$ Soc Clin Psychol 6: 278-296.

Hardwick JC, Ehrlich YH, Hendley ED (1989). Extracellular ATP stimulates norepinephrine uptake in PC12 cells. J Neurochem 53: 1512-1518.

Hebenstreit GF, Fellerer K, Fichte K, Fischer G, Geyer N, Meya U, Sastre-y-Hernandez M, Schony W, Schratzer M, Soukop W (1989). Rolipram in major depressive disorder: Results of a double-blind comparative sstudy with imipramine. Pharmacopsychiatry 22: 156-160.

Hendley ED, Whittemore SR, Chaffee JE, Ehrlich YH (1988). Regulation of norepinephrine uptake by adenine nucleotides and divalent cations: role for extracellular protein phosphorylation. J Neurochem 50:263-273.

Hennings H, Blumberg PM, Pettit GR, Herald CL, Shores R, Yuspa SH (1987). Bryostatin 1, an activator of protein kinase $\mathrm{C}$, inhibits tumor promotion by phorbol esters in SENCAR mouse skin. Carcinogenesis 8:1343-1346.

Hensler JG (2003). Regulation of 5- $\mathrm{HT}_{1 \mathrm{~A}}$ receptor function in brain following agonist or antidepressant administration. Life Sci 72:1665-1682.

Herpfer I, Lieb K (2005). Substance P receptor antagonists in psychiatry: rationale for development and therapeutic potential. CNS Drugs 19:275-293.

Hervás I, Vilaró MT, Romero L, Scorza MC, Medgod G, Artigas F (2001). Desensitization of 5-HT1A autoreceptors by a low chronic fluoxetine dose. Effect of 
the concurrent administration of WAY 100635. Neuropsychopharmacology 24:11-20.

Hirano K, Kimura R, Sugimoto Y, Yamada J, Uchida S, Kato Y, Hashimoto H, Yamada S (2005a). Relationship between brain serotonin transporter binding, plasma concentration and behavioural effect of selective serotonin reuptake inhibitors. $\mathrm{Br} J$ Pharmacol 144:695-702.

Hirano K, Seki T, Sakai N, Kato Y, Hashimoto H, Uchida S, Yamada S (2005b). Effects of continuous administration of paroxetine on ligiand binding site and expression of serotonin transporter protein in mouse brain. Brain Res 1053: 154-161.

Hoffman BJ, Mezey E, Brownstein MJ (1991). Cloning of a serotonin transporter affected by antidepressants. Science 249: 579-580.

Horschitz S, Hummerich R, Schloss P (2001). Down-regulation of the rat serotonin transporter upon exposure to a selective serotonin reuptake inhibitor. Neuroreport 12:2181-2184.

Hug H, Sarre TF (1993). Protein kinase C isoenzymes: Divergence in signal transduction? Biochem J 291: 329-343.

Iceta R, Mesonero JE, Alcalde AI (2007). Effect of long-term fluoxetine treatment on the human serotonin transporter in Caco-2 cells. Life Sci 80:1517-1524.

Iversen L (2006). Neurotransmitter transporters and their impact on the development of psychopharmacology. Br J Pharmacol 147:S82-S88.

Jaken S (1996). Protein kinase C isozymes and substrates. Curr Opin Cell Biol 8:168173. 
Jayanthi LD, Annamalai B, Samuvel DJ, Gether U, Ramamoorthy S (2006). Phosphorylation of the norepinephrine transporter at threonine 258 and serine 259 is linked to protein kinase C-mediated transporter internalization. J Biol Chem 281: 23326-23340.

Jayanthi LD, Samuvel DJ, Blakely RD, Ramamoorthy S (2005). Evidence for biphasic effects of protein kinase $\mathrm{C}$ on serotonin transporter function, endocytosis, and phosphorylation. Mol Pharmacol 67: 2077-2087.

Jayanthi LD, Samuvel DJ, Ramamoorthy S (2004). Regulated internalization and phosphorylation of the native norepinephrine transporter in response to phorbol esters. Evidence for localization in lipid rafts and lipid raft-mediated internalization. $J$ Biol Chem 279:19315-19326.

Katz MM, Koslow SH, Frazer A (1996). Onset of antidepressant activity: reexamining the structure of depression and multiple actions of drugs. Depress Anxiety 4: 257-267.

Katz MM, tekell JL, Bowden CL, Brannan S, Houston JP, Berman N, Frazer A (2004). Onset and early behavioral effects of pharmacologically different antidepressants and placebo in depression. Neuropsychopharmacology 29:566-579.

Kaye DM, Wiviott SD, Kobzik L, Kelly RA, Smith TW (1997). S-nitrosothiols inhibit neuronal norepinphrine transport. Am J Physiol 272: H875-H883.

Kehr W, Debus G, Neumeister R (1985). Effects of rolipram, a novel antidepressant, on monoamine metabolism in rat brain. $J$ Neural Transm 63: 1-12.

Kelly JP, Wrynn AS, Leonard BE (1997). The olfactory bulbectomized rat as a model of depression: an update. Pharmacol Ther 74: 299-316. 
Kikkawa U, Takai Y, Tanaka Y, Miyake R, Nishizuka Y (1983). Protein kinase-C as a possible receptor protein of tumor-promoting phorbol esters. J Biol Chem 258: $1442-1445$.

Kitada Y, Miyauchi T, Kosasa T, Satoh S (1986). The significance of beta-adrenoceptor down regulation in the desipramine action in the forced swimming test. Naunyn Schmiedeberg's Arch Pharmacol 333:31-35.

Klimek V, Stockmeier C, Overholser J, Meltzer HY, Kalka S, Dilley G, Ordway GA (1997). Reduced levels of norepinephrine transporters in the locus coeruleus in major depression. J Neurosci 17: 8451-8458.

Kodama M, Fujioka T, Duman RS (2004). Chronic olanzapine or fluoxetine administration increases cell proliferation in hippocampus and prefrontal cortex of adult rat. Biol Psychiatry 56: 570-580.

Koe BK, Weissman A (1966). P-Chlorophenylalanine: a specific depletory of brain serotonin. J Pharmacol Exp Ther 154:499-516.

Kondo T, Kakegawa W, Yuzaki M (2005). Induction of long-term depression and phosphorylation of the delta2 glutamate receptor by protein kinase $\mathrm{C}$ in cerebellar slices. Eur J Neurosci 22:1817-1820.

Kozisek ME, Deupree JD, Burke WJ, Bylund DB (2007). Appropriate dosing regimens for treating juvenile rats with desipramine for neuropharmacological and behavioral studies. J Neurosci Methods 163:83-91.

Kramer MS, Cutler N, Feighner J, Shrivastava R, Carman J, Sramek JJ, Reines SA, Liu G, Snavely D, Wyatt-Knowles E (1998). Distinct mechanism for antidepressant activity by blockade of central substance P receptors. Science 281: 1642-1645. 
Kugaya A, Seneca NM, Snyder PJ (2003). Changes in human in vivo serotonin and dopamine transporoter availabilities during chronic antidepressant administration. Neuropsychopharmacology 28:413-420.

Lam RW, Tam EM, Grewal A, Yatham LN (2001). Effects of alpha-methyl-paratyrosine-induced catecholamine depletion in patients with seasonal affective disorder in summer remission. Neuropsychopharmacology 25: S97-S101.

Lapiz MD, Bondi CO, Morilak DA (2007a). Chronic treatment witih desispramine improves cognitive performance of rats in an attentional set-shifting test. Neuropsychopharmacology 32: 1000-1010.

Lapiz MD, Zhao Z, Bondi CO, O’Donnell JM, Morilak DA (2007b). Blockade of autoreceptor-mediated inhibition of norepinephrine release by atipamezole is maintained after chronic reuptake inhibition. Int J Neuropsychopharmacol 10: 827833.

Larsen MB, Elfving B, Wiborg O (2004). The chicken serotonin transporter discriminates between serotonin-selective reuptake inhibitors. A species-scanning mutagenesis study. J Biol Chem 279:42147-42156.

Lau T, Horschitz S, Berger S, Bartsch D, Schloss P (2008). Antidepressant-induced internalization of the serotonin transporter in serotonergic neurons. FASEB $J$ 22:1702-1714.

Laux G, Volz HP, Moller HJ (1995). Newer and older monoamine oxidase inhibitors: a comparative profile. CNS Drugs 3:145-148.

Le Poul E, Boni C, Hanoun N, Laporte AM, Laaris N, Chauveau J, Hamon M, Lanfumey L (2000). Differential adaptation of brain 5-HT1A and 5-HT1B receptors and 5-HT 
transporter in rats treated chronically with fluoxetine. Neuropharmacology 39:110122.

Le Poul E, Laaris N, Doucet E, Laporte AM, Hamon M, Lanfumey L (1995). Early desensitization of somato-dendritic 5-HT1A autoreceptors in rats treated with fluoxetine or paroxetine. Naunyn Schmiedebergs Arch Pharmacol 352:141-148.

Leach KL, James ML, Blumberg PM (1983). Characterization of a specific phorbol ester aporeceptor in mouse-brain cytosol. Proc Natl Acad Sci USA 80:4208-4212.

Lenox RA, Frazer A (2002). Mechanism of action of antidepressants and mood stabilizers. In: Davis KL et al., (eds). Neuropsychopharmacology: The Fifth Generation of Progress. Nashville, TN: American College of Neuropsychopharmacology. pp 1139-1163.

Lesch PK, Aulakh CS, Wolozin BL, Tolliver TJ, Hill JL, Murphy DL (1993). Regional brain expression of serotonin transporter mRNA and its regulation by reuptake inhibiting antidepressants. Mol Brain Res 17:31-35.

Leussis MP, Andeersen SL (2008). Is adolescence a sensitive period for depression? Behavioral and neuroanatomical findings from a social stress model. Synapse 62: 2230.

Li Q, Brownfield MS, Levy AD, Battaglia G, Cabrera TM, Van de Kar LD (1994). Attenuation of hormone responses to the 5-HT1A agonist ipsapirone by long-term treatment with fluoxetine, but not desipramine, in male rats. Biol Psychiatry 36:300308. 
Lin JW, Wyszynski M, Madhavan R, Sealock R, Kim JU, Sheng M (1998). Yotiao, a novel protein of neuromuscular junction and brain that interacts with specific splice variants of NMDA receptor subunit NR1. J Neurosci 18: 2017-2027.

Liotti M, Mayberg HS (2001). The role of functional neuroimaging in the neuropsychology of depression. J Clin Exp Neuropsychol 23: 121-136.

Lopez JF, Chalmers DT, Vazquez DM, Watson SJ, Akil H (1994). Serotonin transporter mRNA in rat brain is regulated by classical antidepressants. Biol Psychiatry 35:287290.

López-Muñoz F, Alamo C, Juckel G, Assion HJ (2007). Half a century of antidepressant drugs: on the clinical introduction of monoamine oxidase inhibitors, tricyclics, and tetracyclics. Part I: monoamine oxidase inhibitors. J Clin Psychopharmacol 27:555-559.

Luscombe GP, Martin KF, Hutchins LJ, Gosden J, Heal DJ (1993). Mediation of the antidepressant-like effect of 8-OH-DPAT in mice by postsynaptic 5-HT1A receptors. Br J Pharmacol 108:669-677.

Madsen TM, Treschow A, Bengzon J, Bolwig TG, Lindvall O, Tingstrom (2000). Increased neurogenesis in a model of electroconvulsive therapy. Biol Psychiatry 47: 1043-1049.

Mancinelli A, D’Aranno V, Stasi MA, Lecci A, Borsini F, Meli A (1991). Effect of enantiomers of propranolol on desipramine-induced anti-immobility in the forced swimming test in the rat. Pharmacol Res 23: 47-50.

Mandela P and Ordway GA (2006). The norepinephrine transporter and its regulation. $J$ Neurochem 97: 310-333. 
Masson J., Sagne C., Hamon M, EI MS (1999). Neurotransmitter transporters in the central nervous system. Pharmacol Rev 51:439-464.

Maubach KA, Rupniak NM, Kramer MS, Hill RG(1999). Novel strategies for pharmacotherapy of depression. Curr Opin Chem Biol 3:481-488.

Mehtonen OP, Sogaard J, Roponen P, Behnke K. 2000. Randomized, double-blind comparison of venlafaxine and sertraline in outpatients with major depressive disorder. J Clin Psychiatry 61: 95-100.

Melikian HE, McDonald JK, Gu H, Rudnick G, Moore KR, Blakely RD (1994). Human norepinephrine transporter. Biosynthetic studies using a site-directed polyclonal antibody. J Biol Chem 269:12290-12297.

Melikian HE, Ramamoorthy S, Tate CG, Blakely RD (1996). Inability to N-glycoslate the human norepinephrine transporter reduces protein stability, surface traffiking, a transport activity but not ligand recognition. Mol Pharmacol 50: 266-276.

Millan MJ (2006). Multi-target strategies for the improved treatment of depressive states: Conceptual foundations and neuronal substrates, drug discovery and therapeutic application. Pharmacol Ther 110: 135-370.

Millan MJ, Gobert A, Lejeune F, Newman-Tancredi A, Rivet JM, Auclair A (2001). S33005, a novel ligand at both serotonin and norepinephrine transporters: II. Behavioral profile in comnparison with venlafaxine, reboxetine, citalopram, and clomipramine. J Pharmacol Exp Ther 298:565-580.

Millan MJ, Gobert A, Rivet JM, Adhumeau-Auclair A, Cussac D, Newman-Tancredi A, Dekeyne A, Nicolas JP, Lejeune F (2000). Mirtazapine enhances frontocortical dopaminergic and corticolimbic adrenergic, but not serotonergic, transmission by 
blockade of alpha2-adrenergic and serotonin $2 \mathrm{C}$ receptors: a comparison with citalopram. Eur J Neurosci 12:1079-1095.

Miller HL, Delgado PL, Salomon RM, Heninger GR, Charnery DS (1996a). Effects of alpha-methyl-para-tyrosine (AMPT) in drug-free depressed patients. Neuropsychopharmacology 14:151-157.

Miller HL, Delgado PL, Salomon RM, Berman R, Krystal JH, Heninger GR, Charney DS (1996b). Clinical and biochemical effects of catecholamine depletion on antidepressant-induced remission of depression. Arch Gen Psychiatry 53:117-128.

Mongeau R, Blier P, de Montigny C (1993). In vivo electrophysiological evidence for tonic activation by endogenous noradrenaline of alpha 2 -adrenoceptors on 5hydroxytryptamine terminals in the rat hippocampus. Naunyn Schmiedebergs Arch Pharmacol 347:266-272.

Morilak DA and Frazer A (2004). Antidepressants and brain monoaminergic systems: a dimensional approaoch to understanding their behavioral effects in depression and anxiety disorders. Int J Neuropsyshopharmacol 7:193-218.

Murphy DL, Mitchell PB, Potter WZ (2000). Novel Pharmacological approaches to the treatment of depression. In: Bloom FE, Kupfer DJ (Eds). Psychopharmacology - The forth Generation of Progress. Lippincott Williams \& Wilkins.

Nelson JC, Mazure CM, Jatlow PI, Bowers MB Jr, Price LH (2004). Combining norepinephrine and serotonin reuptake inhibition mechanisms for treatment of depression: a double-blind, randomized study. Biol Psychiatry 56: 535-546.

Nestler EJ, Barrot M, DiLeone RJ, Eisch AJ, Gold SJ, Monteggia LM (2002). Neurobiology of depression. Neuron 34: 13-25. 
Nguyen TT and Amara SG (1996). N-linked oligosaccharides are required for cell lsurface expression of the norepinephrine transporter but do not influence substrate or inhibitor recognition. $J$ Neurochem 67: 645-655.

Nibuya M, Nestler EJ, Duman RS (1996). Chronic antidepressant administration increases the expression of cAMP response element binding protein (CREB) in rat hippocampus. $J$ Neurosci 16: 2365-2372.

Nielsen DM (2006). Corticotropin-releasing factor type-1 receptor antagonists: the next class of antidepressants? Life Sci 78:909-919.

O’Donnell JM (1990). Behavioral effects of beta adrenergic agonists and antidepressant drugs after down-regulation of beta- 2 adrenergic receptors by clenbuterol. $J$ Pharmacol Exp Ther 254: 147-157.

O’Donnell JM, Marek GJ, Seiden LS (2005). Antidepressant effects assessed using behavior maintained under a differential-reinforcement-of-low-rate (DRL) operant schedule. Neurosci Biobehav Rev 29:785-798.

O’Donnell JM, Seiden LS (1984). Altered effects of desipramine on operant performance after 6-hydroxydopamine-induced depletion of brain dopamine or norepinephrine. J Pharmacol Exp Ther 229: 629-635.

O'Donnell JM (1993). Antidepressant-like effects of rolipram and other inhibitors of cyclic adenosine monophosphate phosphodiesterase on behavior maintained by differential reinforcement of low response rate. J Pharmacol Exp Ther 264:11681178. 
O'Donnell JM, Seiden LS (1984). Altered effects of desipramine on operant performance after 6-hydroxydopamine-induced depletion of brain dopamine or norepinephrine. $J$ Pharmacol Exp Ther 229:629-635.

O'Leary OF, Bechtholt AJ, Crowley JJ, Hill TE, Page ME, Lucki I (2007). Depletion of serotonin and catecholamines block the acute behavioral response to different classes of antidepressant drugs in the mouse tail suspension test. Psychopharmacology (Berl) 192:357-371.

Ordway GA, Gambarana C, Frazer A (1988). Quantitative autoradiography of central beta adrenoceptor subtypes: comparison of the effects of chronic treatment with desipramine or centrally administered 1-isoproterenol. J Pharmacol Exp Ther 247: 379-389.

Ordway GA, Gambarana C, Tejani-Butt SM, Areso P, Hauptmann M, Frazer A (1991). Preferential reduction of binding of 125I-iodopindolol to beta-1 adrenoceptors in the amygdala of rat after antidepressant treatments. J Pharmacol Exp Ther 257: 681690.

Ordway GA, Jia W, Li J, Zhu MY, Mandela P, Pan J (2005). Norepinephrine transporter function and desipramine: residual drug effects versus short-term regulation. $J$ Neurosci Methods 143: 217-225.

Oster JL, Anderson ML, McPhie DL, Alkon DL (1989). Imaging of memory-specific changes in the distribution of protein kinase C in the hippocampus. Science 245:866869. 
Owens MJ, Morgan WN, Plott SJ, Nemeroff CB (1997). Neurotransmitter receptor and transporter binding profile of antidepressants and their metabolites. J Pharmacol Exp Ther 283:1305-1322.

Owens MJ, Nemeroff CB (1993), The role of corticotrophin-releasing factor in the pathophysiology of affective and anxiety disorders: laboratory and clinical studies, Ciba Foundation Symposium 172: 296-308.

Pacholczyk T, Blakely RD, Amara SG (1991). Expression cloning of a cocaine- and antidepressant-sensitive human noradrenaline transporter. Nature 350:350-354.

Page ME, Detke MJ, Dalvi A, Kirby LG, Luckii I (1999). Serotonergic meidation of the effects of fluoxetine, but not desipramine, in the rat forced swimming test. Psychopharmacology 147:162-167.

Page ME, Lucki I (2002). Effects of acute and chronic reboxetine treatment on stressinduced monoamine efflux in the rat frontal cortex. Neuropsychopharmacol 27:237247.

Paxinos G, Watson C (1986). The Rat Brain in Stereotaxic Coordinates, 2ed edn. Academic Press: San Diego, CA.

Paxinos G, Watson C (1998). The rat brain in stereotaxic coordinates, $4^{\text {th }}$ edn. Academic Press: San Diego, CA.

Philip PA, Zonder JA (1999). Pharmacology and clinical experience with bryostatin 1: a novel anticancer drug. Expert Opin Investig Drugs 8:2189-2199.

Pilpel Y, Segal M (2004). Activation of PKC induces rapid morphological plasticity in dendrites of hippocampal neurons via Rac and Rho-dependent mechanisms. Eur $J$ Neurosci 19:3151-3164. 
Pineyro G, Blier P (1999). Autoregulation of serotonin neurons: role in antidepressant drug action. Pharmacol Rev 51: 533-591.

Poirier MF, Boyer P (1999). Venlafaxine and paroxetine in treatment-resistant depression: Double-blind, randomised comparison. Br J Psychiatry 175:12-16.

Porsolt RD, Le PM, Jalfre M (1977). Depression: a new animal model sensitive to antidepressant treatments. Nature 266: 730-732.

Qian Y, Galli A, Ramamoorthy S, Risso S, DeFelice LJ, Blakely RD (1997). Protein kinase $\mathrm{C}$ activation regulates human serotonin transporters in HEK-293 cells via altered cell surface expression. $J$ Neurosci 17:45-57.

Ramamoorthy S, Melikian HE, Qian Y, Blakely RD (1998). Biosynthesis, Nglycosylation, and surface trafficking of biogenic amine transporter proteins. Methods Enzymol 296:347-370.

Ramsdell JS, Pettit GR, Tashjian AH (1986). Three activators of protein kinase C, bryostatins, dioleins, and phorbol esters, show differing specificities of action on GH4 pituitary cells. J Biol Chem 261:17073-17080.

Rausch JL, Johnson ME, Kasik KE, Stahl SM (2006). Temperature Regulation in Depression: Functional 5HT1A Receptor Adaptation Differentiates Antidepressant Response. Neuropsychopharmacology 31: 2274-2280.

Rausch JL, Ruegg R, Moeller FG (1990). Gepirone as a 5-HT1A agonist in the treatment of major depression. Psychopharmacol Bull 26:169-71.

Raymond LA, Tingley WG, Blackstone CD, Roche KW, Huganir RL (1994). Glutamate receptor modulation by protein phosphorylation. $J$ Physiol Paris 88:181-192. 
Rossi DV, Burke TF, Hensler JG (2008a). Differential regulation of serotonin-1A receptor-stimulated [(35)S]GTPgammaS binding in the dorsal raphe nucleus by citalopram and escitalopram. Eur J Pharmacol 583:103-107.

Rossi DV, Burke TF, McCasland M, Hensler JG (2008b). Serotonin-1A receptor function in the dorsal raphe nucleus following chronic administration of the selective serotonin reuptake inhibitor sertraline. $J$ Neurochem. [Epub ahead of print]

Rossi DV, Valdez M, Gould GG, Hensler JG (2005). Chronic administration of venlafaxine fails to attenuate 5-HT1A receptor function at the level of receptor-G protein interaction. Int $J$ Neuropsychopharmacol 8:1-14.

Sacchetti G, Bernini M, Gobbi M, Parini S, Pirona L, Mennini T, Samanin R (2001). Chronic treatment with desipramine facilitates its effect on extracellular noradrenaline in the rat hippocampus: studies on the role of presynaptic alpha2adrenoceptors. Naunyn Schmiedeberg's Arch Pharmacol 363: 66-72.

Sairanen M, Lucas G, Ernfors P, Castren M, Castren E (2005). Brain-derived neurotrophic factor and antidepressant drugs have different but coordinated effects on neuronal turnover, proliferation, and survival in the adult dentate gyrus. $J$ Neurosci 25: 1089-1094.

Saito N, Kikkawa U, Nishizuka Y, Tanaka C (1988). Distribution of protein kinase C-like immunoreactive neurons in rat brain. $J$ Neurosci 8:369-382.

Salome N, Stemmelin J, Cohen C, Griebel G (2006). Selective blockade of NK2 or NK3 receptors produces anxiolytic and antidepressant-like effects in gerbils. Pharmacol Biochem Behav 83:533-539. 
Salomon R, Miller HL, Krystal JH (1997). Lack of behavioral effects of monoamine depletion in healthy subjects. Biol Psychiatry 41: 58-64.

Salomon RM, Miller HL, Delgado PL, Charney D (1993). The use of tryptophan depletion to evaluate central serotonin function in depression and other neuropsychiatric disorders. Int Clin Psychopharmacol S2: 41-46.

Sanders (1999). Molecular genetics of mood disorders. In Neurobiology of Mental Illness, D.S. Charney, E.J. Nestler and B.S. Bunney, eds. (New York: Oxford), pp. 299-316.

Santarelli L, Saxe M, Gross C, Surget A, Battaglia F, Dulawa S, Weisstaub N, Lee J, Duman R, Arancio O, Belzung C, Hen R (2003). Requirement of hippocampal neurogenesis for the behavioral effects of antidepressants. Science 301: 805-809.

Santarelli, L., Gobbi, G., Debs, P.C., Sibille, E.T., Blier, P., Hen, R. \& Heath, M.J. (2001). Genetic and pharmacological disruption of neurokinin1 receptor function decreases anxiety-related behaviors and increases serotonergic function. PNAS 98: $1912-1917$.

Scates AC, Doraiswamy PM (2000). A selective norepinephrine reuptake inhibitor for the treatment of depression. The annals of Pharmacotherapy 34:1302-1312.

Schmid JA, Just H, Sitte HH (2001). Impact of oligomerization on the function of the human serotonin transporter. Biochem Soc Trans 29:732-736.

Schomig E, Fischer P, Schonfeld CL, Trendelenburg U (1989). The extent of neuronal reuptake of $3 \mathrm{H}$-noradrenaline in isolated vasa deferentia and atria of the rat. NaunynSchmiedeberg's Arch Pharmacol 340: 502-508. 
Schramm NL, McDonald MP, Limbird LE (2001). The $\alpha 2$-adrenergic receptor plays a protective role in mouse behavioral models of depression and anxiety. J Neurosci 21 : $4875-4882$.

Schreiber R, De Vry J (1993). Neuronal circuits involved in the anxiolytic effects of the 5-HT1A receptor agonists 8-OH-DPAT, ipsapirone and buspirone in the rat. Eur $J$ Pharmacol 249: 341-351.

Scott BW, Wojtowicz JM, Burnham WM (2000). Neurogenesis in the dentate gyrus of the rat following electroconvulsive shock seizures. Exp Neurol 165: 231-236.

Scuvee-Moreau J, Giesbers I, Dreese A (1987). Effect of rolipram, a phosphodiesterase inhibitor and potential antidepressant, on the firing rate of central monoaminergic neuron in the rat. Arch Int Pharmacodyn Ther 288:43-49.

See RE, Adams-Curtis L, Chapman MA (1992). Assessment of dopamine release by in vivo microdialysis in the nucleus accumbens of rats following acute and chronic administration of desipramine. Ann N Y Acad Sci 654: 522-524.

Shelton RC (2004). The dual-action hypothesis: does pharmacology matter? J Clin Psychiatry 65: 5-10.

Shirayama Y, Chen AH, Nakagawa S, Russell DS, Duman RS (2002). Brain-derived neurotrophic factor produces antidepressant effects in behavioral models of depression. J Neurosci 22: 3251-3261.

Smith PK, Krohn PI, Hermanson GT, Mallia AK, Gartner FH, Provenzano MD, Fujimoto EK, Goeke NM, Olson BJ, Klenk DC (1985). Measurement of protein using bicinchoninic acid. Anal Biochem 150: 76-85. 
Smith TD, Kuczenski R, George-Fridedman K, Malley JD, Foote SL (2000). In vivo microdialysis assessment of extracellular serotonin and dopamine levels in awake monkeys during sustained fluoxetine administration. Synapse 38: 460-470.

Song F, Freemantle N, Sheldon TA (1993). Selective serotonin reuptake inhibitors: metaanalysis of efficacy and acceptability. BMJ 306: 683-687.

Steinberg R, Alonso R, Griebel G, Bert L, Jung M, Oury-Donat F, Poncelet M, Gueudet C, Desvignes C, Le Fur G, Soubrié P (2001). Selective blockade of neurokinin-2 receptors produces antidepressant-like effects associated with reduced corticotropinreleasing factor function. J Pharmacol Exp Ther 299:449-458.

Sun MK, Alkon DL (2005). Dual effects of bryostatin-1 on spatial memory and depression. Eur J Pharmacol 512: 43-51.

Sun MK, Alkon DL (2008). Effects of 4-methylcatechol on spatial memory and depression. Neuroreport 19: 355-359.

Sung MK, Alkon D (2005). Protein kinase C substrate activators: potential as novel antidepressants. Drug Dev Res 65: 156-169.

Sung U, Blakely RD (2007). Calcium-dependent interactions of the human norepinephrine transporter with syntaxin 1A. Mol Cell Neurosci 34: 251-260.

Sung U, Jennings JL, Link AJ, Blakely RD (2005). Proteomic analysis of human norepinephrine transporter complexes reveals associations with protein phosphatase 2A anchoring subunit and 14-3-3 proteins. Biochem Biophys Res Commun 333: 671678.

Svenningsson P, Bateup H, Qi H, Takamiya K, Huganir RL, Spedding M, roth BL, McEwen BS, Greengard P (2007). Involvement of AMPA receptor phosphorylation 
in antidepressant actions with special reference to tianeptine. Eur $J$ Neurosci 26: 3509-3517.

Szot P, Ashliegh EA, Kohen R, Petrie E, Dorsa DM, Veith R (1993). Norepinephrine transporter mRNA is elevated in the locus coeruleus following short- and long-term desipramine treatment. Brain Res 618: 308-312.

Tanaka E (1988). Clinically important pharmacokinetic drug-drug interactions: Role of cytochrome P450 enzymes. J Clin Pharm Ther 23:403-416.

Tejani-Butt SM, Brunswick DJ, Frazer A (1990). ${ }^{3} \mathrm{H}$-nisoxetine: a new radioligand for norepinephrine uptake sites in brain. Eur J Pharmacol 191: 239-243.

Thakker DR, Natt F, Hüsken D, van der Putten H, Maier R, Hoyer D, Cryan JF (2005). siRNA-mediated knockdown of the serotonin transporter in the adult mouse brain. Mol Psychiatry 10:782-789.

Thase ME, Clayton AH, Haight BR, Thompson AH, Modell JG, Johnston JA (2006). "A double-blind comparison between bupropion XL and venlafaxine XR: sexual functioning, antidepressant efficacy, and tolerability". J Clin Psychopharmacol 26: $482-488$.

Thase ME, Denko T (2008). Pharmacotherapy of mood disorders. Annu Rev Clin Psyhcol 4: 53-91.

Thase ME, Trivedi MH, Rush AJ (1995). MAOIs in the contemporary treatment of depression. Neuropsychopharmacology 12:185-219.

Torres GE, Caron MG (2003). Center stage for the serotonin transporter: a gain-offunction polymorphism in persons with obsessive-compulsive disorder. Mol Pharmacol 64:196-198. 
Trendelenburg AU, Gaiser EG, Cox SL, Meyer A, Starke K (1999). Mouse postganglionic sympathetic neurons: primary culturing and noradrenaline release. $J$ Neurochem 73:1431-1438.

Uchida J, Kiuchi Y, Ohno M, Yura A, Oguchi K (1998). Ca(2+)-dependent enhancement of $\left[{ }^{3} \mathrm{H}\right]$ noradrenaline uptake in PC12 cells through calmodulin-dependent kinases. Brain Res 809:155-164.

Versiani M, Mehilane L, Gaszner P, Arnaud-Castiglioni R (1999). Reboxetine, a unique selective NRI, prevents relapse and recurrence in long-term treatment of major depressive disorder. J Clin Psychiatry 60:400-406.

Vizi ES, Zsilla G, Caron MG, Kiss JP (2004). Uptake and release of norepinephrine by serotonergic terminals in norepinephrine transporter knock-out mice: implications for the action of selective serotonin reuptake inhibitors. J Neurosci 24: 7888-7894.

Vollmary B, Henn FA (2001). Learned helplessness in the rat: improvements in validity and reliability. Brain Res Brain Res Protoc 8:1-7.

Wachtel H. (1983). Potential antidepressant activity of rolipram and other selective adenosine 3', 5'-monophosphate phosphodiesterase inhibitors. Neuropharmacology 22: $267-272$.

Weinreb O, Bar-Am O, Amit T, Chillag-Talmor O, Youdim MB (2004). Neuroprotection via pro-survival protein kinase $\mathrm{C}$ isoforms associated with $\mathrm{Bcl}-2$ family members. FASEB J 18:1471-1473.

Weinshenker D, White SS, Javors MA, Palmiter RD, Szot P (2002) Regulation of norepinephrine transporter abundance by catecholamines and desipramine in vivo. Brain Res 946:239-246. 
White KJ, Walline CC, Barker EL (2005). Serotonin transporters: Implications for antideprssant drug development. AAPS J 7:E421-E433.

Willner P (1995). Animal models of depression: validity and applications. Advances in Biochem. Psychopharmacol 49: 19-41.

Willner P (1997). Validity, reliability and utility of the chronic mild stress model of depression: A 10-year review and evaluation. Psychopharmacology 134: 319-329.

Wong EH, Sonders MS, Amara SG, Tinholt PM, Piercey MF, Hoffmann WP, Hyslop DK, Franklin S, Porsolt RD, Bonsignori A, Carfagna N, McArthur RA (2000). Reboxetine: A pharmacologically potent, selective, and specific norepinephrine reuptake inhibitor. Biol Psychiatry 47:818-829.

Wong ML, Licinio J (2001). Research and treatment approaches to depression. Nat Rev Neurosci 2: 343-351.

Wyszynski M, Kharazia V, Shanghvi R, Rao A, Beggs AH, Craig AM, Weinberg R, Sheng M (1998). Differential regional expression and ultrastructural localization of alpha -actinin-2, a putative NMDA receptor anchoring protein, in rat brain. $J$ Neurosci 18: 1383-1392.

Xie T, Tong L, McLane MW, Hatzidimitriou G, Yuan J, McCann U, Ricaurte G (2006). Loss of serotonin transporter protein after MDMA and other ring-substituted amphetamines. Neuropsychopharmacology 31: 2639-2651.

Xu F, Gainetdinov RR, Wetsel WC, Jones SR, Bohn LM, Miller GW, Wang YM, Caron MG (2000). Mice lacking the norepinephrine transporter are supersensitive to psychostimulants. Nat Neurosci 3: 465-471. 
Yamamoto H, Kagaya A, Kuroda Y, Mikuni M, Takahashi K (1990). Effect of antidepressants on the GTP binding sites in rat brain homogenate. Jpn J Psychiatry Neurol 44: 133-134.

Yocca, FD (1990). Neurochemistry and neurophysiology of buspirone and gepirone: interactions at presynaptic and postsynaptic 5-HT1A receptors. $J$ Clin Psychopharmacol 10: 6S-12S.

Zhang HT, Huang Y, Masood A, Stolinski LR, Li Y, Zhang L, Dlaboga D, Jin S-LC, Conti M, O’Donnell JM (2008). Anxiogenic-like behavioral phenotype of mice deficient in phosphodiesterase 4B (PDE4B). Neuropsychopharmacology 33:16111623.

Zhang HT, Huang Y, O'Donnell JM (2003). Antagonism of the antidepressant-like effects of clenbuterol by central administration of beta-adrenergic antagonists in rats. Psychopharmacology 170:102-107.

Zhang HT, Zhao Y, Huang Y, Deng C, Hopper AT, De Vivo M, Rose GM, O’Donnell JM (2006). Antidepressant-like effects of PDE4 inhibitors mediated by the highaffinity rolipram binding state (HARBS) of the phosphodiesterase-4 enzyme (PDE4) in rats. Psychopharmacology 186: 209-217.

Zhao Z, Baros AM, Zhang HT, Lapiz MD, Bondi CO, Morilak DA, O'Donnell JM (2008). Norepinephrine Transporter Regulation Mediates the Long-Term Behavioral Effects of the Antidepressant Desipramine. Neuropsychopharmacology [Epub ahead of print].

Zhao ZR, Baros AM, Zhang HT, Lapiz MD, Bondi CO, Morilak DA, O’Donnell JM (2008). Norepinephrine transporter regulation mediates the long-term behavioral 
effects of the antidepressant desipramine. Neuropsychopharmacology [Epub ahead of print].

Zhu CB, Carneiro AM, Dostmann WR, Hewlett WA, Blakely RD (2005). p38 MAPK activation elevates serotonin transport activity via a trafficking-independent, protein phosphatase 2A-dependent process. J Biol Chem 280: 15649-15658.

Zhu CB, Hewlett WA, Feoktistov I, Biaggioni I, Blakely RD (2004). Adenosine receptor, protein kinase $\mathrm{G}$, and p38 mitogen-activated protein kinase-dependent up-regulation of serotonin transporters involves both transporter trafficking and activation. $\mathrm{Mol}$ Pharmacol 65:1462-1474.

Zhu MY, Blakely RD, Apparsundaram S, Ordway GA (1998). Down-regulation of the human norepinephrine transporter in intact 293-hNET cells exposed to desipramine. J Neurochem 70:1547-1555.

Zhu MY, Kim CH, Hwang DY, Baldessarini RJ, Kim KS (2002). Effects of desipramine treatment on norepinephrine transporter gene expression in the cultured SK-NBE(2)M17 cells and rat brain tissue. $J$ Neurochem 82:146-153.

Zhu MY, Kyle PB, Hume AS, Ordway GA (2004). The persistent membrane retention of desipramine causes lasting inhibition of norepinephrine transporter function. Neurochem Res 29: 419-427.

Zhu MY, Ordway GA (1997). Down-regulation of norepinephrine transporters on PC12 cells by transporter inhibitors. J Neurochem 68:134-141.

Zhu MY, Wang WP, Baldessarini RJ, and Kim KS (2005). Effects of desipramine treatment on tyrosine hydroxylase gene expression in cultured neuroblastoma cells and rat brain tissue. Brain Res Mol Brain Res 133:167-175. 
Ziegler VE, Biggs JT, Rosen SH, Meyer DA, and Preskorn Sh (1978). Imipramine and desipramine plasma levels: relationship to dosage schedule and sampling time. $J$ Clin Psychiatry 39: 660-663. 


\section{Zaorui Zhao, Ph.D.}

68 William St, Apt 1R

New Haven, CT 06511

Tel: (304) 906-8591

Email: zrzhaozrzhao@yahoo.com

\section{Curriculum Vitae}

\section{EDUCATION}

- Ph.D.

07/2005-08/2008

--- Department of Pharmaceutical and Pharmacological Sciences, West Virginia

University Health Science Center, Morgantown, WV, USA

- Ph.D Candidate

08/2003-06/2005

---Department of Pharmacology. University of Tennessee Health Science Center, Memphis, TN, USA

- B.S.

09/1995-06/1999

--- Zhejiang University, Department of Pharmacy, Hangzhou, P.R.China

\section{RESEARCH EXPERIENCE}

- Postdoctoral research associate

--- Department of Psychology, Yale University

- Research Assistant

07/2005 - 08/2008

--- Department of Pharmaceutical and Pharmacological Sciences, West Virginia

09/2008 - present

University Health Science Center 
Study on the involvement of norepinephrine transporter and serotonin transporter in the delayed onset of antidepressants.

- Research Assistant

$08 / 2003-06 / 2005$

---Department of Pharmacology. University of Tennessee Health Science Center,

Memphis, TN

- Research Assistant

$08 / 1999-06 / 2003$

---Department of Pharmacology. Zhejiang Academy of Medical Sciences, Hangzhou, P.R.China

Research on the pre-clinical and clinical drug trials; New drug Pharmacokinetic and Phharmacodynamic research. Bioavailability and bioequivalence research.

- Undergraduate internship $02 / 1999-06 / 1999$

--- Department of Pharmacology, Second Military Medical University, Shanghai, P.R.China

Research on the learning and memory mechanism.

\section{Publications}

- Zhao Z, Baros AM, Zhang HT, Lapiz MD, Bondi CO, Morilak DA, O’Donnell JM (2008). Norepinephrine transporter regulation mediates the long-term behavioral effects of the antidepressant desipramine. Neuropsychopharmacology [Epub ahead of print].

- Lapiz MD, Zhao Z, Bondi CO, O'donnell JM, Morilak DA (2007). Blockade of autoreceptor-mediated inhibition of norepinephrine release by atipamezole is maintained after chronic reuptake inhibition. Int J Neuropsychopharmacol. 10(6):827-33.

- Zhou B, Zhang Q, Zhao Z, Li W, Li S, Jiang Y, and Yin M (2002). Effect of pregnenolone sialic glycoside on memory impairment in mice. Academic Journal of Second Military Medical University 23:562-563.

- Zhou B, Zhang Q, Zhao Z, Li W, Li S, Jiang Y, and Yin M (2002).

Dehydroepiandrosterone derivatives attenuates scopolamine-induced Impairment in mice. Pharmacuetical Journal of Chinese PLA. 18:193-195. 
- Wei Y, Zhang M, Wang K, Zhao Z, Liu X, Wu D, Shao Q (2003). Assessment of bioequivalence of Pidotimod Granules. Chinese Journal of New Drugs 12:461463.

- Wei Y, Zhang M, Wang K, Zhao Z, Shao Q (2003). Pharmacokinetics of mifepristone after low oral dose in healthy Chinese women. The Chinese Journal of Clinical Pharmacology 19: 430-433.

\section{Submitted manuscripts}

- Zhao Z, Zhang H, Bootzin E, Millan M, O'Donnell JM. Association of changes in norepinephrine and serotonin transporter expression with the long-term behavioral effects of antidepressant drugs. Submitted to Neuropsychopharmacology on July 2008 .

\section{International Meetings}

- Zhao Z, Zhang H, and O'Donnell JM. Role of PKC Signaling In The Regulation of The Norepinephrine Transporter In Rat Brain. Society for Neuroscience 2007 annual meeting, San Diego, CA

- Zhao Z, Zhang H, Lapiz DS, Bondi CO, Morilak DA, and O'Donnell JM. Desipramine-induced enhancement of noradrenergic neurotransmission in the medial prefrontal cortex demonstrated by in vivo microdialysis. Society for Neuroscience 2006 annual meeting, Atlanta, GA

- Zhao Z, Zhang H, Kane VB and, O'Donnell JM. Involvement of the norepinephrine transporter (NET) in the persistent behavioral effects of desipramine (DMI). Society for Neuroscience 2005 annual meeting. Washington $D C$.

- O'Donnell JM, Crissman AM, Zhao Z. Association of the Down-Regulation of the Norepinephrine Transporter in rat brain with the persistent behavioral effects observed following repeated treatment with desipramine. American College of Neuropsychopharmacology $44^{\text {th }}$ annual meeting 2005.

\section{Presentations and posters}

- Zhao Z, Zhang H, and O'Donnell JM. (2007). Role of PKC signaling in the regulation of the norepinephrine transporter in rat brain. West Virginia University 
Health Science Center 2007 E.J.Van Liere Convocation and research day.

- Zhao Z, Zhang H, and O'Donnell JM. (2006). Persistent Antidepressant Effects Produced by Desipramine-Induced Down-Regulation of the Norepinephrine Transporter in the Rat brain. West Virginia University Health Science Center 2006 E.J.Van Liere Convocation and research day.

\section{Award}

- 2005 - 2007 Department of Pharmaceutical and Pharmacological Sciences West Virginia University Travel award

\section{Professional Associations}

- Society for Neuroscience (SfN) since 2005

- American Society for Pharmacology and Experimental Therapeutics (ASPET) since 2008

- International Brain Research Organization, IBRO since 2005

\section{Technical Proficiencies}

- Techniques Animal behavioral tests, Animal surgeries including stereotaxic surgery, pump implantation, microinjection, in vivo microdialysis. Immunoblotting, Immunohistochemisty, fluorescence microscopy and confocal microscopy, Radioligand binding, Uptake assay, Analytical HPLC, ELISA, Real-time PCR, Reverse-transcriptase PCR, Cell culture, Plasmid transformation and transfection,

- Software Prism, NCBI, Pub Med, Science Direct, MS Office, Photoshop, 